\begin{abstract}
UNIVERSIDADE DE SÃO PAULO
FFCLRP - DEPARTAMENTO DE FÍSICA E MATEMÁTICA

PROGRAMA DE PÓS-GRADUAÇÃO EM FÍSICA APLICADA À MEDICINA E BIOLOGIA
\end{abstract}

\title{
Variabilidade da atividade cerebral em resposta a estímulos vestibular e oculomotor avaliada por fMRI
}

\author{
Hellen Mathei Della Justina
}

Dissertação apresentada à Faculdade de Filosofia, Ciências e Letras de Ribeirão Preto da USP, como parte das exigências para a obtenção do título de Mestre em Ciências, Área: Física Aplicada à Medicina e Biologia.

RIBEIRÃO PRETO - SP 


\author{
UNIVERSIDADE DE SÃO PAULO \\ FACULDADE DE FILOSOFIA CIÊNCIAS E LETRAS DE \\ RIBEIRÃO PRETO
}

\title{
VARIABILIDADE DA ATIVIDADE CEREBRAL EM RESPOSTA A ESTÍMULOS VESTIBULAR E OCULOMOTOR AVALIADA POR fMRI
}

Dissertação de Mestrado apresentada à Faculdade de Filosofia Ciências e Letras de Ribeirão Preto da Universidade de São Paulo para obtenção do Título de Mestre em Ciências, área de concentração Física Aplicada à Medicina e Biologia.

Aluna: Hellen Mathei Della Justina

Orientador: Prof. Dr. Dráulio Barros de Araújo

RIBEIRÃO PRETO - SP

2005 


\section{FICHA CATALOGRÁFICA}

Preparada pela Biblioteca Central

Do Campus Administrativo de Ribeirão Preto

\section{Della Justina, Hellen Mathei.}

Variabilidade da Atividade Cerebral em Resposta a Estímulos Vestibular e Oculomotor Avaliada por fMRI. Ribeirão Preto, 2005. 118p.

Dissertação de Mestrado apresentada à Faculdade de Filosofia Ciências e Letras de Ribeirão Preto da Universidade de São Paulo - Área de Concentração: Física Aplicada à Medicina e Biologia.

Orientador: de Araújo, Dráulio Barros.

1. Sistema Vestibular. 2. Sistema Oculomotor. 3. fMRI. 4. Variabilidade da atividade cerebral. 
Dedico esta obra ao Lincoln, meu noivo, por sua compreensão, carinho e apoio não só durante a elaboração deste trabalho, mas durante toda a nossa convivência. 


\section{AGRADECIMENTOS}

Primeiramente gostaria de agradecer à paciência, dedicação, orientação e ao entusiasmo constante do Prof. Dr. Dráulio Barros de Araújo. Aprendi muito com ele durante esses anos, pois esteve presente não só como orientador, mas como amigo também.

Gostaria de agradecer também ao apoio do Prof. Dr. José Fernando Colafêmina que sempre se mostrou receptivo quanto necessitei esclarecer algumas dúvidas.

Agradeço aos técnicos da ressonância do $\mathrm{HC}$, Reginaldo e Sandra, por tornarem agradáveis as tardes de sábado na ressonância.

A todos os voluntários que participaram deste trabalho, eu sei que é difícil conseguir ficar imóvel no tomógrafo.

Aos amigos do DFM por proporcionarem um ambiente de trabalho agradável e descontraído, Ademar, Gláucio, Ernando, Rond, Dani, Júlio, Mônica, Pablo, Fabio, Nívia, Paulo, Júlia, Rebeca, Cássia, Brunão, Karina, Juliana, Juan, Adelson, Khallil, Rabo, André, Tenysson, Renata e Kamilla.

A todos os amigos que encontrei em Ribeirão Preto, Ju, Teresa, Adilton, Ivana, Sara, Fabiana, Regis, Julinha. Em especial meus queridos amigos bocoiós, a mãe Paula, ao pai Márcio e aos irmãos Kátia e Tiago, agradeço pela amizade, companhia, incentivo....

E por fim, à minha querida família. Meu pai Joadelívio, minha mãe Neide, meu irmão Marcus, minha irmã Scheila e ao meu noivo Lincoln pelo apoio, pela presença constante, mesmo que em pensamento, pela companhia e pelo amor. 
"Se podes olhar, vê. Se podes ver, repara."

José Saramago 


\section{RESUMO}

A avaliação da variabilidade inter-individual da atividade funcional é de grande importância na utilização da ressonância magnética funcional (fMRI) no contexto clínico. O objetivo principal desse estudo é analisar a variabilidade da ativação cerebral dos sistemas vestibular e oculomotor, através da fMRI em resposta à estimulação optocinética horizontal e aos movimentos de rastreio e sacade dos olhos. Para isso, imagens por ressonância magnética foram obtidas de vinte e três voluntários assintomáticos (treze para o estudo optocinético e dez para os estudos rastreio e sacade) em um scanner de $1.5 \mathrm{~T}$ Siemens (Magneton Vision) com seqüências do tipo EPI-BOLD. Os mapas estatísticos foram obtidos no programa

Brain Voyager ${ }^{\top M}$, utilizando o método Modelo Geral Linear. Encontramos ativação significante no córtex visual primário, ao longo do giro occipital médio e inferior, no giro temporal médio, superior e inferior, no giro pós- e pré-central, ao longo do giro frontal inferior, superior e médio, no giro supramarginal, no lobo parietal superior e inferior, na ínsula e no cíngulo anterior e posterior. Grupos de atividade também foram encontrados em estruturas subcorticais (putamen, globo pálido, corpo caloso e tálamo), além do cerebelo. A análise da freqüência de ativação revelou uma alta variabilidade entre voluntários. Contudo, as regiões com maior freqüência de ativação foram as áreas frontais e a área que compreende o giro temporal médio e médio superior. Utilizamos dois métodos para a análise dos índices de lateralização, o primeiro admite um valor estatístico fixo e o segundo leva em consideração a dependência do limiar estatístico com o número de pixels ativados, o segundo método mostrou-se mais confiável. Os índices mostraram uma dominância do hemisfério direito para o estudo optocinético. Já, para os estudos rastreio e sacade, não verificamos essa dominância. Esse estudo permitiu a caracterização das mais freqüentemente áreas envolvidas nas tarefas de estimulação optocinética e dos movimentos de rastreio e sacade dos olhos. A combinação dessas tarefas constitui uma grande ferramenta para determinar a lateralização dessas funções e mapear as maiores áreas envolvidas nos sistemas oculomotor e vestibular. 


\begin{abstract}
Assessing inter-variability of functional activations is of practical importance in the use of functional magnetic resonance imaging (fMRI) in clinical context. The main objective of this study is to analyze the variability of cerebral activation of the vestibular and oculomotor systems through an optokinetic horizontal, a pursuit and saccadic eye movement stimulations by means of fMRI. For this, images of magnetic resonance were acquired of twenty and three asymptomatic volunteers (thirteen for the optokinetic study and ten for the pursuit and saccade stimulations) in scanner of 1.5 T Siemens (Magneton Vision) with EPI-BOLD fMRI sequences. The statistical maps were analyzed in Brain Voyager ${ }^{\text {TM }}$ software, using the method General Linear Model. We find significant activation in primary visual cortex, in middle and inferior occipital gyrus, in middle, superior and inferior temporal gyrus, in postcentral and precentral gyrus, in middle, inferior and superior frontal gyrus, in supramarginal gyrus, in superior and inferior parietal lobule, in insula and in anterior and posterior cingulate gyrus. Groups of activity had been also found in subcorticals structures (putamen, globus pallidus, corpus callosum and thalamus), beyond the cerebellum. The analysis of the activation frequency displays a high variability between volunteers. However, the most frequently activation regions were localized in areas frontals and in regions comprehending the middle and medial superior temporal gyrus. We use two methods for the analysis of the laterality index, the first admits a fixed statistical value and the second takes in consideration the dependence of the statistical threshold within the activated number of pixels, the second method revealed more reliability. The indices had shown a right hemisphere dominance for the optokinetic study but, for the pursuit and saccade stimulations, we do not verify this dominance. Our study allowed the characterization of the most frequently involved foci in tasks of optokinetic and pursuit and saccade eye movement stimulations. The combination of these tasks constitutes a suitable tool for determine the lateralization of these functions and for mapping major areas involved in the oculomotor and vestibular systems.
\end{abstract}




\section{LISTA DE ABREVIATURAS}

ACC

AVC

BOLD

$\mathrm{CBF}$

CBV

DLPFC

ENG

EPI

FEF

FID

fMRI

GLM

$\mathrm{Hb}$

$\mathrm{dHb}$

IL

IPL
Acrônimo do idioma inglês que representa: Anterior Cingulate Córtex

Acidente Vascular Cerebral

Acrônimo do idioma inglês que representa: Blood Oxygen Level Dependent

Acrônimo do idioma inglês que representa: Cerebral Blood Flux

Acrônimo do idioma inglês que representa: Cerebral Blood Volume

Acrônimo do idioma inglês que representa: Dorsolateral Prefrontal Córtex

Electronistagmografia

Acrônimo do idioma inglês que representa: Eco-Planar Imaging

Acrônimo do idioma inglês que representa: Frontal Eye Field

Acrônimo do idioma inglês que representa: Free Induction Decay

Acrônimo do idioma inglês que representa: Functional Magnetic Resnoance Imaging

Acrônimo do idioma inglês que representa: General Linear Model

Hemoglobina oxigenada

Hemoglobina deoxigenada

Índice de Lateralização

Acrônimo do idioma inglês que representa: Inferior Parietal Lobe 
IPS

MRI

MT/MST

NMR

NOC

PCC

PEF

PET

PIVC

PPC

$\mathrm{RF}$

ROI

SEF

$\mathrm{SNC}$

SPL

TE
Acrônimo do idioma inglês que representa: Intraparietal Sulcus

Acrônimo do idioma inglês que representa: Magnetic Resonance Imaging

Acrônimo do idioma inglês que representa: Middle Temporal/Medial Superior Temporal

Acrônimo do idioma inglês que representa: Nuclear Magnetic Resonance

Nistagmo Optocinético

Acrônimo do idioma inglês que representa: Posterior Cingulate Cortex

Acrônimo do idioma inglês que representa: Parietal Eye Field

Acrônimo do idioma inglês que representa: Positron Emission Tomography

Acrônimo do idioma inglês que representa: Parietoinsular Vestibular Córtex

Acrônimo do idioma inglês que representa: Posterior Parietal Córtex

Radiofreqüência

Acrônimo do idioma inglês que representa: Region of Interest

Acrônimo do idioma inglês que representa: Suplementary Eye Field

Sistema Nervoso Central

Acrônimo do idioma inglês que representa: Superior Parietal Lobe

Tempo ao Eco 
TMS

Acrônimo do idioma inglês que representa: Transcranical Magnetic Stimulation

TR

V1

VENG
Tempo de Repetição

Córtex Visual Primário

Vectoelectronistagmografia 


\section{ÍNDICE}

Introdução 5

Capítulo 1

Anatomia e Funções Cerebrais 4

1.1 Anatomia Cerebral 4

1.2 Córtex Cerebral 7

1.2.1 Classificação Estrutural do Córtex 7

1.3 Função Cerebral 8

1.3.1 Córtex Frontal 9

1.3.2 Córtex Parietal 10

1.3.3 Córtex Occipital 11

1.3.4 Córtex Temporal 12

1.3.5 Córtex Insular 13

1.3.6 Cerebelo 15

Capítulo 2 17

Sistema Vestibular e Oculomotor 17

2.1 Anatomia e Fisiologia do Sistema Vestibular 17

2.1.1 Células Ciliadas 18

2.1.2 Estruturas e Fisiologia dos Canais Semicirculares 19

2.1.3 Estruturas e Fisiologia do Sistema Otolítico 23

2.1.4 Caminho Neural do Sistema Vestibular Central 26

2.2 Sistema Oculomotor 27

2.2.1 Ações e Inervações dos Músculos Extraoculares 28 
2.2.2 Tipos de Movimento dos Olhos e Suas Funções 30

2.2.2.1 Movimento Sacádico 30

2.2.2.2 Movimento de Perseguição Lenta 32

2.2.2.3 Movimento de Vergência 33

2.2.2.4 Movimento Vestíbulo-Ocular 33

2.2.3 Avaliação Otoneurológica 34

2.2.3.1 Descrição dos Testes Otoneurológicos 35

Capítulo 3 37

fMRI 37

3.1 Fluxo Sanguíneo Cerebral, Metabolismo e Atividade Neural 37

3.2 Princípios Físicos de Imagem por Ressonância Magnética 38

3.2.1 Magnetização Nuclear 38

3.2.2 Processo de Relaxação 39

3.2.3 Princípio da Formação de Imagem 40

3.2.4 Seqüência de Pulso Eco-Planar 43

3.3 fMRI com Contraste BOLD 45

3.4 Método de Aquisição das Imagens 47

3.4.1 Paradigmas 47

3.5 Preparando os Dados de fMRI para Análise Estatística 49

3.5.1 Correção do Tempo por Fatia 50

3.5.2 Correção de Movimento 50

3.5.3 Filtro Espacial 52

3.5.4 Filtro Temporal 53

3.6 Análise Estatística das Imagens 54 
3.7 Apresentação dos Mapas Estatísticos 57

3.8 Atlas Cerebral 58

Capítulo 4 61

Material e Métodos 61

4.1 Voluntários 61

4.2 Estímulos 61

4.3 Aquisição dos Dados por MRI 62

4.4 Análise dos Dados 62

Capítulo 5 66

Resultados e Discussão 66

5.1 Resultados 66

5.1.1 Estruturas Ativadas Durante o Estudo NOC para Direita 66

5.1.2 Estruturas Ativadas Durante o Estudo NOC para Esquerda 67

5.1.3 Estruturas Ativadas Durante o Estudo Rastreio 68

5.1.4 Estruturas Ativadas Durante o Estudo Sacade 69

5.1.5 Diferenças entre os Estudos 70

5.1.6 Análise da Freqüência de Ocorrência 76

5.1.7 Análise Combinada da Freqüência 78

5.1.8 Índice de Lateralização 80

5.2 Discussão 84

5.2.1 Campo Frontal do Olho 86

5.2.2 Campo Suplementar do Olho 88

5.2.3 Córtex Pré-Frontal Dorsolateral 90 
5.2.4 Campo Parietal do Olho 91

5.2.5 Córtex do Cíngulo 93

5.2.6 V1 e Paraestriado 95

5.2.7 MT/MST 96

5.2.8 Ínsula 98

5.2.9 Cerebelo 100

Capítulo 6 103

Conclusões e Perspectivas 103

6.1 Conclusões 103

6.2 Perspectivas 104

Referências Bibliográficas 106 


\section{INTRODUÇÃO}

Para manter o equilíbrio, o homem conta com três sistemas sensoriais: o sistema vestibular, responsável pelas informações sobre a posição e os movimentos da cabeça; o sistema ocular (ou visual), que fornece a relação espacial dos objetos em relação ao corpo; e o sistema proprioceptivo, que controla a postura e a movimentação corporal. Estes três sistemas devem funcionar sempre em sintonia, caso contrário, o indivíduo apresentará desequilíbrio, que poderá se manifestar de diversas formas, de acordo com o órgão afetado.

Existem quatro tipos básicos de movimento dos olhos: o movimento sacádico, o de perseguição lenta, o movimento vestíbulo-ocular e o movimento de vergência. O movimento sacádico é um movimento extremamente rápido que os olhos executam - voluntária ou involuntariamente - entre um ponto de fixação e outro. O movimento de perseguição lenta ocorre quando nossos olhos fixam um objeto que se move e acompanham-no onde quer que ele vá. O movimento vestíbulo-ocular é uma resposta reflexa a rápidas alterações de posição da cabeça. $\mathrm{O}$ último grupo de movimentos, que provocam o desvio do olhar, é o movimento de vergência, diferente dos anteriores, em que os olhos se movem conjugadamente, neste os olhos convergem ou divergem, o que ocorre naturalmente quando um objeto se aproxima ou se afasta do observador.

O sistema de perseguição lenta pode ser estudado pelo chamado teste optocinético, em que barras horizontais ou verticais movem-se continuamente. Como resultado desse estímulo, os olhos seguem, automaticamente, uma barra especifica até atingir o final da sua excursão. Há então um rápido movimento sacádico na direção oposta, seguido novamente por uma perseguição lenta. Esse padrão de alteração entre movimentos rápidos e lentos é resposta a um estímulo chamado Nistagmo Optocinético (NOC). Estudando a intensidade, duração e direção da estimulação NOC podemos ter informações preciosas sobre processos patológicos do sistema vestibular. Lesões no córtex vestibular, mais precisamente na ínsula posterior humana, levam a uma percepção de inclinação da vertical visual mas não de inclinação da postura corporal e de perda do balanço lateral. Entretanto, alguns pacientes com AVC (acidente vascular cerebral) mostram um padrão inverso. 
Apesar dos processos visual e vestibular da percepção da orientação visual estarem inalterados, eles utilizam suas extremidades não paralisadas para empurrarem em direção ao lado parético, levando a uma inclinação do corpo fazendo com que caiam para o lado hemiparético. Esse surpreendente comportamento de pacientes com AVC foi primeiramente descrito por Patricia Davies, em 1985, a qual denominou de pusher syndrome [Davies (1985 apud Karnath \& Broetz 2003)]. Recentemente, a origem do pushing foi identificada como uma alteração da percepção da orientação do corpo em relação à gravidade. Esses pacientes sentem seu corpo como se estivesse orientado verticalmente quando na realidade ele está inclinado para o lado ipsilateral à lesão (18 em média) [para revisão consulte Karnath \& Broetz (2003)]. Foi com o intuito de estudarmos essa síndrome que demos início a este primeiro projeto. Antes do estudo de uma patologia desconhecida, como no caso do pushing, é essencial que se entenda os padrões normais da atividade cerebral, bem como sua variabilidade.

Portanto, uma maneira de avaliarmos as funções vestibulares e também a função oculomotora no nível cortical e subcortical é através da Imagem Funcional por Ressonância Magnética (Functional Magnetic Resonance Imaging - fMRI) [Dieterich et al. 1998; Petit \& Haxby 1999]. A fMRI tornou-se uma das principais técnicas de mapeamento das funções cerebrais nos últimos anos, principalmente, por ser uma técnica não-invasiva e pela sua ótima resolução espacial [Ogawa et al. 1990a,b; Di Salle et al. 1999]. Embora ainda existam questões referentes aos métodos utilizados, os achados em psicologia, patologia e neurociência em geral são consistentes o bastante para que essa técnica sirva de referência em estudos de processos cognitivos elevados, além das aplicações clínicas (entre as quais destaca-se o mapeamento pré-cirúrgico) e estudos envolvendo os processos de reorganização cortical.

A avaliação da variabilidade inter-individual da atividade funcional é também um fator muito importante na utilização da fMRI no contexto clínico. Portanto, o objetivo principal deste trabalho foi analisar a variabilidade da ativação cerebral dos sistemas vestibular e oculomotor, através da técnica de fMRI em resposta à estimulação optocinética horizontal e aos movimentos de rastreio e sacade do olho. 
Além de implementarmos a técnica de fMRI como um possível método de diagnóstico em exames otoneurológicos.

Para tanto trataremos, neste manuscrito, diversos aspectos teóricos e experimentais. O primeiro capítulo trata dos aspectos anatômicos e fisiológicos do cérebro humano, além de abordar a organização funcional dos lobos, do córtex insular e do cerebelo. O segundo capítulo visa facilitar a compreensão dos sistema vestibular e oculomotor incluindo, portanto, a anatomia e fisiologia do sistema vestibular, e o sistema oculomotor, além da descrição dos principais exames para avaliação otoneurológica. No capítulo três descrevemos os princípios físicos da Imagem por Ressonância Magnética, os princípios da formação de imagem, além de tratarmos dos aspectos teóricos do contraste BOLD (Blood Oxygen Level Dependent) e também dos processos envolvidos no pré e pós-processamento da imagem.

Os três últimos capítulos dessa dissertação foram destinados à descrição dos métodos experimentais, aos resultados e discussões e, por fim, às conclusões e perspectivas da nossa pesquisa. 


\section{Capítulo 1}

\section{ANATOMIA E FUNÇÕES CEREBRAIS}

\subsection{Anatomia Cerebral}

O sistema nervoso central humano pode ser dividido segundo vários critérios: de segmentação, embriológicos, funcionais e anatômicos. Essa divisão tem sentido puramente didática. Considerando-se os princípios anatômicos, o sistema nervoso central divide-se em medula espinhal e encéfalo que, por sua vez, tem três partes: cérebro, cerebelo e tronco encefálico (composto pelo mesencéfalo, ponte e bulbo) (figura 1.1). O cérebro, que corresponde à parcela mais importante da cavidade craniana, ocupando cerca de $80 \%$ do seu volume total, é dividido em diencéfalo e telencéfalo.

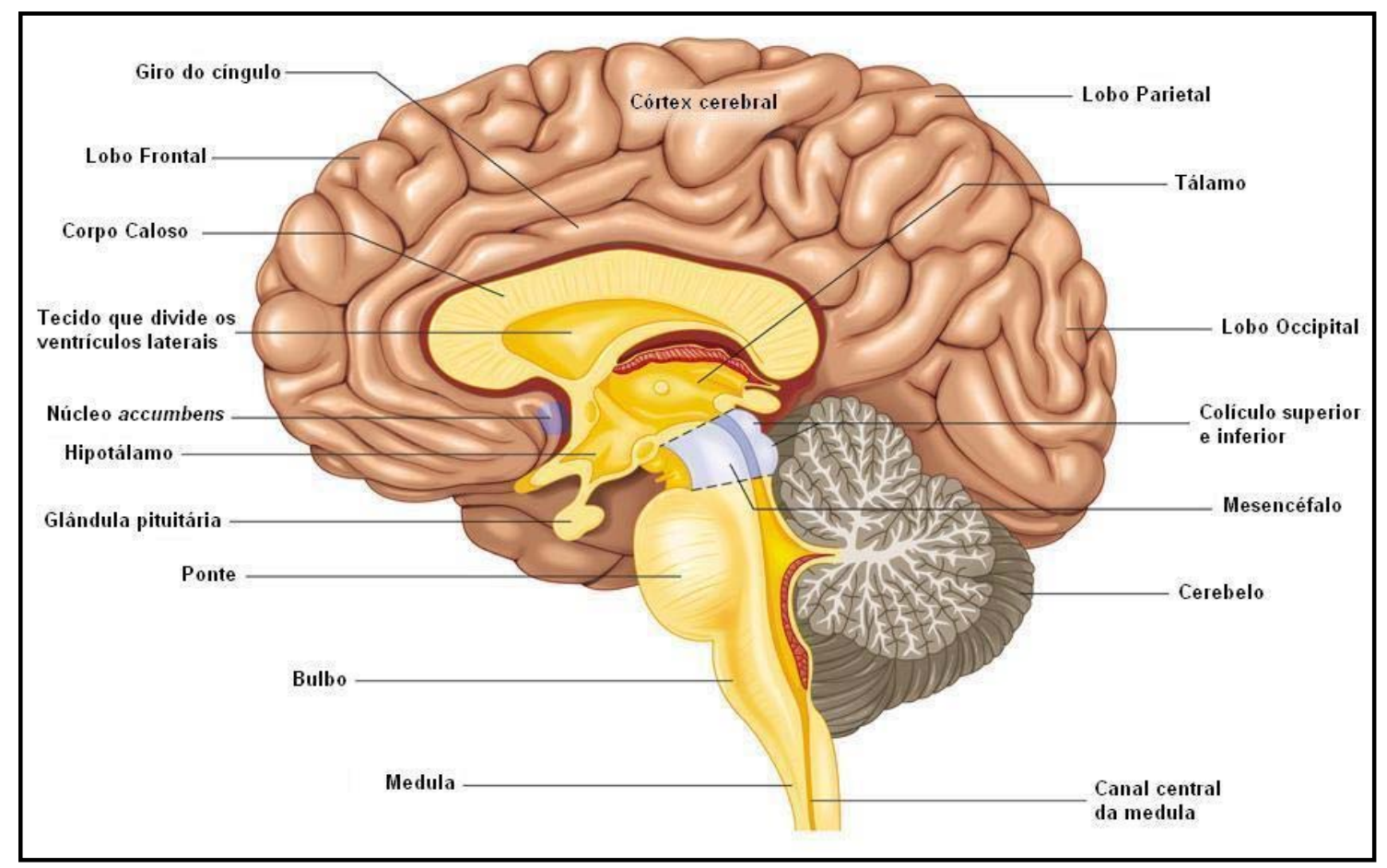

Figura 1.1 - Visão sagital do cérebro humano e suas estruturas anatômicas importantes. Figura modificada de: http://mywebpages.comcast.net/epollak/PSY255_pix/PSY255_pix.htm 
O diencéfalo compreende as seguintes estruturas: tálamo, hipotálamo, epitálamo e sub-tálamo. Já o telencéfalo é constituído pelos dois hemisférios cerebrais, que encontra na fissura longitudinal suas fronteiras mediais. Anatomicamente, os dois hemisférios são praticamente idênticos, possuindo quatro lobos: frontal, parietal, occipital e temporal (figura 1.2). Além desses, existe ainda mais internamente o lobo da insula. Os lobos cerebrais recebem sua denominação de acordo com os ossos do crânio, com os quais se relacionam. A divisão em lobos, embora de grande importância clínica, não corresponde a uma divisão funcional, exceto pelo lobo occipital, que parece ser todo, direta ou indiretamente, relacionado com a visão.

Toda a superfície do córtex cerebral é recortada por depressões denominadas de sulcos, os quais se distribuem ao longo de todo o volume, delimitando, assim, as regiões elevadas, conhecidas como giros. Os padrões dos sulcos e giros do cérebro variam em cada cérebro podendo ser diferente nos dois hemisférios de um mesmo indivíduo. Os principais sulcos são: o sulco lateral (de Sylvius), que separa, em suas porções anteriores, o lobo frontal do lobo temporal e o sulco central (de Rolando), que separa o lobo parietal do frontal (figura 1.2).

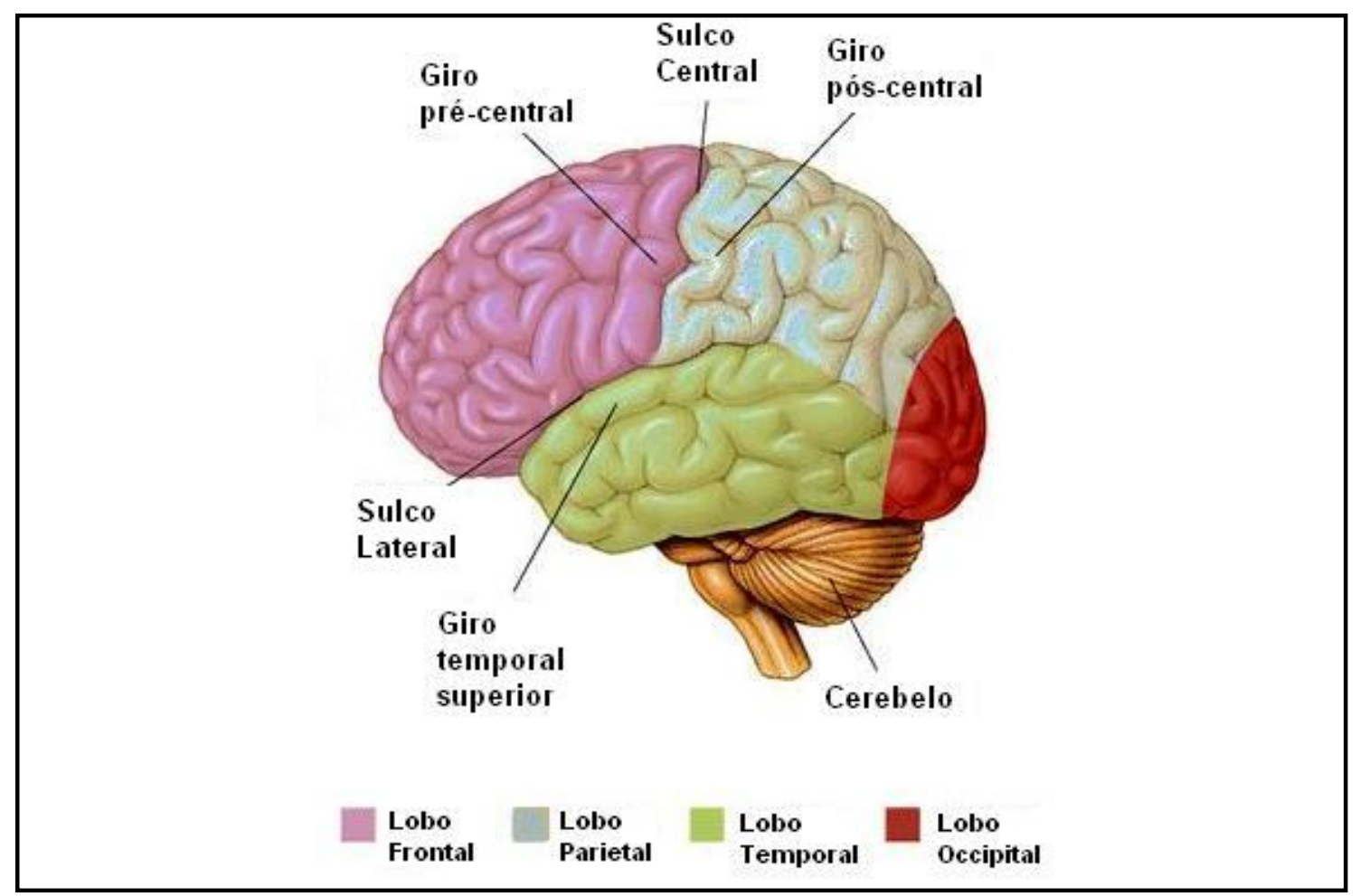

Figura 1.2 - Representação dos quatro lobos cerebrais com seus principais sulcos e giros. Figura modificada de http://www.driesen.com/brain_view_-_2.htm 
O lobo frontal contém três sulcos principais denominados de: sulco précentral, sulco frontal superior e sulco frontal inferior. Os dois últimos recortam o lobo frontal, em porções ântero-posteriores, perpendiculares ao sulco central. O sulco pré-central, por sua vez, é praticamente paralelo ao sulco central, formando entre eles o giro pré-central. Em porções súpero-mediais do sulco frontal superior, delimitado medialmente pela fissura longitudinal, está o giro frontal superior. Entre os sulcos frontal superior e inferior está o giro frontal médio. Por fim, o giro frontal inferior, localizado abaixo do sulco frontal inferior, é dividido em três partes pelos ramos anterior e ascendente do sulco lateral: orbital, triangular e opercular.

O lobo temporal é recortado por dois sulcos principais: temporal superior e inferior. Esses sulcos, juntamente com o sulco lateral, formam os principais giros do lobo temporal, que percorrem porções laterais do cérebro, ântero-posteriormente. O giro temporal superior é delimitado acima pelo sulco lateral e abaixo pelo sulco temporal superior. Entre os sulcos exclusivos do lobo temporal está o giro temporal médio. Abaixo do sulco temporal inferior encontra-se o giro temporal inferior.

No lobo parietal, encontram-se os giros: pós-central, parietal superior e inferior. O sulco pós-central segue a topografia do sulco pré-central, paralelo ao sulco central, formando o giro pós-central. O sulco intraparietal forma o giro parietal superior e inferior, sendo o segundo subdividido em supramarginal e angular.

Podemos dizer grosseiramente que o último lobo, o occipital, não contém nenhum sulco proeminente que sirva para determinação de pontos de referência anatômicos.

É interessante notar que, muito embora a fissura longitudinal divida o cérebro em dois hemisférios, eles não estão isolados. A ligação entre os dois se dá, principalmente, pela projeção de fibras nervosas através de uma comissura ${ }^{1}$ conhecida como Corpo Caloso. Este é localizado em porções mediais inferiores do córtex cerebral.

\footnotetext{
${ }^{1}$ Comissura é uma estrutura anatômica formada por fibras nervosas que cruzam perpendicularmente o plano mediano cerebral
} 


\subsection{Córtex Cerebral}

O córtex cerebral corresponde a uma camada delgada, com espessura aproximada de $3 \mathrm{~mm}$ e $2000 \mathrm{~cm}^{2}$ de área, que reveste, com uma substância de cor acinzentada, a caixa craniana.

Assim como o sistema nervoso central, o córtex cerebral pode ser dividido tomando-se como base vários aspectos. Além dos quatro lobos, ele - o córtex cerebral - é constituído por mais duas outras partes. Com a porção medial dos lobos frontal, parietal e occipital forma-se o lobo límbico. Dada a sua complexidade e importância nos processos funcionais, muitas vezes o lobo límbico é conhecido por sistema límbico. Além dele, outro constituinte muito importante do córtex cerebral é o córtex insular, que não é visível na superfície do córtex, por localizar-se sobre a parede medial do sulco central.

\subsubsection{Classificação Estrutural do Córtex}

O córtex cerebral tem sido objeto de meticulosas investigações histológicas nas quais foram estudados diversos aspectos de sua estrutura, tais como a composição e característica das diversas camadas, disposição e espessura das raias e estrias. Com base nesses estudos, o córtex cerebral pode ser dividido em áreas citoarquitetônicas, havendo vários mapas de divisão. Assim, von Economo distinguiu no córtex cerebral do homem 109 áreas, enquanto o casal Vogt conseguiu identificar 200 áreas. Contudo, a divisão mais aceita é a de Brodmann que identificou 52 áreas designadas por números (figura 1.3). As áreas de Brodmann são muito conhecidas e amplamente utilizadas na clínica e na pesquisa médica. 


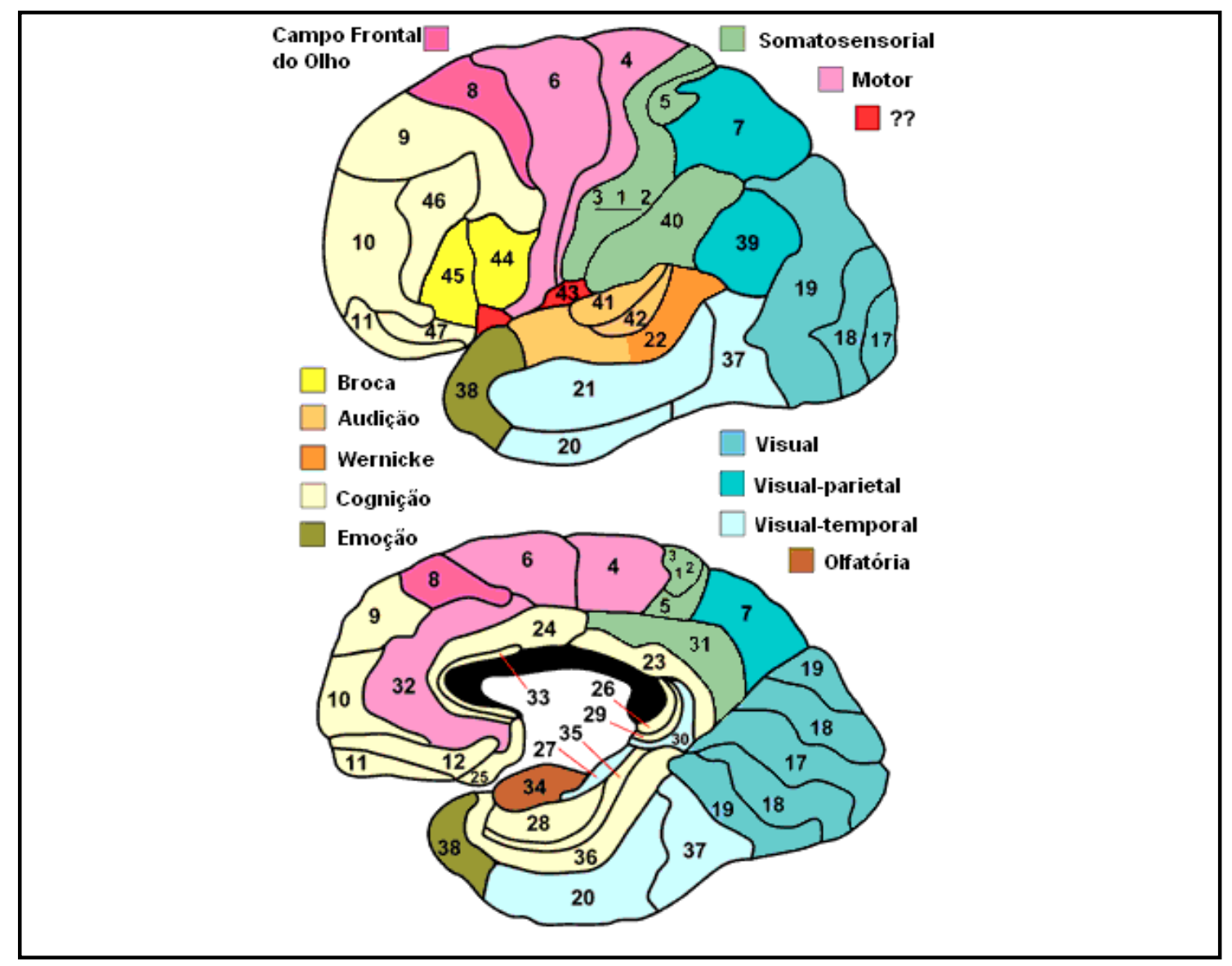

Figura 1.3 - Áreas de Brodmann no cérebro humano com atribuição funcional. Figura modificada de http://spot.colorado.edu/ dubin/talks/brodmann/brodmann.html

\subsection{Função Cerebral}

Do ponto de vista funcional as áreas corticais não são homogêneas como se acreditava no inicio do século XIX. Em 1861, o cirurgião francês Piere Paul Broca conduziu o que hoje muitos acreditam ter sido o primeiro estudo a oferecer uma prova anatômica de localizações específicas de funções cerebrais. Através dessa pesquisa ficou constatado que lesões de determinadas regiões do lobo frontal, hoje conhecida como área de Broca, estavam relacionadas a distorções na habilidade de fala. Desde então, a especialização funcional de diferentes áreas cerebrais, a integração funcional dessas regiões, e a determinação de suas conexões físicas, têm despertado grande interesse na comunidade de neurocientistas. Note, no entanto, que a localização funcional deve ser percebida como uma especialização de algumas áreas cerebrais, estando elas altamente conectadas umas às outras. 
Atualmente, a funcionalidade cerebral é esquematicamente dividida em dois grandes grupos: as áreas de projeção e as de associação. As áreas de projeção referem-se àquelas diretamente relacionadas à sensibilidade ou motricidade. As regiões de associação seguem uma subdivisão proposta pelo pesquisador russo Alexander Luria. Segundo esse modelo, o grau de interação entre uma função cerebral específica e as áreas de projeção indica o papel destas dentro da hierarquia funcional, caracterizando-a em secundárias e terciárias.

As áreas secundárias, também conhecidas como unimodais, receberiam um conjunto de fibras aferentes projetadas de suas respectivas regiões primárias. Portanto, regiões primárias visuais, por exemplo, projetariam um conjunto de fibras em áreas de associação unimodal visual. As áreas terciárias, ou supramodais, não teriam nenhuma conexão física direta com áreas de projeção, sendo responsáveis por processos cognitivos elevados, como memória, emoção, e consciência. As vias de comunicação dessas regiões seriam estabelecidas através de projeções derivadas de áreas unimodais ou outras áreas supramodais.

A finalidade geral das maiores áreas de associação tem sido estabelecida pela descrição de pacientes com lesões corticais, por imagens funcionais em sujeito normais e por estudos comportamentais e eletrofisiológicos em primatas não humanos. A seguir descreveremos as principais funções das áreas de associação, do córtex insular e do cerebelo.

\subsubsection{Córtex Frontal}

Diversos são os déficits funcionais que resultam de danos do lobo frontal humano, particularmente quando os dois hemisférios estão envolvidos. Estes danos são causados pelo fato do córtex frontal possuir várias funções, mais numerosas do que qualquer outra região neocortical (consistente com o fato que o lobo frontal em humanos e outros primatas é o maior dos lobos cerebrais e compreenderem o maior número de áreas citoarquitetônicas). Particularmente, a natureza devastadora do déficit comportamental após danos do lobo frontal reflete o papel dessa parte do cérebro em manter a personalidade individual. O córtex frontal integra informações perceptuais complexas dos córtices sensorial e motor e, também, dos córtices de associação parietal e temporal. O resultado é uma avaliação própria em relação ao 
mundo, a qual permite que os comportamentos sejam planejados e executados normalmente. Quando essa habilidade é comprometida, o indivíduo afetado geralmente possui dificuldade em executar comportamentos complexos que seriam apropriados para uma dada circunstância. Essas deficiências na habilidade normal de combinar os comportamentos que exigem um andamento do presente ou do futuro são interpretadas como uma mudança na personalidade do paciente.

O córtex dorsolateral frontal (BA 9/46), em especial, está envolvido em várias funções cognitivas incluindo a informação espacial [Courtney et al. 1998], o monitoramento e a manipulação da memória de trabalho (working memory) [Petrides 1994], a seleção de reposta [Rowe et al. 2000] e a implementação de estratégias que facilitem a memória [Bor et al. 2003]. O córtex frontal ventrolateral também está envolvido num vasto conjunto de processos cognitivos compreendendo a seleção, a comparação e o julgamento de estímulos para memória de longo e curto prazo [Petrides 1994], a informação não espacial [Courtney et al. 1997], o aprendizado inverso [Cools et al. 2002] e a seleção de estímulos [Rushworth et al. 1997]. Já o córtex órbito-frontal está envolvido em processos que incluem valores motivacional e emocional, incluindo a representação dos reforços primários como o gosto, o cheiro e o tato [Gottfried et al. 2002], a representação da relação do aprendizado entre um estímulo neural arbitrário e a recompensa por punição [Tremblay et al. 1999] e a integração dessas informações para guiar a seleção de resposta, a supressão e a tomada de decisão [Elliott et al. 2000].

\subsubsection{Córtex Parietal}

A descrição, geralmente considerada a primeira evidência da ligação entre lesão no lobo parietal com déficits de atenção e de percepção da consciência, foi feita pelo neurologista inglês W. R. Brain, em 1941, que relatou três pacientes com lesões unilaterais no lobo parietal. Baseado em vários estudos de pacientes, desde o trabalho pioneiro de Brain, esses déficits são agora referidos como síndrome da negligência espacial.

Um dos sintomas da negligência espacial é a inabilidade do paciente perceber e observar objetos ou, até mesmo, seu próprio corpo como uma parte do espaço 
apesar do fato da acuidade visual, a sensação somática e a habilidade motora permanecerem intactas.

Essencialmente, a síndrome da negligência é associada a danos do córtex parietal direito. Há evidências que a distribuição desigual dessa função cognitiva particular é devido ao fato do córtex parietal direito mediar a atenção das duas metades, direita e esquerda, do corpo e do espaço extra corporal, enquanto que o hemisfério esquerdo media a atenção apenas para o direito [Mesulam (1981 apud Nobre 1997)].

A ativação do córtex parietal posterior foi descrita durante tarefas envolvendo atenção de combinações apresentadas [Corbetta et al. 1995], vigilância [Pardo et al. 1991] e movimento indireto do braço [Deiber et al. 1991]. Estudos com lesões também sustentam a idéia de que o córtex parietal posterior é parte de um caminho especializado para programação da ação. Vários estudos têm sugerido que o córtex parietal posterior tem atividade relacionada a estímulos sensoriais, atenção e mais recentemente à intenção de movimento. O córtex parietal posterior executa um papel importante no planejamento da ação, com uma área especializada no movimento dos olhos e uma no alcance de movimentos [Snyder et al. 2000].

A atividade parietal também é relatada em estímulos envolvendo a memória de trabalho espacial Jansma et al. 2000] e não espacial [LaBar et al. 1999], a imaginação [Trojano et al. 2000], a rotação mental [Harris et al. 2000; Richter et al. 2000], a inibição de resposta [Garavan et al. 1999], cálculo [Rueckert et al. 1996; Stanescu-Cosson et al. 2000] e, também, em funções que tipicamente não são atribuídas ao córtex parietal como o processamento da dor [Apkarian et al. 1999], engolir [Hamdy et al. 1999] e meditação [Lazar et al. 2000]. "Claramente, é absurdo sustentar que as áreas parietais são especializadas por apenas um desses processos" [Culham \& Kanwisher 2001].

\subsubsection{Córtex Occipital}

Estudos anatômicos e eletrofisiológicos em macacos indicam a descoberta de múltiplas áreas envolvidas no processo da informação visual nos lobos occipital, parietal e temporal. Cada uma dessas áreas contém um mapa do espaço visual e cada uma é largamente dependente do córtex visual primário para a sua ativação. As 
respostas pertencentes aos neurônios em algumas dessas áreas sugerem que eles são especializados em diferentes aspectos das cenas visuais. Por exemplo, a área temporal média (MT) contém neurônios que respondem seletivamente à direção de um movimento, sem considerar a cor. Em comparação, neurônios em uma outra área cortical chamada V4 respondem seletivamente à cor de um estímulo visual sem considerar a direção do movimento.

A descrição clínica de um déficit visual seletivo após a localização de um dano em várias regiões do córtex extraestriado também apóia funções especializadas das áreas extraestriadas em humanos. Por exemplo, um caso muito conhecido de um paciente que sofreu um derrame que prejudicou a região extraestriada, considerada homóloga à área MT no macaco, era incapaz de apreciar o movimento de um objeto. Um outro exemplo de um déficit visual específico é o resultado de um dano do córtex extraestriado na acromatopsia cerebral, esse paciente perdeu a habilidade de enxergar o mundo colorido enquanto outros aspectos da visão permaneceram em bom funcionamento.

Baseado em conexões anatômicas entre áreas visuais, diferenças em respostas eletrofisiológicas e o efeito de lesões corticais, um consenso tem surgido que as áreas corticais extraestriadas são organizadas em dois sistemas largamente separados que eventualmente alimentam informações em áreas corticais associativas nos lobos temporal e parietal. Um sistema chamado divisão ventral, inclui a área V4 e conduz o córtex extraestriado a parte inferior do lobo temporal. Esse sistema é responsável pela alta resolução da forma e do reconhecimento de objetos. A divisão dorsal, a qual inclui a área temporal média, conduz o córtex extraestriado ao lobo parietal. Esse sistema é responsável pelos aspectos espaciais da visão como a análise do movimento e a relação da posição entre objetos e a cena visual.

\subsubsection{Córtex Temporal}

Evidências clínicas de pacientes com lesões do córtex de associação no lobo temporal indicam que uma das maiores funções dessa parte do cérebro é o reconhecimento e a identificação de estímulos observados. Danos no lobo temporal podem resultar em dificuldade de reconhecimento, identificação e também em uma dificuldade de nomear diferentes categorias de objetos. Essas desordens, 
comumente chamadas de agnosias (do grego "não saber"), são um pouco diferentes da síndrome de negligência. Os pacientes com agnosia reconhecem a presença de um estímulo, mas não são capazes de informar o que esse estímulo representa.

Um dos estudos mais completos sobre agnosia após dano do córtex de associação temporal em humanos é a inabilidade de reconhecer e identificar faces. Essa desordem, chamada prosopagnosia (prosopo - do grego para face e pessoa), foi identificada por neurologistas no século XIX e permanece até hoje sob investigação. Após danos do lobo temporal, tipicamente no lobo temporal direito, os pacientes são incapazes de identificar indivíduos pelas suas características faciais e, em alguns casos, não reconhecem nem mesmo a face. Todavia, tais indivíduos estão perfeitamente atentos em algum tipo de estímulo visual apresentado e podem descrever aspectos particulares ou elementos desse sem dificuldade. Em geral, lesões do lobo temporal direito levam a uma agnosia para faces e objetos, enquanto lesões de regiões correspondentes ao lobo temporal esquerdo tendem a resultar em dificuldades relacionadas à linguagem.

$\mathrm{Na}$ parte caudada do córtex temporal superior, Chakraborty \& Thier (2000 apud Karnath 2001) identificaram a área visual posterior de Sylvian, a qual é localizada profundamente no sulco lateral, como uma estrutura decisiva para o senso subjetivo da estabilidade espacial do macaco. Mais rostrolateralmente, mas conectado próximo à área posterior de Sylvian, está o córtex parieto-insular vestibular (PIVC) [Grüsser et al. 1990a, 1990b]. Essa área integra as vias vestibulares, somatosensorial e visual para gerar uma representação neural multimodal do movimento do indivíduo e da orientação espacial. A última região do córtex temporal superior caudal circunda áreas como a temporal média superior (MST) e a temporal média (MT). Essas áreas são parte do sistema dorsal do processamento de informação visual e estão principalmente envolvidos na análise de movimento.

\subsubsection{Córtex Insular}

O lobo insular em primatas, incluindo humanos, executa papeis como: sensação visceral, visceral motora (autônomo), associação motora, vestibular e está, também, relacionado à linguagem [Augustine (1985 apud Augustine 1996)]. Estudos ao longo da década passada têm ampliado o papel da ínsula para incluir sua 
designação como uma área somatosensorial, uma área sensorial variada e como uma componente do córtex de integração límbico. Também foi sugerido que a ínsula está envolvida na doença de Alzheimer e em funções complexas como memória de trabalho e atenção visual seletiva.

A descrição da ínsula como uma área visceral sensorial parece justificável baseado em funções previamente observáveis [Augustine (1985 apud Augustine 1996)]. Novas técnicas sugerem que a insula anterior é a localização anatômica do gosto [Ogawa 1994]. Alguns relatos aumentam a probabilidade de um padrão para a sensação visceral geral e especial através da ínsula envolvendo a língua (gosto), a garganta, o esôfago e outras possíveis áreas do trato gastrintestinal [Roper et al. 1993; Aziz et al. 1995].

Além da designação como área sensorial visceral geral e especial, dados funcionais também atribuem à ínsula um papel somatosensorial. Um estudo fisiológico da ativação sensorial no campo granular da ínsula [Schneider et al. 1993] sugere que neurônios nesse campo respondem a estímulos cutâneos. Outro aspecto da função somatosensorial executado pela ínsula é a retransmissão das informações somatosensoriais para estruturas límbicas no lobo temporal [Friedman (1986 apud Augustine 1996); Schneider et al. 1993].

O envolvimento da ínsula em fobias simples pode mediar seu papel como uma área sensorial variada com o contexto do córtex de integração límbico [Rauch et al. 1995]. Esse papel também foi sugerido devido o seu envolvimento na doença de Alzheimer [Fowler et al. (1980 apud Augustine 1996)]. Tais comportamentos complexos com suas componentes autônomas e viscerais podem representar níveis mais altos das funções envolvidas no córtex insular.

Há várias evidências na literatura que apóiam a designação da ínsula como uma área motora visceral (autônoma). Tais dados são baseados em vários estudos nos quais estimulações em primatas e humanos foram realizadas, com observações do fenômeno visceral motor, durante convulsões [Augustine (1985 apud Augustine 1996)]. De acordo com esses estudos há uma sugestão recente do papel da ínsula no disparo do vômito [Fiol et al. (1988 apud Augustine 1996)] e mudanças cardiovasculares durante estimulações insulares em macacos [Zhang et al. 1999]. 
Há um importante papel da ínsula como área de associação motora envolvendo membros superiores, incluindo as mãos [Chollet et al. 1991; Weiller et al. 1992] e movimentos sacádicos do olho [Petit et al. 1993]. Os relatos das conexões insulares com várias estruturas límbicas sugerem um papel da insula na atenção espacial, na memória ou nos aspectos motivacionais do controle oculomotor.

A relação da ínsula com o sistema vestibular é observada através de identificações neurofisiológicas de neurônios vestibulares, em macacos, no córtex parieto-insular vestibular (Parietoinsular Vestibular Cortex - PIVC). Essa região cortical está localizada no banco superior do sulco lateral próximo ao final posterior da ínsula, o qual inclui neurônios na parte posterior e superior do córtex insular granular [Grüsser et al. 1990a]. Com poucas exceções, todos os neurônios vestibulares no PIVC respondem à estimulação visual e somatosensorial e são classificados como unidades vestibulares polimodais [Grüsser et al. 1990b]. Sugere-se que a insula posterior é provavelmente homóloga ao PIVC em macacos e que o PIVC é a área cortical vestibular dominante e o centro de integração de várias áreas vestibulares no lobo parietal.

Além disso, acredita-se que a área somatosensorial secundária e o córtex insular executam um papel importante no processamento de absorção da dor [Zhang et al. 1999]. Outros relatos sugerem que a sensação termal é representada no córtex insular [Augustine 1996].

Uma associação da ínsula anterior com a emoção gerada internamente é sugerida pela sua ativação com a geração de tristeza, ansiedade antecipatória, pânico, ódio e excitação sexual evocada visualmente [Phillips et al. 1997; Reiman 1997; Mayberg et al. 1999; Stoleru et al. 1999].

\subsubsection{Cerebelo}

O cerebelo é considerado, hoje, como uma estrutura especializada na regulação de funções perceptivas, cognitivas e motoras geradas em outras porções do sistema nervoso [Kandel 2000; Thach et al. 1992 ]. O estudo das conexões do cerebelo mostra que cada hemisfério cerebelar controla os neurônios motores do seu lado, o que é uma importante diferença com os hemisférios cerebrais que controlam o neurônio motor do lado oposto. Outra importante diferença entre o 
cérebro e o cerebelo é que esse funciona sempre em nível involuntário e inconsciente.

Podemos observar três subdivisões do cerebelo: o arquicerebelo - que está relacionado com a manutenção do equilíbrio e movimentos de olhos, cabeça e pescoço durante a imobilidade e movimento; o paleocerebelo - que auxilia no movimento coordenado do tronco e das pernas; e o neocerebelo - que exerce controle sobre os movimentos coordenados finos dos membros, particularmente das extremidades superiores.

A idéia do cerebelo como coordenador de movimentos surgiu entre os fisiologistas do século XIX, através da observação de animais que apresentaram distúrbios motores após a remoção ou lesão do órgão. Hoje, o emprego de técnicas de imagens e outros experimentos neurobiológicos, sugerem que o cerebelo participa de forma ativa de outras atividades, como raciocínio espacial, distúrbios de linguagem, compreensão e distinção de fonemas, na memória de curta duração, aprendizado de tarefas motoras [Kim \& Thompson 1997], na atenção, no controle de atos impulsivos, nas emoções [Allen et al. 1997], nas funções cognitivas superiores e de percepção [Delgado-Garcia 2001], na habilidade de planejar tarefas e, possivelmente, até mesmo em condições especiais como a esquizofrenia e o autismo.

Através de estudos com pessoas e animais saudáveis verificou-se que o cerebelo apresenta-se ativo durante atividades como fome, sede, audição, consciência dos movimentos e percepção de dor. 


\section{Capítulo 2}

\section{SISTEMA VESTIBULAR E OCULOMOTOR}

\subsection{Anatomia e Fisiologia do Sistema Vestibular}

O sistema vestibular é responsável por sentir o movimento da cabeça e manter a estabilidade das imagens na fóvea (área central da retina onde há melhor acuidade visual) e, também, pelo controle postural durante a locomoção. Sinais representando os movimentos rotacionais e translacionais da cabeça, como a inclinação da cabeça relativa à gravidade, são transmitidos para os órgãos vestibulares no ouvido interno. Essas informações sensoriais são, então, utilizadas para controlar os reflexos responsáveis por manter a estabilidade das imagens na fóvea durante os movimentos da cabeça. As informações dos receptores vestibulares também são importantes para a postura e para o modo de locomoção. Quando os receptores vestibulares estão funcionando normalmente, esses promovem uma acurácia excelente da representação dos movimentos da cabeça nas três dimensões. Desordens das funções vestibulares resultam em anormalidades desses reflexos e deixam a sensação de informações reflexas anormais sobre a movimentação dos receptores vestibulares [Minor et al. 1998].

Podemos dividir o sistema vestibular em periférico e central. O sistema vestibular periférico é composto pelos órgãos otolíticos, responsáveis pelo equilíbrio estático, que nos fornece a noção exata da posição do corpo e da cabeça com respeito ao espaço à nossa volta [Hungria 1991], e pelos canais semicirculares, os quais detectam acelerações angulares. Contudo, o sistema vestibular central é composto pelos núcleos vestibulares, localizados no soalho do IV ventrículo.

O sistema vestibular está situado no osso temporal, possuindo uma forma complicada e, por esta razão, é denominado labirinto. Na verdade, há dois labirintos: um ósseo, que aloja o segundo, o membranoso. O labirinto ósseo consiste de três partes: a cóclea, o vestíbulo e os canais semicirculares (figura 2.1). A cóclea apresenta-se como uma espiral em torno de um eixo. Por sua vez o vestíbulo é uma cavidade oval situada entre a cóclea e os canais semicirculares, apresentando duas 


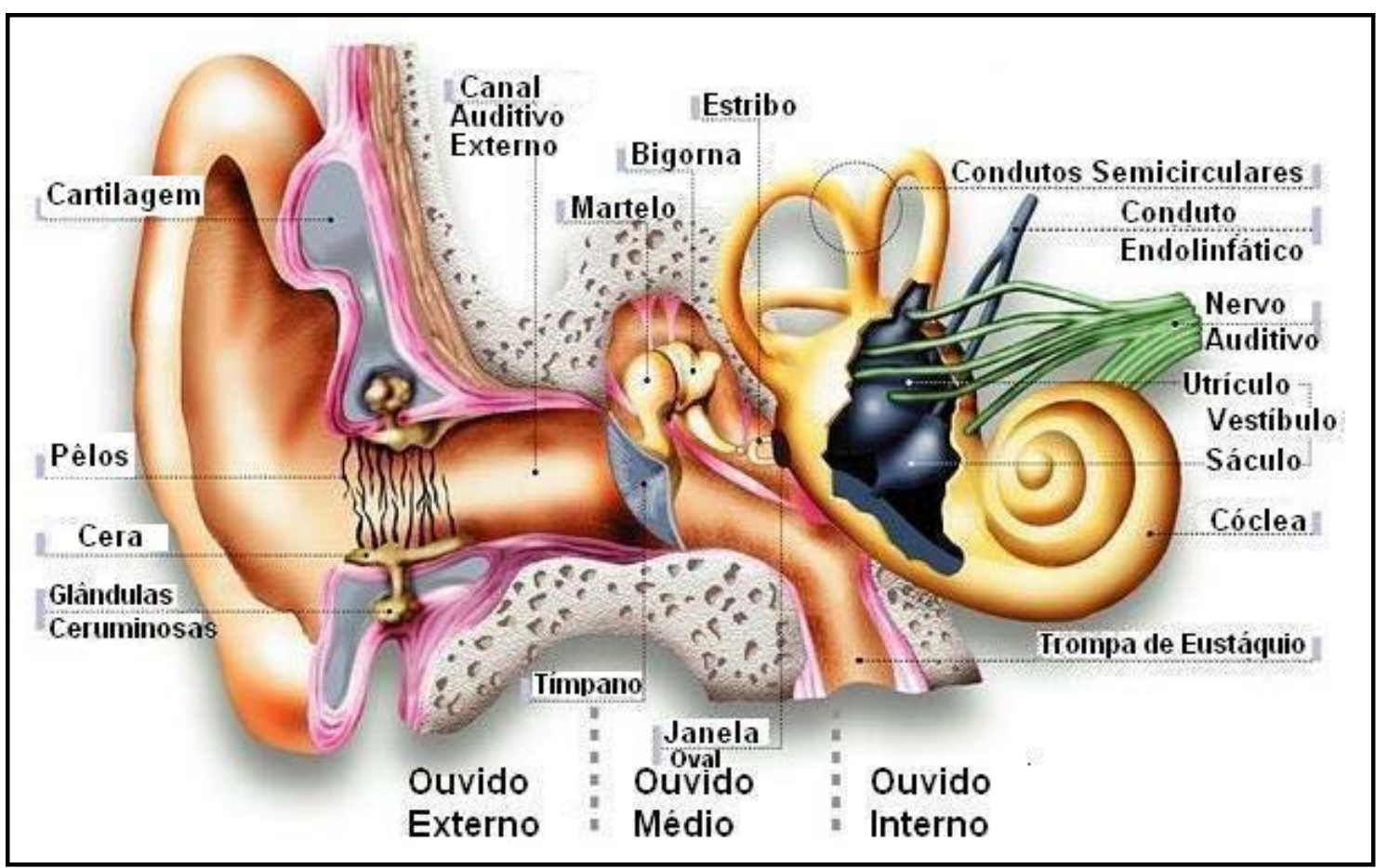

Figura 2.1 - Estruturas anatômicas do ouvido. Representação do Ouvido Externo, Médio e Interno.

vesículas membranosas - o sáculo e o utrículo. Já os canais semicirculares são três e dispõem-se de tal modo a ocupar os três planos geométricos, formando entre si ângulos de cerca de $90^{\circ}$.

\subsubsection{Células Ciliadas}

As células ciliadas estão presentes tanto nos canais semicirculares como nos órgãos otolíticos, são as estruturas capazes de transformar o estímulo mecânico (aceleração) em sinal neural. Essas células sensoriais apresentam dois tipos de cílios: os cinocílios, em número de um para cada célula, sendo maior e situado lateralmente, e os estereocílios, mais finos, curtos e numerosos, localizados lateralmente ao cinocílio. O potencial de membrana da célula ciliada depende da inclinação destes cílios, da seguinte maneira: inclinação dos cílios na direção do cinocílio leva a uma despolarização da membrana e na direção contrária à hiperpolarização (figura 2.2). Esse movimento do estereocílio na direção do cinocílio nos órgãos vestibulares abre mecanicamente os canais transdutores localizados na ponta do estereocílio, despolarizando a células ciliada e causando a liberação dos neurotransmissores excitatórios até as fibras do nervo vestibular. 


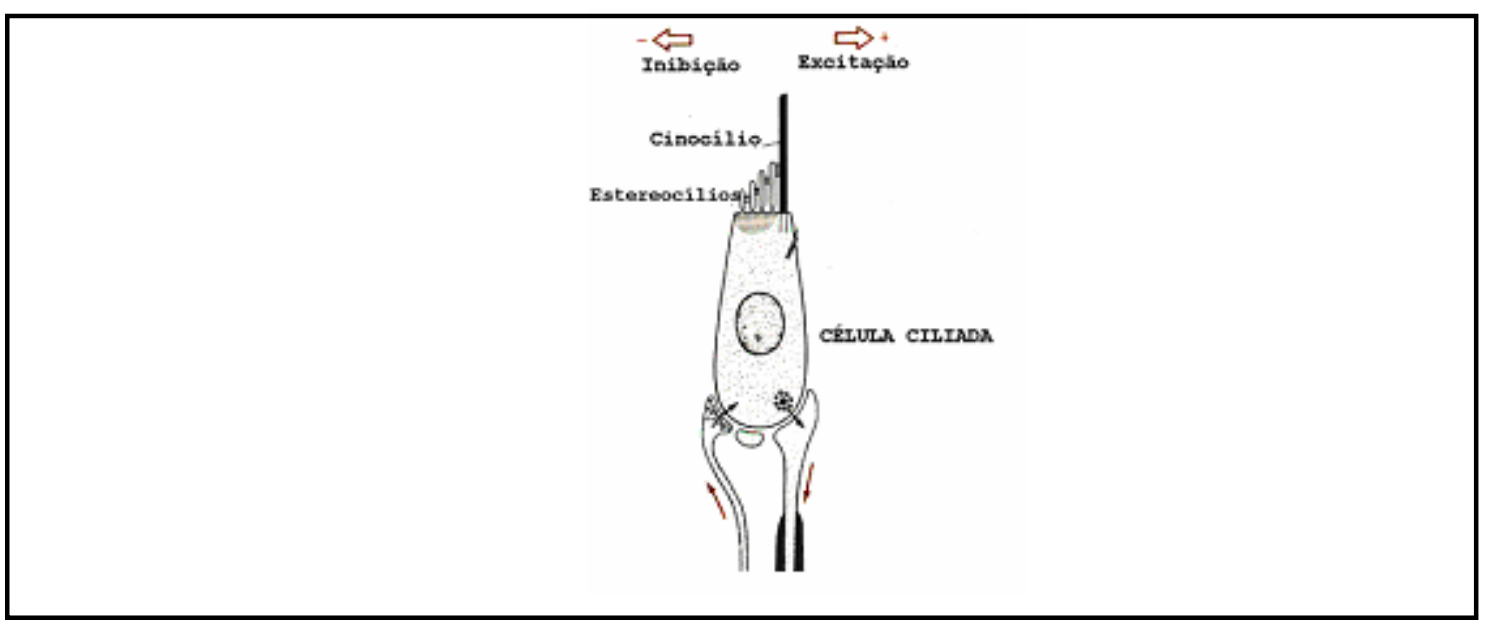

Figura 2.2 - Representação das células ciliadas. Quando os estereocílios inclinam-se na direção dos cinocílios causam a despolarização e quando inclinam na direção contrária causam hiperpolarização.

É importante dizer que o conjunto dessas células em cada órgão vestibular possui uma orientação específica. No canal semicircular horizontal estas células ciliadas estão organizadas de tal forma que todos os cinocílios estão no sentido do utrículo, e nos canais semicirculares anterior e posterior estão dispostas de maneira inversa, com os cinocílios no sentido oposto ao utrículo, o que em ambos os casos forma um eixo de despolarização. Já no utrículo e no sáculo estas células estão arranjadas com seus cinocílios na direção de uma linha curva (figura 2.7).

\subsubsection{Estruturas e Fisiologia dos Canais Semicirculares}

De cada lado do crânio há três canais semicirculares: o horizontal (ou lateral), o anterior e o posterior (figura 2.3). O canal horizontal, na realidade, não ocupa o plano horizontal quando a cabeça está em posição normal, pois apresenta, em relação ao plano horizontal, um ângulo de $30^{\circ}$ aberto anteriormente. Esses canais apresentam-se cheios de endolinfa e estão dispostos perpendicularmente entre si. 


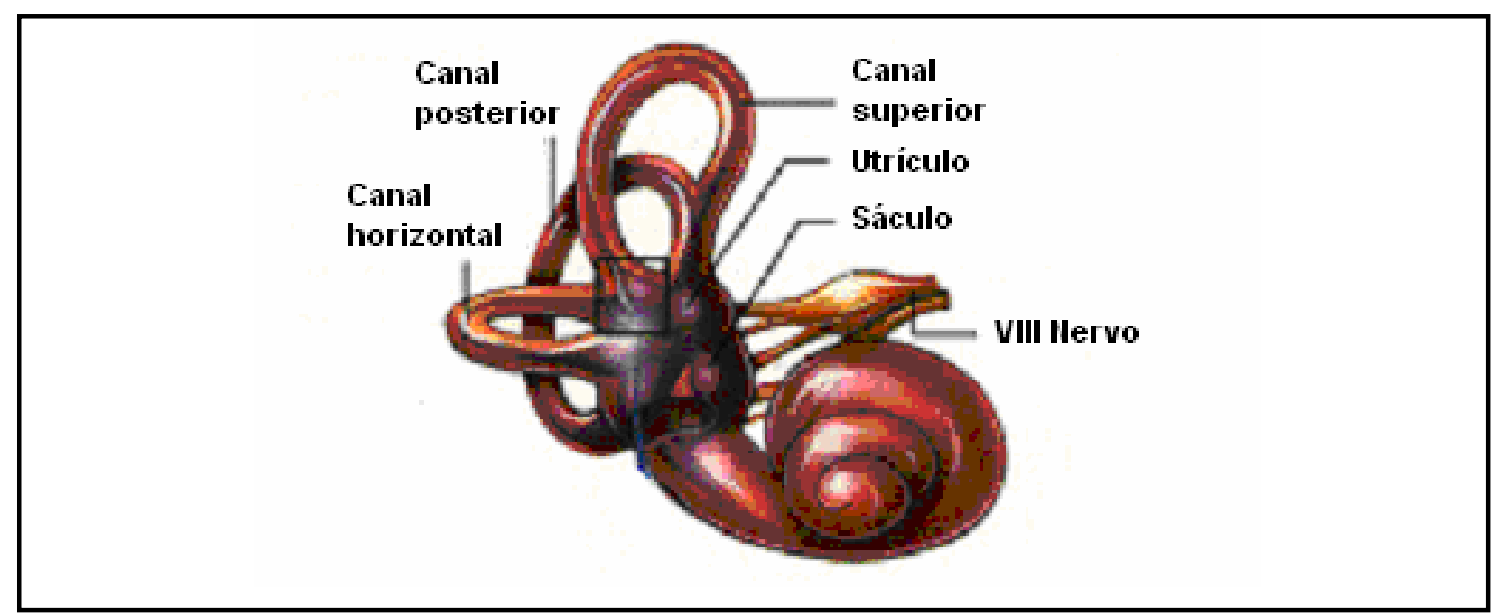

Figura 2.3 - Aparelho Vestibular. Representação dos três canais semicirculares e dos órgãos otolíticos membranosos.

Em uma das extremidades de cada canal semicircular está uma dilatação, a ampola. Nessa encontram-se as células receptoras ciliadas. Estas, juntamente com as células de sustentação, formam a crista ampular (figura 2.4). Como estrutura acessória, há a cúpula gelatinosa, que faz saliência na endolinfa, e enche o interior da ampola. Como o peso específico da cúpula gelatinosa é igual ao da endolinfa, ela não se desloca durante a aceleração linear. Como a cúpula preenche a ampola, a endolinfa não flui ao redor dela. Os estereocílios e cinocílios das células da crista estão mergulhados na cúpula gelatinosa (figura 2.4).

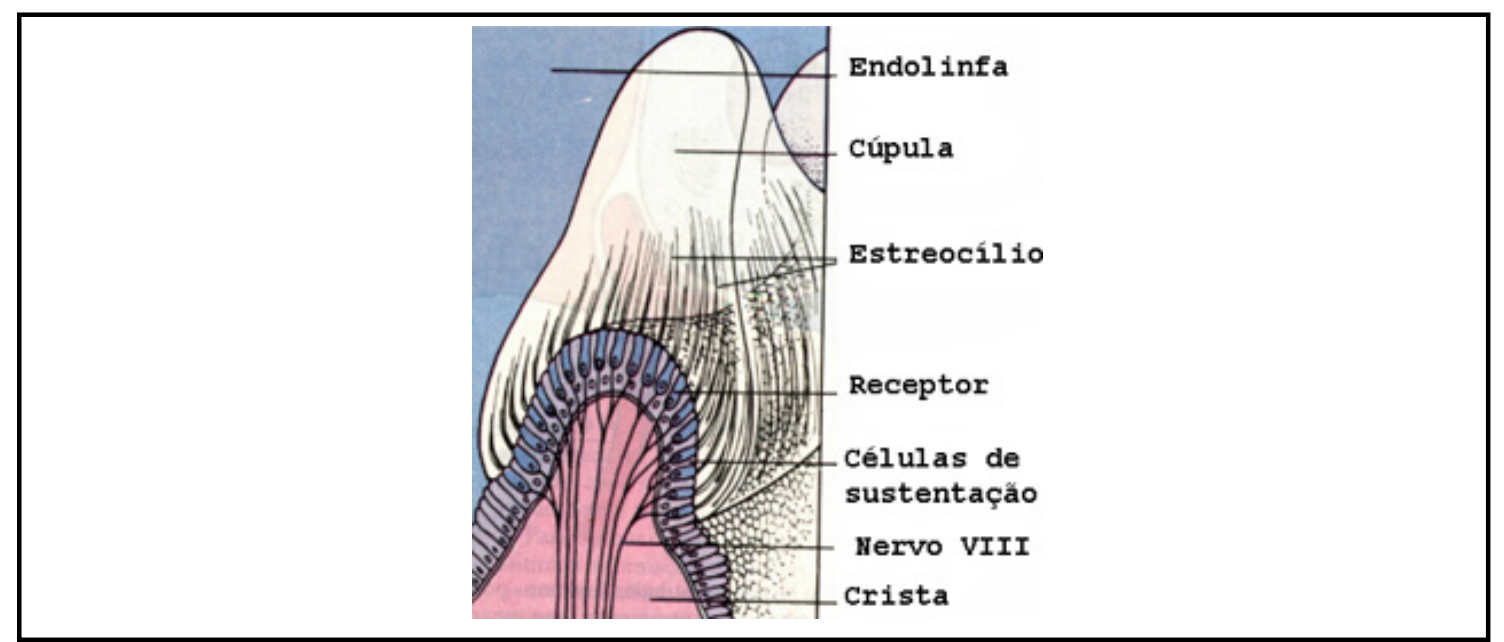

Figura 2.4 - Representação estrutural da ampola e de suas células ciliadas.

Durante um movimento rotatório, a endolinfa adquire velocidade idêntica à do ducto semicircular (movimento uniforme). Com a parada do movimento, e pelo princípio da inércia, a endolinfa continua a deslocar-se no mesmo sentido do 
movimento giratório, até se deter. Essa corrente endolinfática desloca a cúpula e os cílios da crista ampular, produzindo as sensações subjetivas e objetivas da rotação [Steinhausen (1933 apud Hungria 1991)].

Quando a cabeça é submetida a uma aceleração angular no plano horizontal, por exemplo, quando rodamos a cabeça ou a inclinamos para frente e para trás, existe o deslocamento da endolinfa, afetando a cúpula. $\mathrm{O}$ deslocamento da endolinfa é oposto ao da rotação da cabeça, constituindo uma corrente de endolinfa em direção à ampola (ampulípeta), no canal horizontal do lado da rotação. Já no canal oposto, a endolinfa se deslocará em direção oposta à ampola (corrente ampulífuga) (figura 2.5).

Quando, por exemplo, a cabeça é girada para a esquerda, a corrente ampulípeta será no canal horizontal esquerdo, e esta determinará um deslocamento da cúpula em direção ao utrículo. Isso acarretará um deslocamento dos estereocílios em direção ao cinocílio, esse padrão de inclinação dos cílios da crista ampular direita por forças tangenciais provocará alterações da permeabilidade da membrana das células sensoriais e diminuirá o potencial negativo da membrana pela entrada na célula de íons positivos. Ocorrendo, conseqüentemente, uma despolarização, que leva ao aparecimento de um potencial de ação, acarretando em uma estimulação positiva. A freqüência de descarga de repouso que existia nos neurônios aumenta devido a essa estimulação e o sistema nervoso central é informado de que a cabeça girou para o lado esquerdo (figura 2.5). 


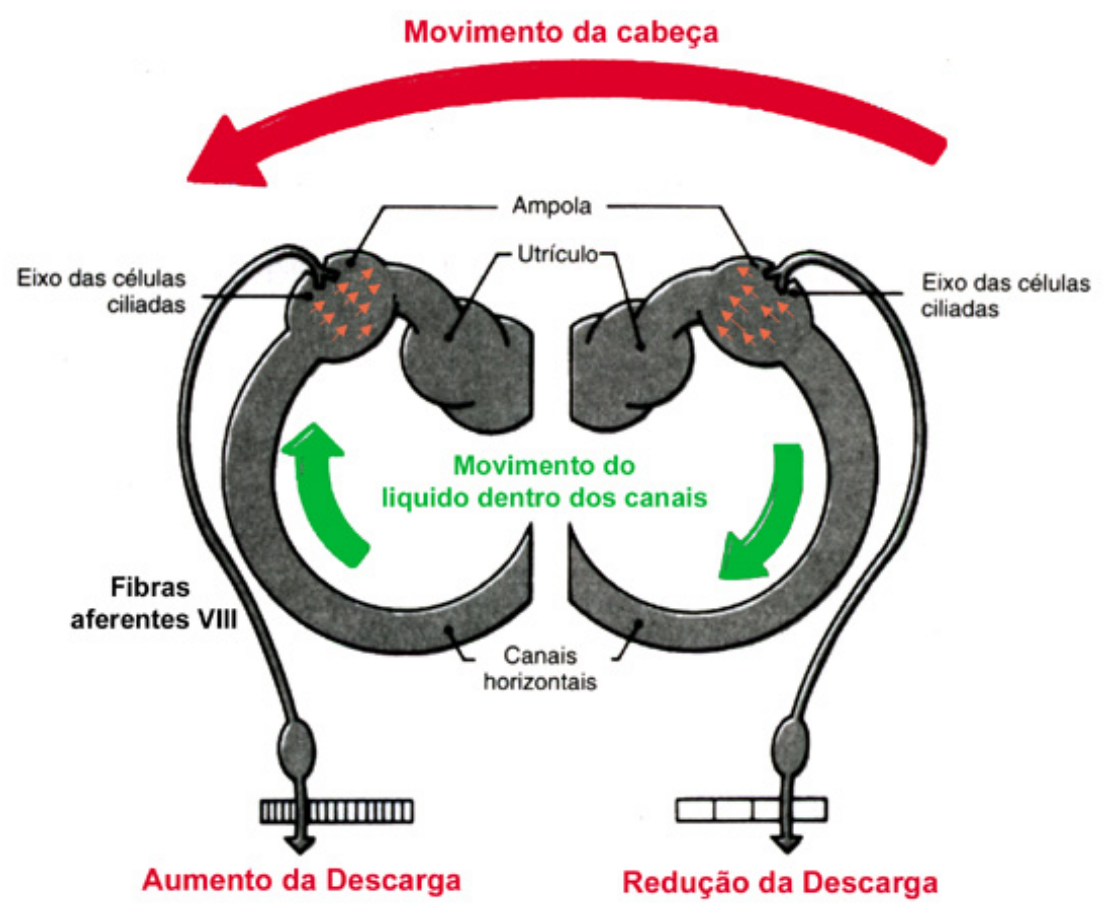

Figura 2.5 - Observe o movimento de rotação da cabeça para a esquerda na figura (seta vermelha). Repare que os cinocílios de cada crista dos canais semicirculares horizontais estão todos orientados em direção ao utrículo (conjunto de setinhas pequenas). As setas em curvas (verde) representam os movimentos passivos do líquido endolinfático no sentido contrário ao movimento da cabeça. No lado esquerdo o líquido se move em direção à ampola e no lado direito, afastando-se dela.

Como do lado direito a corrente foi ampulífuga, a cúpula inclina-se em direção oposta ao utrículo e os cinocílios deslocam-se em direção aos estereocílios. Isso acarreta uma estimulação negativa ineficaz, determinando uma hiperpolarização nas células receptoras e uma freqüência de descarga menor do que a de repouso nos neurônios vestibulares. O sistema nervoso central, quando a cabeça gira para a esquerda, recebe freqüência de descarga maior dos receptores vestibulares deste lado e menor do lado oposto, interpretando que realmente a cabeça girou para a esquerda.

Quando o movimento é mantido, a velocidade da endolinfa é a mesma que a das estruturas dos canais, não havendo estimulação. Ao cessar o movimento que estávamos realizando para a esquerda, aparecerá uma corrente ampulípeta do lado direito com estimulação positiva desse lado. Do lado esquerdo, a corrente será ampulífuga, havendo estimulação negativa.

Como foi exposto, os canais semicirculares detectam a rotação quando a cabeça começa girar numa direção ou quando a rotação cessa. Logo, a perda de 
funções desses receptores leva a um desequilíbrio relacionado à movimentação rápida da cabeça. Essas características de funcionamento conferem uma função preditiva dos canais, uma vez que eles podem determinar o início do movimento de rotação da cabeça de uma pessoa, comunicando ao sistema nervoso central que a pessoa estará desequilibrada dentro em pouco, levando à necessidade de correção. A predição de desequilíbrio permite que o sistema nervoso faça ajustes adequados das diferentes partes do corpo na tentativa de manter o equilíbrio [Costa et al. 1994].

\subsubsection{Estruturas e Fisiologia do Sistema Otolítico}

Vimos como o sistema responde a diferenças na aceleração. Contudo, também temos outro sistema responsável pelo processamento das informações de inclinação, esses sistema é conhecido como sistema otolítico, e é composto por dois órgãos, o utrículo e o sáculo, cada um formado por uma membrana basal que sustenta as células ciliadas. Sobre essas células sensoriais há uma estrutura acessória de aspecto gelatinoso em que estão mergulhados os cílios das células sensitivas (figura 2.6). A massa gelatinosa contém muitos cristais de carbonato de cálcio, de pequenas dimensões, formando a membrana otolítica. Esses cristais, mais densos do que o material gelatinoso, são chamados otólitos.

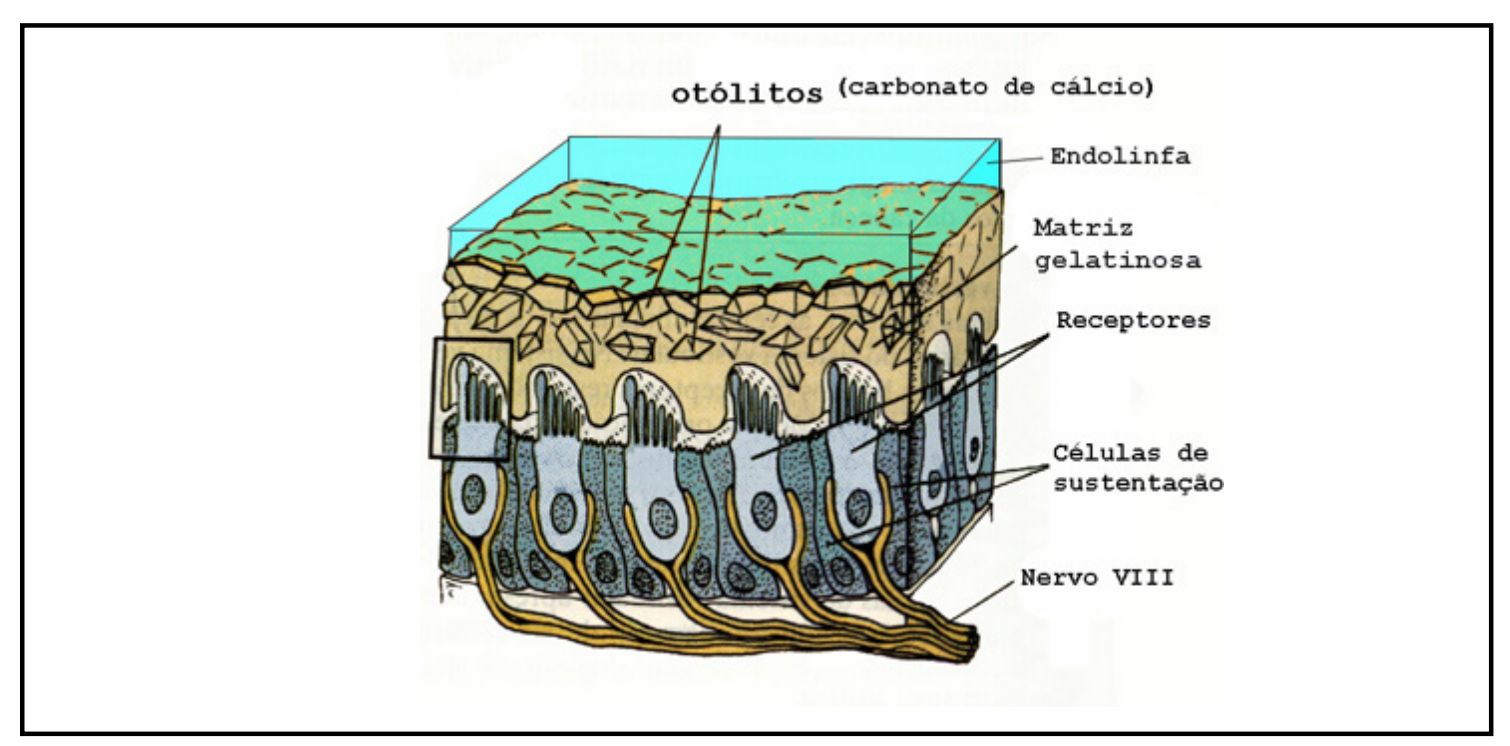

Figura 2.6 - Membrana basal dos órgãos otolíticos.

O conjunto das células ciliadas e células de sustentação, que constituem a estrutura receptora, é chamado mácula. Existe a mácula sacular com sua membrana 
otolítica no sáculo, e a mácula utricular com sua membrana otolítica no utrículo. A linha curva que atravessa a mácula é denominada estríola (figura 2.7). Quando o corpo humano encontra-se ereto, a mácula sacular apresenta-se na posição vertical e a utricular na horizontal [Costa et al. 1994].

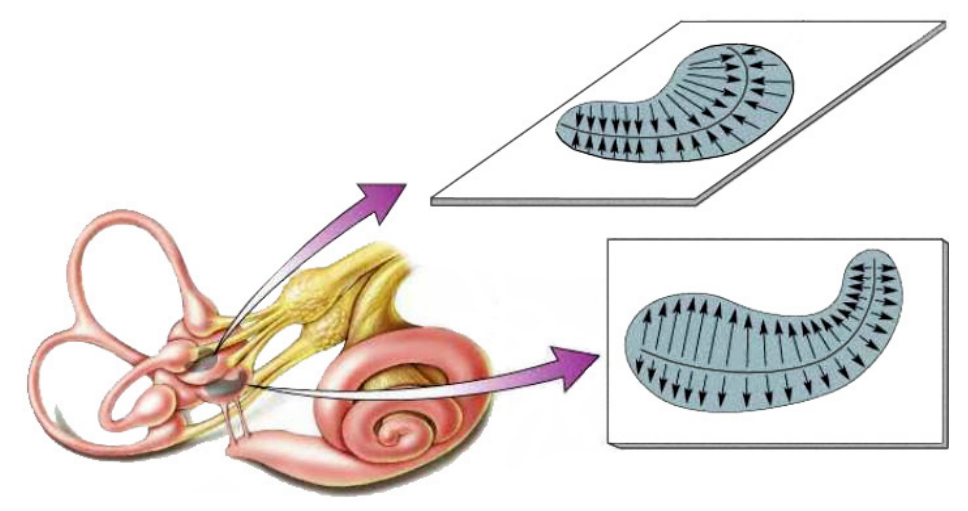

Figura 2.7 - Orientação das células ciliadas nas máculas utricular e sacular.

Quando a cabeça está em posição vertical, a mácula utricular estará em repouso, não havendo estimulação efetiva, pois os cílios estarão verticalizados, sem forças tangenciais atuando sobre eles. Quando há inclinação da cabeça ocorre uma descarga de impulsos, espontânea, nos axônios que se ligam às células sensitivas. $\mathrm{Na}$ mácula sacular, devido à sua posição verticalizada, ocorrerá uma estimulação efetiva porque os otólitos atraídos pela força gravitacional provocam o deslocamento das membranas otolíticas em relação ao epitélio sensorial da mácula. Assim, os estereocílios deslocam-se em relação aos cinocílios devido às forças tangenciais a que são submetidos. Essa inclinação dos cílios altera a permeabilidade da membrana da célula sensorial, provocando fluxo de íons positivos para o interior da célula, diminuição do potencial da membrana negativo e, conseqüente, despolarização, com formação de um potencial de ação. Sua amplitude dependerá da intensidade do estímulo: quanto maior seu valor, maior será a freqüência de descarga de impulsos nos axônios das células nervosas da mácula.

Como as células sensoriais são agrupadas de modos diferentes, com seus cílios em posições opostas na mácula, conforme a posição da cabeça, existirão células estimuladas positivamente (deslocamento dos estereocílios em direção ao cinocílio) e células estimuladas negativamente (deslocamento do cinocílio em direção ao estereocílio). No primeiro caso, a freqüência de descarga de impulsos nos 
axônios será maior do que a freqüência de repouso e, no segundo caso, a freqüência será menor do que a de repouso. Quando a cabeça forma um ângulo com a vertical, haverá um deslocamento dos órgãos otolíticos, e devido à gravidade, haverá forças tangenciais atuando em diferentes máculas e diferentes áreas receptoras em cada mácula (figura 2.8). Desse modo, todas as posições da cabeça podem ser captadas pelos axônios das máculas, que enviam essas informações a várias localizações cerebrais. Tais informações provocam movimentos reflexos que permitem a adaptação das posições do tronco e dos membros em relação à posição da cabeça, mantendo assim, o equilíbrio [Costa et al. 1994].

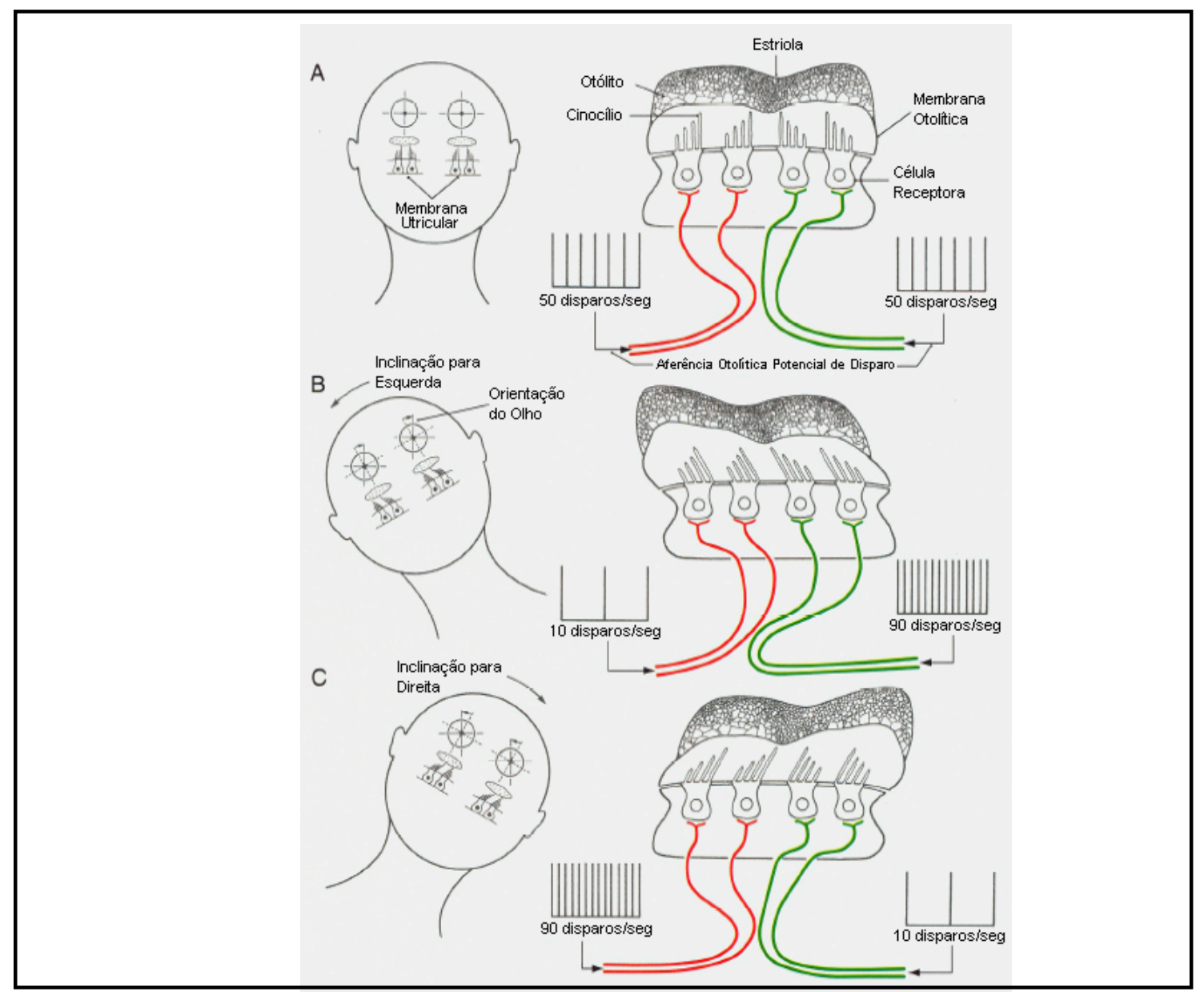

Figura 2.8 Resposta da mácula utricular à inclinação da cabeça. Quando a cabeça está na posição normal (A), as fibras aferentes possuem potenciais de disparo equivalentes nos dois lados da estríola (linhas vermelha e verde). Quando há inclinação da cabeça para a esquerda (B) ou para a direita (C), as células ciliadas e suas inervações são excitadas ou inibidas, dependendo da sua posição em relação a estríola; o peso do otólito causa a deflexão dos estereocílios. As células ciliadas na porção mais inclinada da estríola aumentam o potencial de disparo, e aquelas na porção menos inclinada diminuem o potencial de disparo. 


\subsubsection{Caminho Neural do Sistema Vestibular Central}

Dos pólos inferiores das células sensoriais partem fibras nervosas que vão formar o nervo vestibular, o qual é formado pelos nervos vestibulares superior e inferior. As fibras nervosas provenientes das ampolas lateral e anterior, e do utrículo reúnem-se para formar o nervo vestibular superior. As fibras do canal posterior e do sáculo formam o nervo vestibular inferior.

A maioria das fibras dos nervos vestibulares dirige-se aos núcleos vestibulares, localizados no soalho do IV ventrículo. Algumas se dirigem diretamente ao cerebelo. Os núcleos enviam fibras ascendentes, tanto diretas como cruzadas, ao cerebelo, à formação reticular da região do bulbo-protuberancial, aos núcleos oculomotores e as fibras descendentes para a medula (figura 2.9). Em ordem de importância, a função dos canais semicirculares consiste em enviar informações sobre os movimentos da cabeça: 1) aos olhos; 2) à musculatura do pescoço; 3) à musculatura corpórea em geral [Hungria 1991].

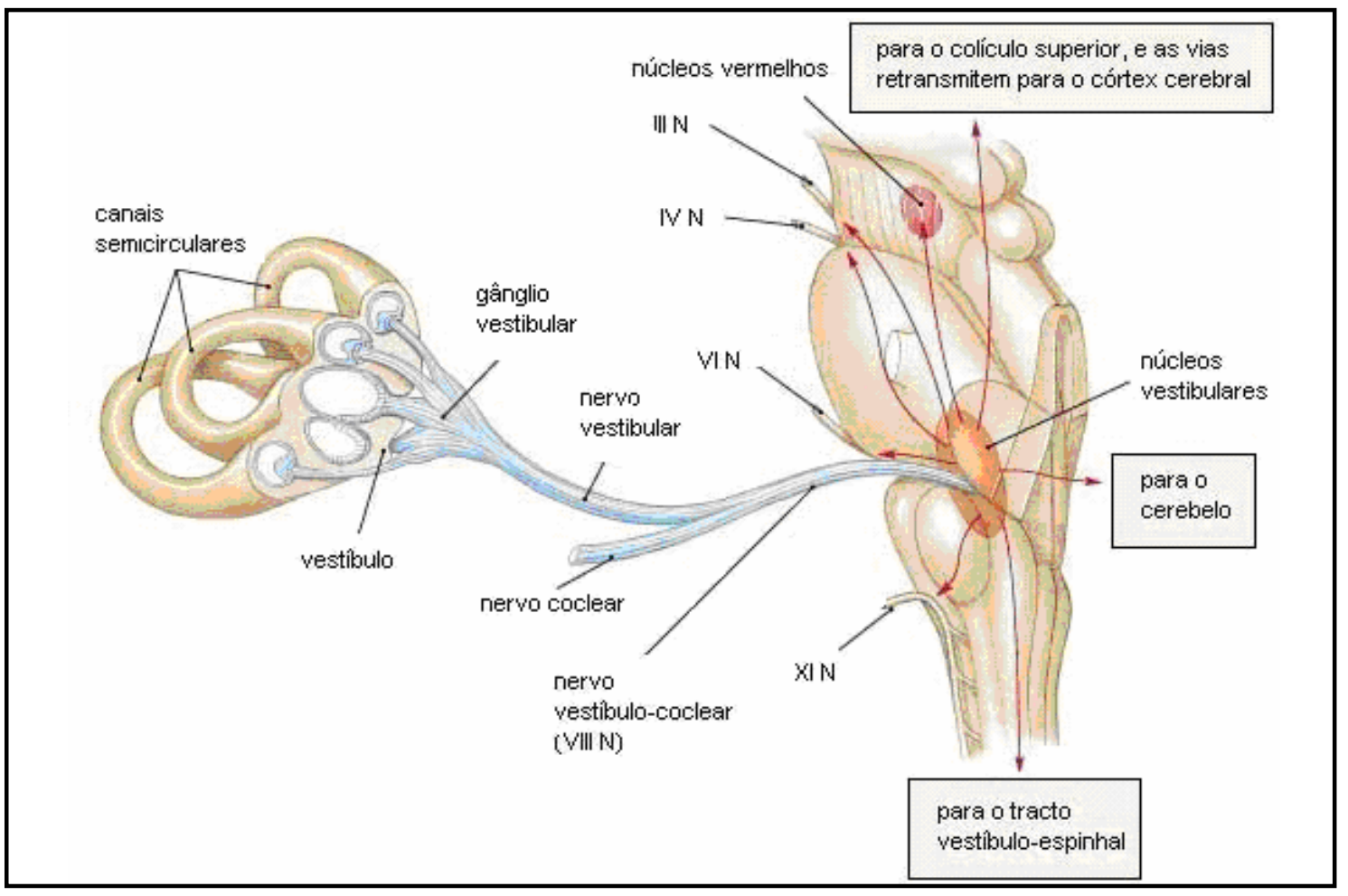

Figura 2.9- Fibras vestibulares e suas vias ascendentes e descentes.

O sistema vestibular comunica-se com os órgãos através das ramificações vestibulares no VIII nervo craniano que chega ao cérebro e o cerebelo. Essas estruturas coordenam muito dos processos necessários para computar a posição e 
articular o movimento da cabeça. Os nervos vestibulares originam-se de uma população de neurônios, os quais residem no gânglio vestibular ou de Scarpa. Essas células inervam os canais semicirculares e os órgãos otolíticos, enquanto os processos centrais projetando-se, através da porção vestibular do VIII nervo craniano, para os núcleos vestibulares. Os núcleos vestibulares são centros importantes de integração, recebendo impulsos dos núcleos vestibulares do lado oposto, como do cerebelo, do sistema visual e do somatosensorial.

Investigações utilizando técnicas de imagem em primatas [Vitte et al. 1996; Berthoz 1996] indicam que o sistema vestibular cortical apresenta diferentes regiões envolvidas, como por exemplo, a região pré-motora do córtex frontal (área 6v, área do córtex do cíngulo), áreas parietais (área 2v, área 7), áreas temporal (VPS e MST) e uma região central chamada córtex parieto-insular vestibular, constituindo parte da insula granular e da região retroinsular próxima ao córtex auditivo. Foi sugerido por Guldin \& Grüsser (1998), que essas diferentes áreas processam informações que possuem ligação com o movimento da cabeça em relação ao espaço e aos movimentos da cabeça em relação a outras partes do corpo. Além disso, essas áreas realimentariam informações monosinápticas para os núcleos vestibulares no tronco encefálico. Portanto, o sistema vestibular cortical deve ser capaz de possuir uma influência direta nos reflexos vestibulares. $O$ que indica que o sistema vestibular cortical é fortemente envolvido com a percepção espacial, e, também, na atualização da representação interna da posição do corpo em relação ao espaço externo e no estabelecimento da memória espacial [Berthoz et al. 1995]. Existem relatos de que o PIVC também pode ser encontrado em humanos. Brandt e colegas indicaram que pacientes com lesões nessa região possuem danos significativos da percepção subjetiva vertical [Brandt et al. 1994].

\subsection{Sistema Oculomotor}

Há muitos tipos de movimentos oculares, que servem a diferentes funções. Quanto à coordenação binocular, podem ser conjugados, se os dois olhos se movem no mesmo sentido e com mesma velocidade, ou disjuntivos, caso se movam em sentidos diferentes (convergentes ou divergentes). Quanto à velocidade, podem ser sacádico, se forem muito rápidos e independentes do movimento dos objetos 
externos, ou de rastreio, se forem lentos e ligados ao deslocamento de algum objeto. Finalmente, quanto à trajetória podem ser radiais, quando o eixo visual se desloca angularmente para qualquer direção, ou torcionais, quando ele permanece fixo, movendo-se o olho em rotação à sua volta. Todos esses movimentos são coordenados por uma série de músculos, descritos a seguir.

\subsubsection{Ações e Inervações dos Músculos Extraoculares}

Os músculos motores dos olhos compreendem os músculos reto, superior, inferior, medial e lateral, e o músculo oblíquo, superior e inferior (figura 2.10). Esses músculos são responsáveis pelos movimentos dos olhos ao longo de três eixos diferentes: horizontal, na direção do nariz (adução) ou para longe do nariz (abdução); vertical, elevação ou depressão; e o torcional, movimentos que trazem o topo do olho em direção ao nariz (intorção) ou para longe do nariz (extorção).

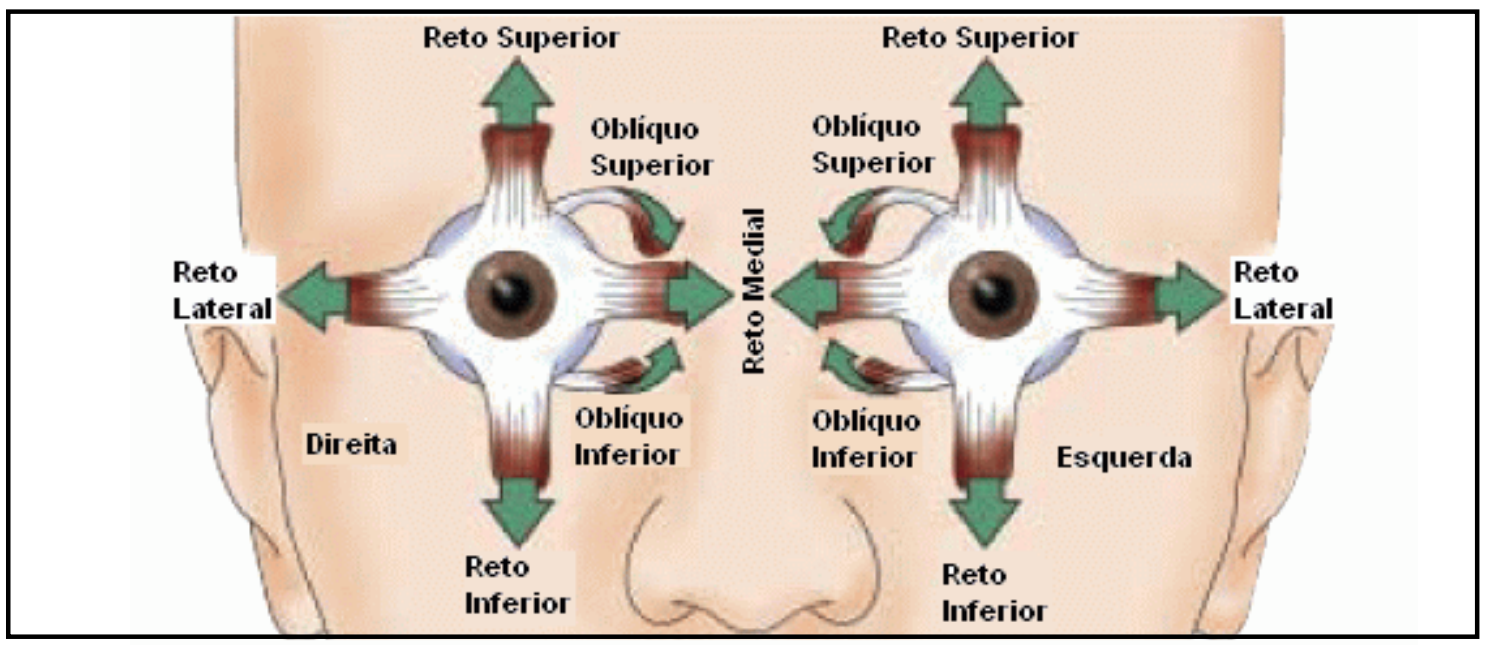

Figura 2.10 - Representação dos músculos motores do olho. Figura modificada de Purves et al. 2001.

Os movimentos horizontais são controlados inteiramente pelos músculos reto medial e lateral, responsáveis pela adução e pela abdução, respectivamente. Outros movimentos mais complexos como a depressão ou elevação do olho requer a ação coordenada dos músculos reto superior e inferior, com os músculos oblíquos. A contribuição relativa dos grupos reto e oblíquo depende da posição horizontal do olho. Na posição primária (olho para frente), os dois grupos contribuem para movimentos verticais. A elevação é feita pela ação do músculo reto superior e do músculo oblíquo inferior, enquanto que a depressão é feita pela ação do músculo 
reto inferior e oblíquo superior. Quando os olhos estão abduzidos, o músculo reto é o primeiro a mover-se na vertical. A elevação é feita pela ação do reto superior e a depressão é feita pela ação do reto inferior. Quando o olho é aduzido, os músculos oblíquos são os primeiros a moverem-se na vertical. A elevação é feita pela ação do músculo oblíquo inferior, enquanto a depressão é feita pela ação do músculo oblíquo superior. Os músculos oblíquos são também os responsáveis pelo movimento torcional.

A musculatura extraocular é inervada por neurônios motores que formam os três nervos cranianos: os abducentes, os trocleares e os oculomotores (figura 2.11). Os nervos abducentes (VI nervo craniano) deixam o tronco cerebral da junção ponte-bulbo e inervam o músculo reto lateral. O núcleo troclear (IV nervo craniano) sai da porção caudal do mesencéfalo chegando ao músculo oblíquo superior. Em distinção a todos os outros nervos cranianos, o nervo troclear deixa a superfície dorsal do tronco cerebral e atravessa a linha média para inervar o músculo oblíquo superior do lado contralateral. O nervo oculomotor (III), o qual sai da parte dorsal do mesencéfalo, perto do pedúnculo cerebral, projetando-se sobre todo o resto dos músculos extraoculares. 


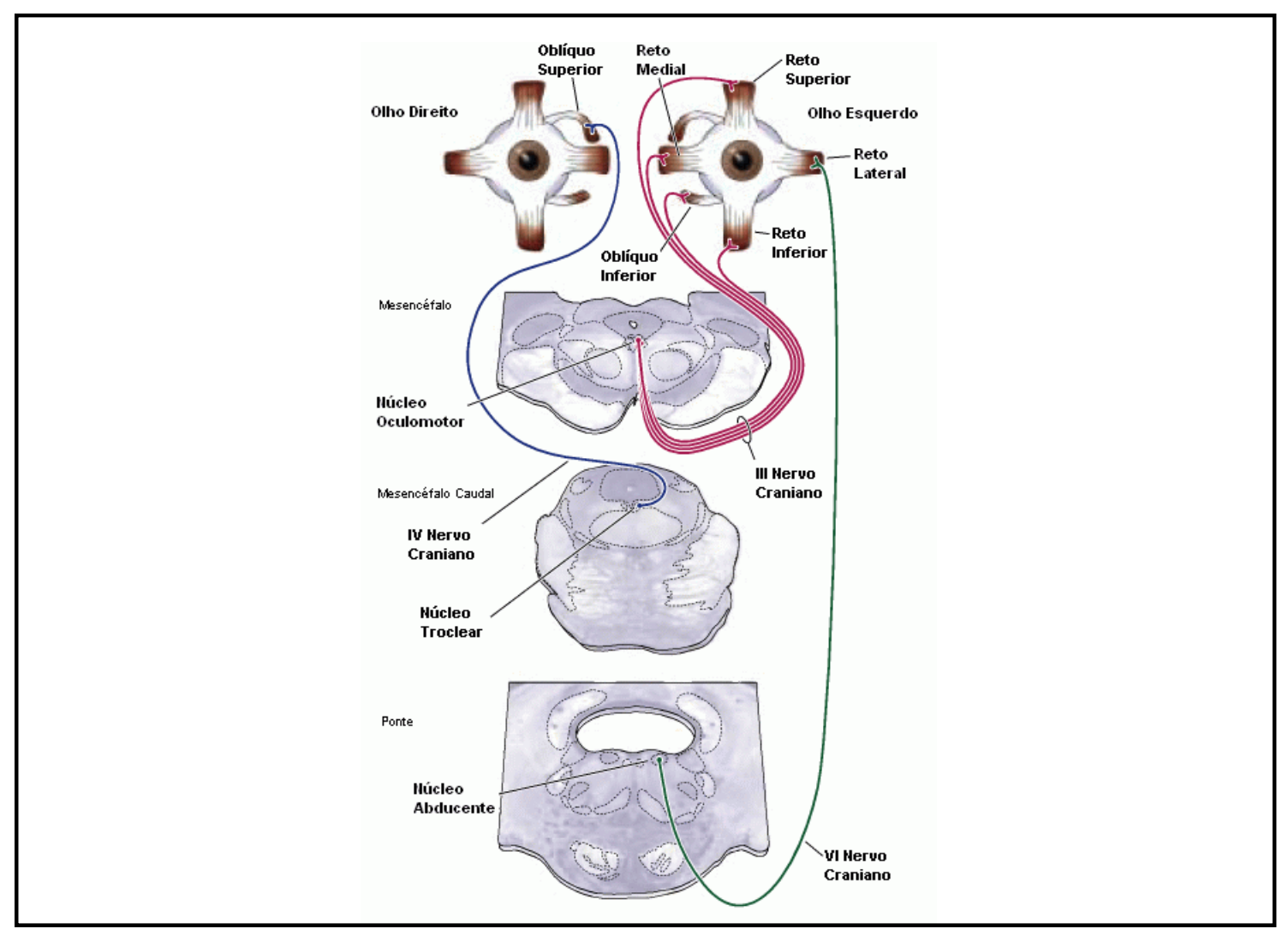

Figura 2.11 - Organização dos vários nervos e núcleos cranianos que governam o movimento dos olhos, mostrando suas inervações e as dos músculos extraoculares. Figura modificada de Purves et al. 2001.

\subsubsection{Tipos de Movimento dos Olhos e Suas Funções}

Existem quatro tipos básicos do movimento dos olhos: movimento sacádico, movimento de perseguição lenta (rastreio), movimento de vergência e movimento vestíbulo-ocular. As funções de cada tipo do movimento do olho são introduzidas a seguir.

\subsubsection{Movimento Sacádico}

São movimentos balísticos dos olhos que mudam de orientação abruptamente para um ponto de fixação. O alcance na amplitude vai desde movimentos pequenos que fazemos, por exemplo, enquanto estamos lendo, até movimentos maiores que fazemos enquanto olhamos fixamente ao redor de uma sala. O movimento sacádico pode ser voluntário, mas também ocorre reflexivamente toda vez que os olhos estiverem abertos, mesmo enquanto estamos fixando um alvo. 
A evolução temporal de um movimento sacádico é mostrada na figura 2.12 . Após o acesso de um alvo para o movimento sacádico (neste exemplo, o estímulo foi o movimento de um alvo já fixado), há um atraso de $200 \mathrm{~ms}$ antes de começar o movimento do olho. Durante esse atraso, a posição do olho em relação à fóvea é computada, e a diferença entre a posição inicial e a de destino, ou "erro motor", é convertido num comando motor que ativa os músculos extraoculares para mover o olho para a direção apropriada. Se o alvo move de novo durante esse tempo, o movimento sacádico irá perder o alvo e um segundo movimento sacádico precisa ser feito para corrigir o erro.

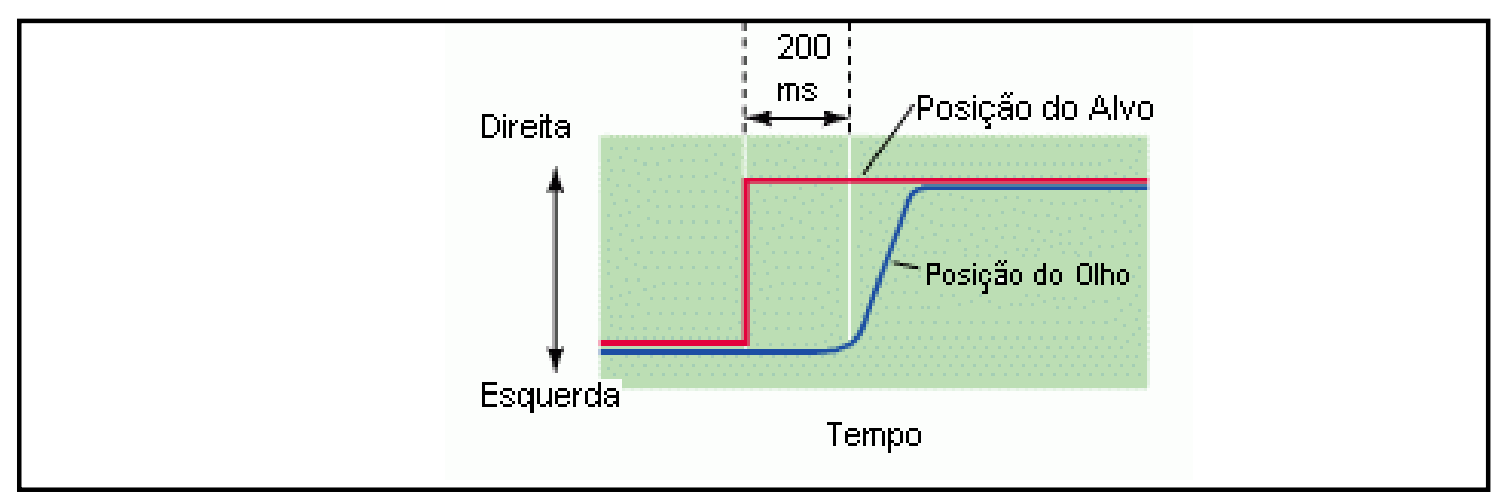

Figura 2.12 - Métrica do movimento sacádico do olho. A linha vermelha indica a posição de um alvo fixo, a linha azul indica a posição da fóvea. Quando o alvo move repentinamente para a direita, há um atraso de $200 \mathrm{~ms}$ antes do olho começar a mover para a nova posição do alvo. Figura modificada de Purves et al. 2001.

Uma visão geral do controle neural para o movimento sacádico pode ser descrita como uma informação visual originada no lobo occipital tornando-se saliente no lobo parietal devido a diversas áreas de atenção. Essas áreas de atenção estão localizadas na parte posterior do SPL (Superior Parietal Lobe), e na parte posterior do IPS (Intraparietal Sulcus) e talvez em outras áreas intraparietais como o IPL (Inferior Parietal Lobe) (giro supramarginal e giro angular) [Wardak et al. 2002; Bilsey \& Goldberg 2003]. Um sacade reflexivo é provocado pelo PEF (Parietal Eye Field) caso as circunstâncias externas requeiram uma resposta rápida. Esse reflexo é produzido via tracto parieto-colicular direto, passando pela parte posterior da cápsula interna. No caso de uma resposta atrasada, a informação visual é transmitida do PEF ao FEF (Frontal Eye Field) para fixação operante e pela área intraparietal para o DLPFC (Dorsolateral Prefrontal Cortex) para memorização espacial. A execução de um sacade intencional é realizada pelo FEF, o qual está preparado para 
responder a influência do giro do cíngulo, o que influência, via um processo de motivação intencional, todas as outras áreas oculomotoras frontais [PierrotDeseilligny et al. 2004].

\subsubsection{Movimento de Perseguição Lenta}

São movimentos de rastreio do olho designados para manter na fóvea um estímulo que se movimenta lentamente. Tais movimentos possuem controle voluntário, no sentido que o observador pode escolher acompanhar ou não um estímulo em movimento. Surpreendentemente, no entanto, somente observadores treinados podem fazer um movimento de rastreio lento na ausência de um alvo em movimento. A maioria das pessoas que tentam mover seus olhos em rastreio sem um alvo em movimento acaba por fazer um movimento sacádico involuntário.

Um modelo para o circuito neural do movimento de perseguição lenta descrito por Krauzlis [Krauzlis 2004] consiste em um circuito aparentemente simples, o qual conecta áreas dos lobos temporal e frontal com regiões motoras do cerebelo relacionadas à perseguição. As áreas temporal média (Middle Temporal MT) e temporal média superior (Medial Superior Temporal-MST), no sulco temporal superior, processam o movimento visual e os sinais oculomotores, que são tipicamente requeridos para o movimento de perseguição. Esses são transmitidos para os flóculos e para os paraflóculos ventrais, via núcleos visuo-motores, no núcleo pontino, primeiramente ao núcleo pontino dorsolateral. Essas regiões cerebelares acessam as saídas dos núcleos motores dos músculos dos olhos através da projeção nos núcleos vestibulares. Em paralelo com esse caminho, um segundo caminho cortico-ponto-cerebelar origina-se no FEF e continua através dos núcleos reticulares tegmento pontino, os quais, como o núcleo pontino dorsolateral, promovem saídas exclusivamente para o cerebelo, nesse caso para os lobos VI e VII do vermis. Outras regiões corticais também estão envolvidas no controle neural do movimento de perseguição lenta, como o SEF (Suplementary Eye Field) e também áreas parietais, as quais incluem o PEF e a região parieto-occipital, a qual está relacionada com mudanças de atenção. A maioria das áreas corticais que mediam o sistema de perseguição lenta mostra algumas sobreposições com o sistema do 
movimento sacádico [Petiti \& Haxby 1999; O’Driscoll et al. 2000; Heide et al. 2001; Schmid et al. 2001; Tanabe et al. 2002].

\subsubsection{Movimento de Vergência}

É o movimento responsável por alinhar a fóvea de cada olho com alvos localizados em diferentes distâncias do observador. Diferente de outros tipos de movimento dos olhos nos quais os dois olhos movem-se na mesma direção, os movimentos de vergência não são conjugados, eles envolvem a convergência ou divergência das linhas de observação de cada olho para ver um objeto que está perto ou longe. Convergência é uma das três respostas reflexivas visuais obtidas pelo interesse em um objeto que está próximo. As outras componentes são acomodações das lentes, as quais trazem o objeto para o foco, e contração da pupila, a qual cresce a profundidade do campo e a nitidez da imagem na retina.

\subsubsection{Movimento Vestíbulo-Ocular}

Esse tipo de movimento estabiliza o olho em relação ao mundo externo, é uma compensação dos movimentos da cabeça. Essa resposta reflexiva previne que a imagem visual "deslize" na superfície da retina quando a posição da cabeça varia. A ação do movimento vestíbulo-ocular pode ser apreciada fixando um objeto e movendo a cabeça de um lado para o outro, os olhos automaticamente compensam os movimentos da cabeça movendo na mesma direção, para o lado oposto, mantendo, assim, a imagem do objeto mais ou menos no mesmo lugar na retina. $\mathrm{O}$ sistema vestibular detecta breves mudanças transientes da posição da cabeça e produz rapidamente movimentos corretivos do olho. Informações sensoriais dos canais semicirculares direcionam o olho para mover-se na direção oposta ao do movimento da cabeça. Enquanto o sistema vestibular opera efetivamente pra neutralizar rápidos movimentos da cabeça, ele é relativamente insensível a movimentos lentos ou a rotações persistentes da cabeça. Por exemplo, se o reflexo vestíbulo-ocular é testado com uma rotação contínua e sem estímulo visual sobre o movimento da imagem, i.e., com os olhos fechados ou no escuro, o movimento compensatório dos olhos cessa após 30 s de rotação. No entanto, se o mesmo teste

é feito com estímulo visual, o movimento dos olhos persiste. O movimento 
compensatório dos olhos neste caso é feito pela ativação do sistema de perseguição lenta, o qual não "confia" na informação vestibular, mas no estímulo visual indicando movimento do campo visual.

\subsubsection{Avaliação Otoneurológica}

A integração realizada pelo Sistema Nervoso Central (SNC) tem que incluir, além dos sinais de natureza diversa que lhe são enviados, um outro tipo de integração relacionada à distribuição espacial dos receptores periféricos. Uma vez que existem dois conjuntos completos de receptores, um de cada lado do crânio, pressupõe-se que as mensagens enviadas ao SNC pelos dois conjuntos devam ser harmônicas. A integração central pode, contudo, acomodar diferenças entre os dois sistemas desde que sejam constantes, mas não pode acomodar diferenças súbitas ou transitórias. Estas diferenças representam a causa essencial das vertigens periféricas.

O fenômeno da compensação labiríntica é de grande importância para o tratamento clínico cirúrgico das labirintopatias periféricas. $\mathrm{Na}$ verdade, existe uma fase inicial de supressão em que os testes labirínticos não provocam respostas nem do lado são, nem do lado lesado. Gradativamente, começam a ressurgir as respostas, a princípio mais intensas do lado são, e, aí, já está em uma fase de compensação propriamente dita.

Nem todos os distúrbios periféricos, contudo, exigem compensação. Pequenas diferenças entre os dois lados são corrigidas por um mecanismo mais simples, que é o da acomodação. Estímulos labirínticos repetidos, tais como acontecem nas piruetas das bailarinas e patinadores do gelo, induzem a uma habituação, também de origem central, mas com nítidas características de aprendizado e retenção.

A inter-relação vestíbulo-oculomotora é da mais alta importância. A locomoção do corpo implica em movimentos complexos, que exigem a compensação dos movimentos dos olhos, de acordo com os movimentos da cabeça. Os movimentos compensatórios dos olhos têm o nome de nistagmos e apresentam, em circunstâncias fisiológicas, amplitudes pequenas. Nas doenças vestibulares, contudo, após excitarmos os receptores periféricos de várias formas, poderemos registrar, ou mesmo tornar visíveis, a olho nu, esses movimentos. 
Observa-se que o nistagmo apresenta uma componente rápida e uma componente lenta. A primeira é a que se observa mais nitidamente e, por convenção, a direção do nistagmo é a direção da sua componente mais rápida. Ela se origina da formação reticular e parece constituir um movimento inicial, preparatório, para os movimentos de compensação da posição do globo ocular. A componente lenta, por sua vez, origina-se, efetivamente, do sistema vestibular, e o seu estudo representa, no momento presente, a melhor estimativa da função vestibular [Hungria 1991].

Entretanto, nem todos os nistagmos são vestibulares, há o nistagmo optocinético. O nistagmo optocinético é uma resposta reflexiva normal dos olhos em resposta a movimentos de larga escala da cena visual por exemplo, é o nistagmo optocinético que um observador imaginário perceberia, através da janela de um trem em movimento, nos olhos de um passageiro, a contemplar a paisagem. Esse tipo de movimento dos olhos não deve ser confundida com o nistagmo patológico que pode resultar de certos tipos de lesão do cérebro, por exemplo, lesão do sistema vestibular ou do cerebelo, que é fisiológico, resultando do deslocamento das imagens visuais na retina. E há o nistagmo ocular, presente em indivíduos com distúrbios de musculatura ocular, com perda da capacidade de fixação visual, mas com perfeito equilíbrio [Mangabeira 1973].

A exploração clínica do aparelho vestibular, comumente denominada exame otoneurológico, permite a obtenção de dados sobre o funcionamento dos receptores periféricos e sobre os diferentes setores das vias vestibulares centrais. Trata-se de um teste que investiga, de maneira importante, a função da formação reticular, daí a sua grande sensibilidade em relação a patologias neurológicas [Brandt \& Scrupp 2005]. Procuraremos descrever, em linhas gerais, as etapas dessa avaliação clínica.

\subsubsection{Descrição dos Testes Otoneurológicos}

O estudo dos movimentos oculares é realizado através de vários tipos de provas. Inicialmente, estudam-se os movimentos oculares espontâneos (encontrado no olhar de frente) e semi-espontâneos (nas posições cardinais do olhar), obtidos solicitando-se ao paciente que execute movimentos voluntários dos olhos. Depois, o 
rastreio ocular, o nistagmo optocinético e o nistagmo induzido por estímulos rotatórios - essa prova utiliza uma cadeira rotatória com o intuito de estimular, simultaneamente, os dois labirintos - e calóricos, nessa estimula-se cada ouvido com água ou ar, em temperaturas que provoquem correntes de convecção na endolinfa, deslocando mecanicamente as cristas. A grande importância da prova calórica é a estimulação isolada de apenas um canal lateral de cada vez.

Nos dias atuais, a maioria dos otoneurologistas utiliza a electronistagmografia (ENG) para o registro elétrico dos movimentos do olho durante os estudos da função labiríntica, permitindo diagnósticos mais precisos. Nos últimos anos, tem-se realizado pesquisas com a vectoelectronistagmografia (VENG), um método de registro com três canais que permite a detecção de nistagmos de direção oblíqua, sensibilizando ainda mais os recursos diagnósticos [Hungria 1991].

Uma outra maneira de avaliarmos as funções vestibulares no nível cortical e subcortical é através da fMRI. A fMRI tornou-se uma das principais técnicas de mapeamento das funções cerebrais nos últimos anos, principalmente, por ser uma técnica não-evasiva e pela sua ótima resolução temporal [Ogawa et al. 1990a,b; Di Salle et al. 1999]. Para um melhor entendimento dessa técnica ela será descrita em seguida. 


\section{Capítulo 3}

fMRI

\subsection{Fluxo Sanguíneo Cerebral, Metabolismo e Atividade Neural}

A maioria das técnicas de imagem, em particular as utilizadas para avaliar a função cerebral, faz uso da conexão existente entre o fluxo sanguíneo cerebral, Cerebral Blood Flow (CBF), a demanda de energia e a atividade neural.

Angelo Mosso, em 1881, foi o primeiro a demonstrar a correlação entre a demanda da energia e o CBF. Ele mediu a pulsação cerebral de um paciente, com uma lesão ao longo de todo o lobo frontal. Mosso observou um aumento repentino na pulsação, presumivelmente devido ao aumento de fluxo, imediatamente após o paciente ser instruído a realizar um simples cálculo aritmético [Mosso (1881 apud Logothetis 2002)]. Por sua vez, as primeiras evidências experimentais, em pequenos animais, da ligação entre fluxo e atividade neural foram fornecidas por Roy e Sherrington, em 1890. Neste trabalho eles indicaram que alguns efeitos do metabolismo cerebral estimulava a atividade vasomotora, a qual provavelmente alterava o fornecimento vascular regional em reposta à variação local da atividade funcional [Roy \& Sherrington (1890 apud Logothetis 2002)]. Alguns anos depois, em 1928, o neurocirurgião John Fulton [Fulton (1928 apud Logothetis 2002)], relatou um aumento de fluxo sanguíneo acompanhado por um aumento na atividade neural regional no lobo occipital, em um outro paciente.

A primeira medida quantitativa da relação entre o fluxo sanguíneo cerebral regional e o consumo de oxigênio em humanos foi realizada utilizando técnicas de radio-traçadores desenvolvida por Ter Pogossian et al. (1970 apud Logothetis 2002) e Raichle et al. (1976 apud Logothetis 2002). As imagens de tomografia por emissão de pósitrons (PET) mostraram que mapas de ativação cerebral regional podem ser produzidos detectando o efeito indireto da atividade neural a algumas variáveis como, CBF [Fox et al. (1988 apud Logothetis 2002)], o volume de sangue cerebral, do inglês, Cerebral Blood Volume (CBV) [Fox \& Raichle 1986], e oxigenação sanguínea [Fox \& Raichle 1986; Fox et al. (1988 apud Logothetis 2002)]. 
Finalmente, nas últimas décadas, outra técnica tem sido utilizada, que combina investigações anatômicas e funcionais. Esse novo método é a Ressonância Magnética Funcional (Functional Magnetic Resonance Imaging - fMRI), que oferece uma melhora substancial da resolução espaço-temporal comparado a qualquer outro método não-invasivo [Logothetis 2002]. Como essa técnica baseia-se nas imagens por ressonância magnética, achamos importante fazer uma introdução, ainda que superficial, do mecanismo de formação das imagens por ressonância magnética, ou Magnetic Resonance Imaging (MRI).

\subsection{Princípios Físicos de Imagem por Ressonância Magnética}

\subsubsection{Magnetização Nuclear}

As imagens por Ressonância Magnética Nuclear (Nuclear Magnetic Resonance NMR) exploram as diferenças de algumas propriedades da magnetização criada por um campo magnético estático intenso. Para uma melhor descrição desse fenômeno devemos introduzir alguns conceitos básicos.

Toda a matéria é composta por átomos, os quais contém três tipos de partículas, os prótons, os nêutrons e os elétrons. Os prótons e nêutrons compõem o núcleo. Entretanto, diferentes átomos possuem diferentes composições nucelares. O núcleo de hidrogênio, o mais abundante no corpo humano, contém apenas um próton (número atômico e massa igual a 1).

As leis do eletromagnetismo afirmam que um campo magnético é criado quando uma partícula carregada se move. No modelo clássico, o núcleo de hidrogênio possui um elétron com carga negativa que efetua uma rotação, em torno do próton, que causará um campo magnético induzido, como um pequeno magneto. Esse magneto é representado pelo momento magnético $\boldsymbol{\mu}$. Analogamente, também podemos associar aos próton e nêutrons um momento magnético $\boldsymbol{\mu}$. Desse modo, átomos com prótons ou nêutrons desemparelhados apresentarão uma propriedade de possuir um momento magnético nuclear.

$\mathrm{Na}$ ausência de um campo magnético aplicado, os momentos magnéticos têm uma orientação ao acaso. Já, quando os núcleos estão na presença de um campo 
magnético, estes alinham-se ao campo e precessionam em torno da direção do campo. Essa freqüência de precessão é dada pela chamada equação de Larmor,

$$
f=\frac{\gamma B_{0}}{2 \pi}
$$

em que $f$ é a freqüência de precessão (em Hz), $\gamma$ é uma constante chamada de razão giromagnética e $B_{0}$ é o campo magnético estático.

A excitação desse sistema, ou ressonância, é proporcionada por um pulso de radiofreqüência $(\mathrm{RF})$, na freqüência de Larmor do átomo em questão, quando alguns spins no estado de mais baixa energia absorvem essa energia e transitam para um estado de maior energia. Como a excitação destrói o equilíbrio térmico, imediatamente após o pulso de RF, o excesso de spins no nível mais alto de energia retorna gradualmente ao seu estado de equilíbrio emitindo energia na mesma freqüência da onda de rádio, que pode ser detectado por uma bobina. A tensão induzida na bobina receptora de RF tem característica de um co-seno amortecido e é conhecido como FID (Free Induction Decay).

O primeiro sinal de ressonância foi medido em 1946 por dois grupos trabalhando independentemente, Bloch et al. (1946 apud de Araújo 2002), em Stanford, e Purcell et al. (1946 apud de Araújo 2002), em Harvard. Eles foram capazes de medir o sinal de ressonância de uma amostra de água e de parafina, respectivamente.

\subsubsection{Processo de Relaxação}

Vimos que após a excitação do sistema, ele tende a retornar para o estado de mais baixa energia. Esse processo de relaxação é um dos responsáveis pela formação de uma imagem por ressonância. O processo pelo qual extraímos a informação espacial para produzir uma imagem e o processo que gera o contraste entre as estruturas da imagem, isto é, a diferença entre tecidos é diretamente dependente da densidade de spin, dos chamados tempos de relaxação T1 e T2, e outros parâmetros físicos do tecido, como a difusão, perfusão ou fluxo.

A densidade de prótons é determinada pelo número de spins que contribuem para a magnetização transversal, componente da magnetização perpendicular ao campo magnético estático. Em tecidos biológicos, isso corresponde basicamente à 
concentração de água e gordura. O tempo de relaxação T1 (longitudinal) é um processo exponencial referente à reconstrução da magnetização longitudinal " $z$ ” (ao longo da direção $\mathrm{B}_{0}$ ). Esse retorno ocorre devido ao movimento Browniano das moléculas vizinhas, o qual gera flutuações do campo magnético. Quanto mais próxima a flutuação está da freqüência de Larmor, mais rápida é a relaxação. As diferenças entre os valores da relaxação T1 dos tecidos provocam o contraste em imagens ponderadas em T1. T2, também chamado de tempo de relaxação transversal ou spin-spin, reflete a defasagem dos spins do plano "xy", isso é causado pela alteração do campo local, a qual induz uma alteração na freqüência de precessão. Tal variação aleatória do campo altera a freqüência de precessão dos prótons, resultando numa perda de coerência de fase e conseqüentemente da magnetização transversal.

$\mathrm{Na}$ realidade, um outro processo também contribui para a diminuição de T2: a inomogeneidade do campo estático. Esse fato leva à necessidade de definirmos o tempo de relaxação T2*, que reflete as variações devido aos dois processos independentes: inomogeneidade de campo e flutuações locais devido à vizinhança.

\subsubsection{Princípio da Formação de Imagem}

Para criarmos uma imagem a partir de um processo físico, como, por exemplo, a NMR, devemos criar uma codificação da informação espacial desse processo. Lauterbur, em 1973, mostrou que projeções de um objeto podem ser geradas e as imagens podem ser reconstruídas, como em tomografia computadorizada por Raios-X, pela superposição de gradiente de campo linear sobre o campo estático principal [Lauterbur (1973 apud Logothetis 2002)]. Aqui, o termo gradiente designa a alteração dinâmica do campo magnético ao longo de uma dimensão particular (por exemplo, $G_{x}=\frac{\partial B z}{\partial x}$ ). Assim, se aplicarmos gradientes de campo magnético nas 3 direções, a equação de Larmor torna-se:

$$
\omega=\gamma\left(B_{0}+G_{x} x+G_{y} y+G_{z} z\right)
$$

O gradiente determina uma extensão das freqüências de Larmor, e essas freqüências podem promover informação exata da posição. 
Existem alguns elementos básicos nas seqüências de MRI para a codificação da informação espacial, isto é, gradientes para a seleção da fatia $\left(G_{z}\right)$, para a codificação da freqüência (leitura) $\left(G_{\mathrm{x}}\right)$ e para a codificação de fase $\left(G_{\mathrm{y}}\right)$.

Para uma melhor compreensão de como é adquirida uma imagem, a figura 3.1 mostra um diagrama típico da seqüência de pulso do tipo spin eco.

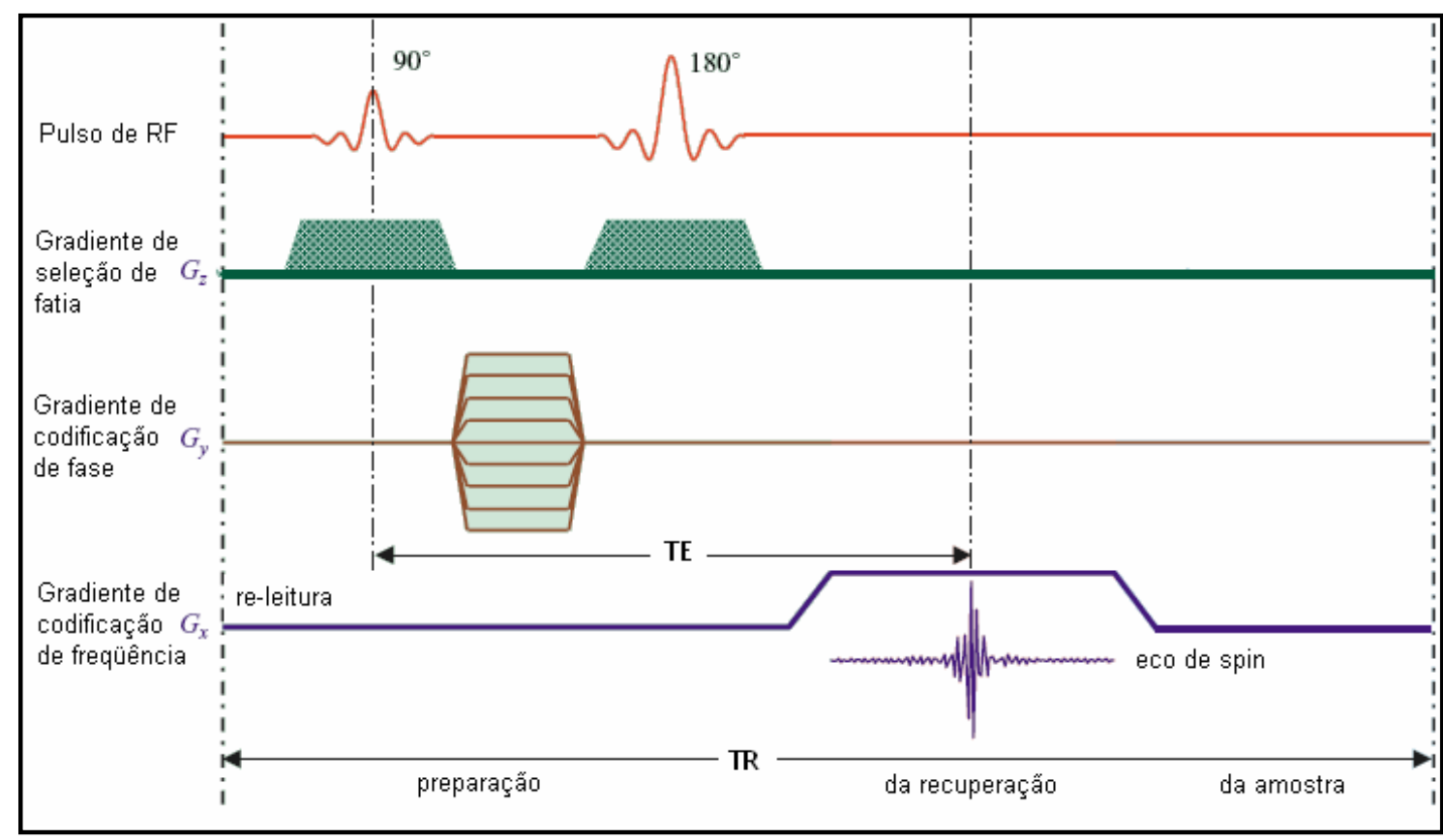

Figura 3.1 - Diagrama simplificado de uma seqüência de pulso. TE, tempo ao eco; TR, tempo de repetição; $G_{x}, G_{y}, G_{z}$, gradientes de codificação de freqüência, de codificação de fase e de seleção de fatia, respectivamente. Figura modificada de Logothetis 2002.

A seqüência de pulsos é composta por três fases distintas: (i) a preparação da magnetização transversal, (ii) a coleta real dos dados, e (iii) recuperação suficiente da magnetização longitudinal antes da próxima repetição começar. $\mathrm{Na}$ primeira fase, o gradiente de seleção de fatia $\left(G_{z}\right)$ é aplicado durante um pulso de RF de $90^{\circ}$. O gradiente de codificação de fase $\left(G_{y}\right)$ é aplicado logo após o término do pulso de RF. Quando o gradiente é desligado, todos os spins retornam para uma condição de freqüência uniforme, e a informação espacial é preservada apenas na forma de seus ângulos de fase, os quais permanecem diferentes de acordo com suas localizações ao longo do eixo y (por isso a direção de codificação de fase). Para a recuperação da informação de fase individual, é necessário que os gradientes de codificação de fase tenham diferentes amplitudes durante cada repetição. Um segundo pulso de RF $\left(180^{\circ}\right)$ combinado com um segundo gradiente de seleção de fatia inverte a fase da 
magnetização transversal e, então, produz um eco de spin após o tempo TE/2. Finalmente, um terceiro gradiente $\left(G_{x}\right)$ é utilizado para criar a dependência na posição da freqüência durante a coleta do eco de spin.

Para uma imagem com $N_{\mathrm{x}} N_{\mathrm{y}}$ pixels, os pontos $N_{\mathrm{x}}$ são amostrados com o mesmo gradiente de leitura $G_{x}$, enquanto que na codificação da fase o gradiente $G_{y}$ é aumentado com o tempo. Em cada etapa de leitura, o sinal coletado consiste da mesma freqüência diferindo apenas na fase. Os dados adquiridos da matriz $N_{\mathrm{x}} N_{\mathrm{y}}$, são usualmente denominados espaço-k (Figura 3.2c), com:

$$
k_{x, y, z}=\gamma \int G_{x, y, z} d t
$$

representando a imagem no domínio do espaço recíproco [Jezzard \& Clare 2001].

Para entendermos melhor como se dá essa nova representação, vejamos a figura 3.2. A figura 3.2a mostra um pulso de RF típico utilizado para excitar os spins nucleares e transferir a macromagnetização para o plano transversal. Na figura 3.2b observamos as componentes real e imaginária do sinal de ressonância. Em 3.2c mostramos a seqüência de pulsos representada no espaço-k em um experimento de eco de spin. Cada linha é um eco com a mesma composição de freqüência, mas com diferentes codificações de fase. Linhas superiores e inferiores possuem o maior gradiente de codificação de fase e por isso, maior defasagem (sinal mais fraco). O maior eco está no centro do espaço-k, onde não ocorre codificação de fase. Em 3.2d observamos a transformada de Fourier ao longo da direção de leitura. Finalmente, em 3.2e vemos a transformada de Fourier ao longo da direção da codificação de fase, resultando na imagem final. 

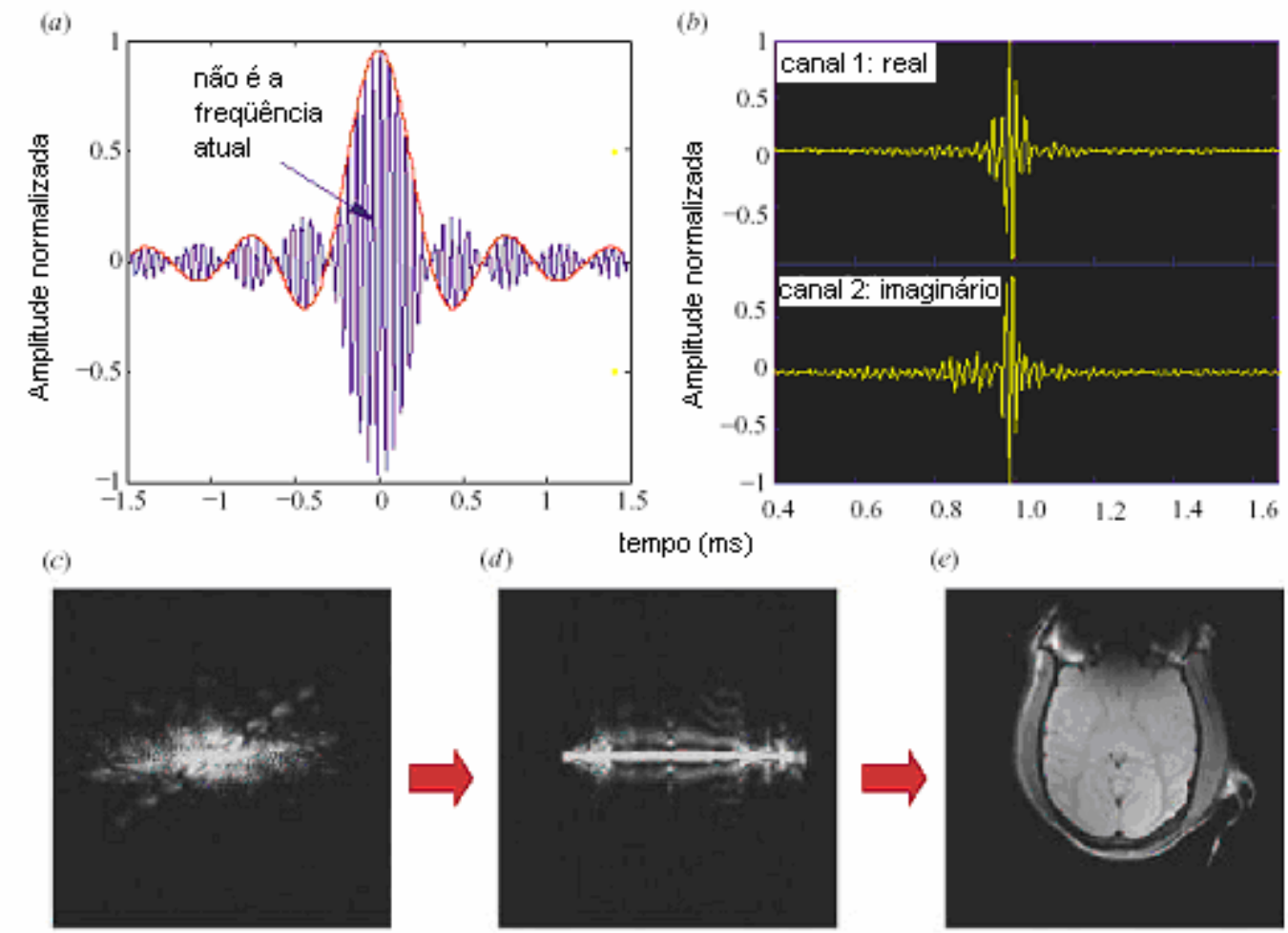

(d)

(e)

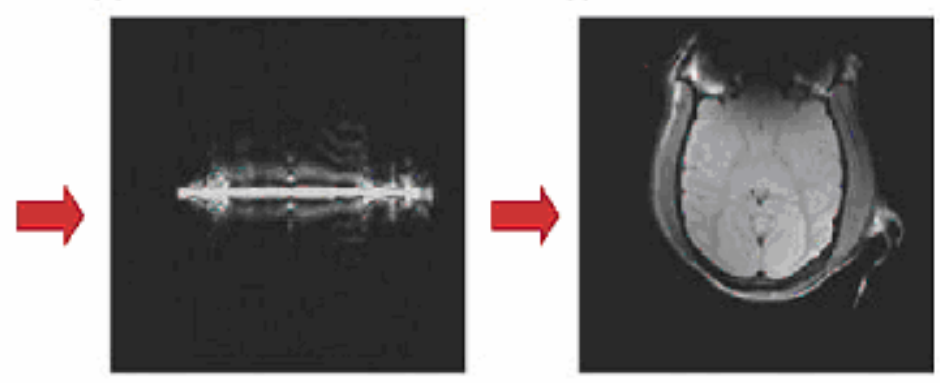

Figura 3.2 - Formação da imagem. Figura modificada de Logothetis 2002.

\subsubsection{Seqüência de Pulso Eco-Planar}

Em muitos métodos de MRI, a aquisição de cada linha no espaço-k é precedida pela excitação de RF. O pulso de TR (Tempo de Repetição) é imposto pela razão da recuperação da magnetização longitudinal, e as etapas da codificação de fase são determinadas pela resolução desejada. Decrescendo qualquer uma dessas, a qualidade da imagem será afetada. Isso torna muito lentas as aquisições das imagens convencionais de alta resolução espacial se comparamos o sinal de MRI com a atividade neural fundamental. A seqüência de pulso do tipo eco-planar (ecoplanar imaging - EPI) [Mansfield (1977 apud de Araújo 2002)] permite a aquisição muito mais rápida dos dados. A velocidade da EPI vem da habilidade de amostrar uma matriz bi-dimensional inteira no espaço-k pela aplicação de um único pulso de radiofreqüência. Isso pode ser visto esquematicamente na figura 3.3a, a qual mostra uma seqüência do tipo EPI, moldado no espaço-k (Figura 3.3b). 


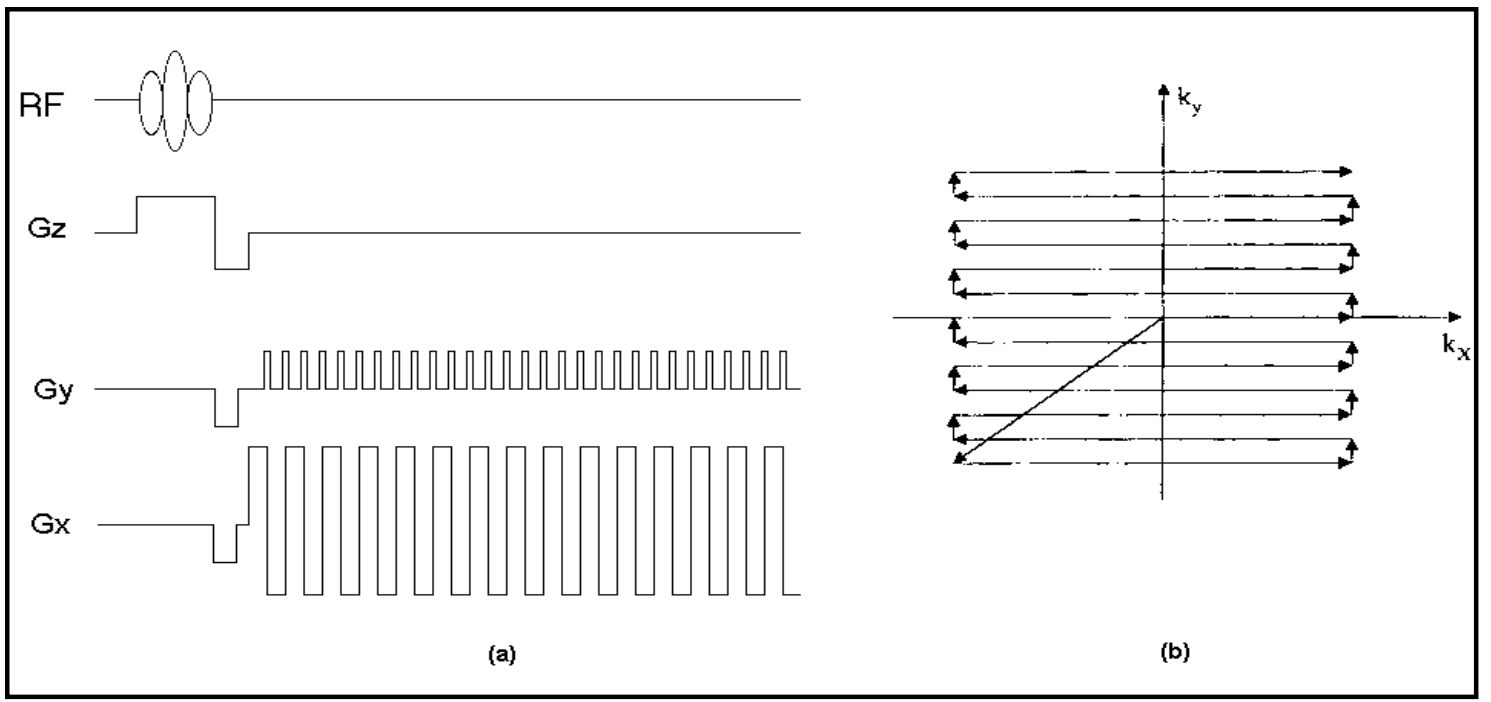

Figura 3.3 - Diagrama da seqüência de pulso EPI (a) e representação do espaço-k (b).

Seguindo a seleção da imagem, (imediatamente após cada coordenada do espaço-k em $(0,0))$ gradientes negativos, $G_{x}$ e $G_{y}$, são aplicados para posicionar a coordenada do espaço-k no seu canto inferior esquerdo. Uma única linha na direção $K_{x}$ do espaço-k é então adquirida. Um pequeno gradiente positivo é então aplicado (sem re-excitar os spins) para mover as coordenadas do espaço-k uma linha para cima (durante esse tempo nenhum dado é coletado). Um gradiente $G_{x}$ negativo então dirige as coordenadas do espaço-k para trás e varre uma segunda linha, adquirindo os dados. Esse processo de utilizar um pequeno acréscimo do gradiente $\mathrm{G}_{\mathrm{y}}$ para posicionar as coordenadas do espaço-k uma linha acima, seguido por um gradiente $G_{x}$ positivo ou negativo para dirigir a trajetória para frente ou para trás através do $K_{x}$, esse processo é repetido até que todo o espaço-k tenha sido preenchido. A espessura da fatia pode ser ajustada alterando a intensidade do gradiente de campo, e a posição central da fatia pode ser ajustada alterando a freqüência do pulso de excitação.

Há restrições que afetam a escolha de uma seqüência de pulso EPI. Primeiramente, o fato do sinal decair com a constante de tempo T2* durante a aquisição do espaço-k. Isso implica em uma seqüência bastante afetada por artefatos de susceptibilidade. Tipicamente, são adquiridas imagens com matrizes de 64 x 64 ou 128 x 128 com um único pulso de RF. Mas essa penalidade na resolução da imagem é compensada por uma melhora significativa da resolução temporal. Uma 
imagem EPI de 64 x 64 ou de 128 x 128 pode ser adquirida em até 30 ms, com uma varredura do volume total de 2 a 4 s [Jezzard \& Clare 2001].

\section{3 fMRI com Contraste BOLD}

Linus Pauling, em 1936, mostrou que a propriedade magnética da molécula de hemoglobina dependia da sua ligação com o oxigênio. A hemoglobina oxigenada (Hb) é diamagnética, isto é, não possui elétrons desemparelhados e seu momento magnético é zero. Já, a hemoglobina deoxigenada ( $\mathrm{dHb}$ ) é paramagnética. Ela possui dois elétrons desemparelhados e um momento magnético diferente de zero. Mas, foram Thulborn e colegas que mostraram que a natureza paramagnética da hemoglobina deoxigenada $(\mathrm{dHb})$ influenciava no sinal de MR. Nesse trabalho, Thulborn et al. mostraram que havia pouca diferença entre os valores da relaxação transversal para a $\mathrm{Hb}$ e a $\mathrm{dHb}$, a baixos campos (i. e., campos menores que $1.0 \mathrm{~T}$ ) mas, a fortes campos magnéticos (i. e., campos maiores que $1.5 \mathrm{~T}$ ) esses valores diferenciavam significativamente [Thulborn et al. (1982 apud Huettel et al. 2004)].

Baseado em relatos prévios de que a desoxigenação decresce o valor de T2* no sangue, Ogawa e colaboradores (1990a) hipotetizaram que a manipulação da proporção de oxigênio no sangue deveria afetar a visibilidade dos vasos sanguíneos em imagens ponderadas em T2*. Eles testaram essa hipótese com experiência em roedores anestesiados, utilizando um tomógrafo de alto campo (7 T e $8.4 \mathrm{~T}$ ), manipulando a proporção de oxigênio que o animal respirava. Quando os roedores estavam respirando $100 \%$ de oxigênio ou $100 \%$ de monóxido de carbono, imagens por seqüência do tipo gradiente-eco dos cérebros dos roedores mostraram diferenças estruturais, mas poucos vasos sanguíneos. Mas quando os roedores respiravam normalmente ( $21 \%$ de oxigênio), as imagens mostraram um caráter bem diferente. Linhas finas escuras tornaram-se visíveis no córtex cerebral. Se a concentração de oxigênio fosse reduzida a $0 \%$, as linhas tornavam-se ainda mais proeminentes. Ogawa e colaboradores concluíram que essas linhas finas representavam o efeito da susceptibilidade magnética causada pela presença $\mathrm{da} \mathrm{dHb}$ paramagnética nos vasos sanguíneos, os quais causam distorções locais do campo em imagens por seqüência do tipo gradiente-eco. Em outras condições, devido à 
hemoglobina estar ligada ao oxigênio e ao monóxido de carbono ela provocava pouco efeito no campo magnético [Ogawa et al. 1990a].

Ogawa e colaboradores consideraram que esse relato, o qual viria a ser chamado de contraste blood-oxygenation-level dependent (BOLD), poderia possibilitar a medida de mudanças na atividade cerebral. Eles hipotetizaram, então, dois possíveis mecanismos para o contraste BOLD: mudanças no metabolismo do oxigênio ou mudanças no fluxo sanguíneo. No primeiro mecanismo, a atividade neural causaria aumento da demanda metabólica e, então, aumento do consumo de oxigênio. Isso aumentaria a quantidade de $\mathrm{dHb}$, dando um contraste do fluxo sanguíneos. No segundo mecanismo, o aumento da demanda metabólica decresceria a quantidade de $\mathrm{dHb}$

Em seu próximo experimento in vivo, Ogawa e colegas (1990b) manipularam a indução de gases em ratos anestesiados enquanto mediam o contraste BOLD em alto campo. Para verificar que o contraste BOLD resultava, ao menos em parte, da demanda metabólica do oxigênio, eles compararam níveis altos e baixos de anestesia. O contraste BOLD foi muito maior a níveis de baixa anestesia comparado a níveis de alta anestesia. Esses resultados indicaram que a demanda metabólica para o oxigênio era pré-requisito para o contraste BOLD [Ogawa et al. 1990b].

Resumindo, o contraste BOLD depende da quantidade de $\mathrm{dHb}$ presente na região cerebral, o que por sua vez depende do balanço entre o consumo de oxigênio e o fornecimento de oxigênio. Entretanto, parece razoável que o aumento da atividade neural resulte num aumento do consumo de oxigênio e então um maior decréscimo do sinal MR, como Ogawa e colegas originalmente hipotetizaram. No entanto, quando nós medimos um aumento da atividade neural nós encontramos um aumento de sinal de MR.

As observações de Fox et al. (1988 apud Huettel et al. 2004) explicam esse paradoxo. A disparidade entre a utilização do oxigênio e a demanda de oxigênio significa que mais oxigênio é fornecido para uma região cerebral do que é consumido. O contraste BOLD que acompanha a atividade neural ocorre não porque a $\mathrm{Hb}$ aumenta a sinal de $\mathrm{MR}$, mas porque ela substitui a $\mathrm{dHb}$ que tem ocultado a intensidade do sinal de MR [Fox et al. (1988 apud Huettel et al. 2004)]. 
Os primeiros estudos com o contraste BOLD em fMRI foram relatados em 1992 pro três grupos distintos. Kwong et al. utilizaram uma seqüência do tipo gradiente-eco EPI para estudar a atividade do córtex visual [Kwong et al. 1992]. Ogawa et al. publicaram um estudo similar, no qual avaliaram a mudança do sinal fMRI numa seqüência gradiente-eco quando era apresentado um estímulo visual de longa duração [Ogawa et al. 1992]. O terceiro trabalho publicado em 1992 foi por Bandettini e colegas, no qual relaram atividade significativa no córtex motor primário através da utilização de uma tarefa motora [Bandettini et al. 1992].

\subsection{Método de Aquisição das Imagens}

Atualmente, um exame típico de fMRI é dividido, basicamente, em duas partes. Em um primeiro momento, são adquiridas as imagens EPI que resultam nas localizações funcionais para uma região cerebral específica. Em seguida, um segundo conjunto de imagens é obtido. Nessa série, o paciente/voluntário deve permanecer imóvel. As imagens têm por objetivo servir de substrato para a representação dos resultados estatísticos, uma vez que apresentam uma boa resolução anatômica, com voxels de, pelo menos, $1,5 \mathrm{~mm}^{3}$ [de Araújo 2002].

\subsubsection{Paradigmas}

Os paradigmas em fMRI correspondem a uma série de tarefas apresentadas ou a serem apresentadas aos indivíduos a fim de se observar áreas de atividade cerebral. O seu planejamento é fundamental para a obtenção de bons resultados, que reflitam a atividade de regiões específicas de interesse, devendo engajar uma circuitaria neuronal bastante restrita.

Os paradigmas são desenhados a partir de estímulos, enquadrados em três grupos, que determinam a maneira de pós-processamento das imagens: paradigmas em bloco, alternam períodos de atividade (“on") com períodos de repouso (“off”), paradigmas contínuos ou paramétricos em que os estímulos são apresentados continuamente, em geral de forma aleatória e os paradigmas evento-relacionado em que os estímulos são apresentados por um curto período e são intercalados com 
longos períodos de repouso. Aqui, descreveremos com mais detalhes apenas o paradigma em bloco, que utilizamos nesse trabalho.

O paradigma em bloco é o mais utilizado atualmente em experiências de fMRI. O sinal adquirido durante uma condição de bloco é comparada a outro bloco envolvendo diferentes condições de tarefas. Para efeito de ilustração, imagine um protocolo de imagens funcionais projetado para o isolamento e mapeamento da atividade cerebral associada ao movimento voluntário dos dedos das mãos. Enquanto as imagens funcionais estão sendo adquiridas, um paradigma experimental em bloco é aplicado, de acordo com a figura 3.4b. Nela observamos um diagrama de tempo demonstrando a ocorrência de um paradigma de dois estados. Em um primeiro instante, formando a linha de base, o voluntário/paciente encontra-se na condição de repouso: não há movimentação dos dedos. Esses períodos são intercalados por condições ativas, nas quais ocorre a movimentação dos dedos. O processo é repetido até que um número suficiente de imagens seja obtido. No diagrama 3.4b, ilustramos a situação em que oito períodos de inatividade são intercalados com oito períodos de movimento das mãos.

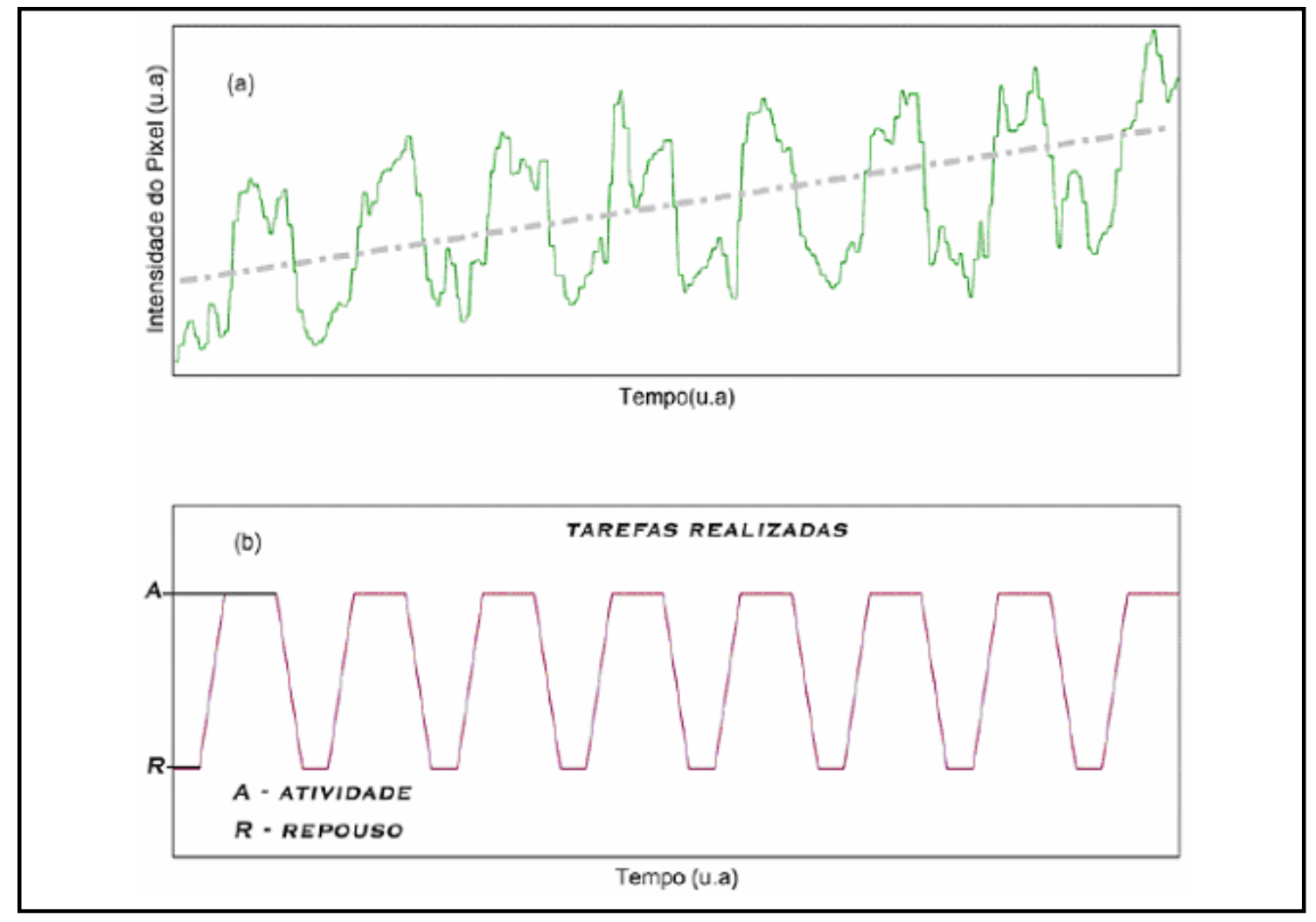

Figura 3.4 - Sinal típico de um pixel em um paradigma de bloco (a) e sua função de correlação (b) indicada pela presença temporal de tarefa realizada [de Araújo 2002]. 
Como resultado, voxels da imagem presentes em regiões corticais ativas são seguidos de alterações no contraste da imagem. Como esses estados de atividade são intercalados com estados de repouso, o sinal proveniente dessa região forma um padrão topográfico semelhante àquele mostrado na figura 3.4a.

Mesmo se tratando de um processo simples, paradigmas dessa natureza são largamente utilizados no mapeamento de diversas áreas funcionais, tanto por PET quanto por fMRI. Além de áreas primárias, esses processos também têm sido utilizados na caracterização de regiões responsáveis por processos cognitivos elevados, como memória e linguagem [de Araújo 2002].

\subsection{Preparando os Dados de fMRI para Análise Estatística}

O mecanismo de contraste BOLD, aliado a técnicas de aquisição rápida, permite a visualização direta de um grande número de processos cerebrais. Infelizmente, as alterações no contraste das imagens não são grandes, o que impossibilita uma inspeção visual direta, tornando necessária a utilização de algoritmos computacionais para a identificação dessas áreas. As alterações de contraste dependem da intensidade do campo estático aplicado, mas, em uma situação mais habitual de campos da ordem de $1.5 \mathrm{~T}$, as variações de contraste podem chegar a 3-4\% [Weisskoff \& Kiihne 1992]. Os paradigmas em bloco foram o primeiro alvo para o desenvolvimento de análises estatísticas de fMRI [Friston et al. 1994]. Entretanto, antes de analisar as séries temporais por ferramentas estatísticas, é importante que elas passem por algumas etapas de pré-processamento, para auxiliar na eliminação de alguns artefatos conhecidos.

O propósito do pré-processamento é remover vários tipos de artefatos nos dados, e condicionar os dados, para maximizar a sensibilidade de análises estatísticas posteriores, e também, em algumas situações, aumentar a validade estatística. As últimas análises estatísticas são geralmente vistas como a parte mais importante da análise de fMRI. No entanto, sem as etapas de pré-processamento, a análise estatística é, na melhor das hipóteses, grandemente reduzida, e na pior, inválida [Smith 2001]. Aqui nós descreveremos uma série de procedimentos computacionais utilizados no pré-processamento das séries temporais. Dentre elas podemos citar: a 
correção temporal entre fatias, a correção de movimento e a aplicação de filtros espaciais e temporais.

\subsubsection{Correção do Tempo por Fatia}

Conforme dissemos anteriormente, os exames de fMRI são coletados de modo a fazer várias imagens de uma região cerebral em instantes de tempo distintos. Cada uma dessas aquisições é formada por um conjunto de fatias, conhecido como volume. Por sua vez, as fatias que compõem os volumes são adquiridas em instantes ligeiramente defasados no tempo. Desse modo, para facilitar a análise estatística, devemos corrigir as séries temporais tornando-as alinhadas, em fase. Para corrigir esses erros, algumas análises experimentais modificam a resposta hemodinâmica preditora, assim cada fatia é comparada a uma função da resposta hemodinâmica com tempos ligeiramente diferentes. A correção entre os tempos das fatias mais utilizada é a interpolação temporal. Essa utiliza a informação dos pontos temporais vizinhos para estimar a amplitude do sinal de MR. É importante salientar que o método de interpolação pode perfeitamente recuperar as informações perdidas entre as fatias.

\subsubsection{Correção de Movimento}

Pequenos movimentos da cabeça, numa escala menor que $1 \mathrm{~mm}$, são uma das maiores fontes de erro na análise dos dados de fMRI se não identificada ou corrigidas corretamente. Uma condição subjacente para uma análise bem-sucedida é a necessidade dos pixels permanecerem espacialmente invariantes ao longo de toda a aquisição das imagens. Qualquer tipo de movimento viola esse princípio, daí a necessidade de evitá-los a qualquer custo.

Podemos classificar os artefatos de movimento em intrínsecos e extrínsecos. O primeiro é decorrente de flutuações internas provenientes do movimento dos tecidos intracranianos. Sendo bem mais difíceis de detectar e de corrigir, eles levam a um aumento na variação do sinal de MR. Além disso, processos fisiológicos como respiração e batimento cardíaco afetam as imagens resultantes. Além de provocarem o movimento dos tecidos, esses ritmos fisiológicos fazem aparecer uma inomogeneidade de campo. 
O segundo tipo de movimento é mais facilmente detectável e de mais fácil controle [Friston et al. 1996]. Ele é decorrente das alterações nos sinais de MR que resultam do movimento involuntário da cabeça do indivíduo. Vimos que as alterações de contraste devido à resposta hemodinâmica são de aproximadamente 3\%. Ademais, grande parte das análises estatísticas busca por diferenças no contraste entre os dois estados experimentais: repouso e atividade. Esse artefato resulta em padrões de atividade falsos: regiões que anteriormente apresentavam baixo contraste passam a padrões de brilho mais intenso. Ele é especialmente visível em regiões de alto contraste espacial, como o conjunto de pixels que definem uma região de fronteira na imagem.

Para restringir o nível de contaminação nesses exames, é aconselhável planejar experiências que minimizem o movimento do indivíduo, e ter a certeza de que ele esteja confortavelmente acomodado no interior do tomógrafo. Contudo, métodos de correção posteriores também existem [Woods et al. 1992].

O processo de correção começa com uma estimativa da extensão do movimento da cabeça. A fim de simplificar os cálculos e trazer o processo a níveis aceitáveis, a suposição é geralmente feita considerando o movimento da cabeça como um processo de corpo rígido, isto é, que a cabeça muda sua posição e orientação, mas não se submete a mudanças de forma.

O problema de estimar o movimento da cabeça pode ser formulado em termos da computação da transformação da imagem (os acertos da translação em $x$, $y$ e $z$ e rotações ao redor dos eixos $x, y$ e $z$ ) que irão combinar a imagem num ponto temporal $t$ para o mesmo modelo ou alvo da imagem. O modelo de referência é comumente escolhido como o primeiro volume da imagem nas séries temporais de fMRI [Friston et al. 1996].

As correções de movimento serão aplicadas da seguinte forma: as matrizes de rotação e de translação, $\vec{R}$ e $\vec{T}$ serão definidas com respeito ao volume de referência, de modo que:

$$
\vec{x}^{(2)}=\vec{R} \vec{X}^{(1)}+\vec{T}
$$


em que $\vec{x}^{(1)}$ e $\vec{x}^{(2)}$ são as posições dos vetores dos voxels antes e depois das transformações de rotação e translação. Essa operação é realizada até que a soma dos quadrados da diferença entre pixels de duas imagens subseqüentes seja minimizada. Fazendo com que o volume a ser corrigido esteja ajustado ao volume de referência.

\subsubsection{Filtro Espacial}

O pré-processamento de fMRI pode passar ainda pela aplicação de um filtro espacial sobre cada volume. Embora controverso, uma vez que sua aplicação leva a uma perda na resolução espacial da imagem, a possibilidade de obter uma significância estatística mais robusta acaba por fazer com que esses métodos sejam comumente utilizados. Há duas razões para a aplicação do filtro espacial como uma etapa de pré-processamento. Primeiro, ele pode causar o aumento da relação sinal ruído dos dados. A medida da relação sinal ruído estabelece quão grande é o sinal de interesse comparado ao nível de ruído. O sinal de interesse, nesse caso, é a mudança na intensidade da imagem a qual estabelece os resultados da aplicação de um estímulo. O ruído é a variação aleatória inevitável, na intensidade da imagem, o qual está presente mesmo quando nenhum estímulo é aplicado. Segundo, etapas estatísticas procedentes certamente podem requerer que as imagens funcionais sejam espacialmente suavizadas.

O ponto principal da filtragem espacial nos dados de fMRI é reduzir o nível de ruído enquanto mantém o sinal subjacente. Como o filtro é efetivamente uma média local, então o valor do "ruído" na vizinhança local irá tender a cancelar um com o outro. A fim de que o sinal subjacente não seja reduzido junto com o ruído, é necessário que o tamanho da máscara do filtro não seja maior do que o tamanho da região ativada.

Os filtros geralmente utilizados são do tipo Gaussiano, em que é realizada a convolução das imagens EPIs com funções do tipo [de Araújo 2002]:

$$
f(x, y, z)=\exp \left\{-\left[\frac{x^{2}}{2 s_{x}^{2}}+\frac{y^{2}}{2 s_{y}^{2}}+\frac{z^{2}}{2 s_{z}^{2}}\right]\right\},
$$


em que $x, y$ e $z$ correspondem às posições geométricas das imagens, e $s_{x}, s_{y}$ e $s_{z}$ são os desvios padrão da função, definida pelo usuário. As características do filtro são bem definidas pelo parâmetro largura a meia altura, ou FWHM (Full Width at Half Maximum), que determina a forma de atuação do filtro sobre a imagem. Não existe uma forma direta de determinação dos melhores parâmetros dos filtros a serem utilizados nas análises, uma vez que uma melhoria da relação sinal-ruído implica na redução da resolução espacial, mas é comum utilizar uma largura entre 3 a $10 \mathrm{~mm}$ FWHM para imagens de fMRI.

\subsubsection{Filtro Temporal}

O ponto principal da filtragem temporal é remover componentes indesejáveis da série temporal sem, é claro, danificar o sinal de interesse. Por exemplo, se uma estimulação é aplicada durante 30 s, seguida por 30 s de repouso, e esse padrão é repetido várias vezes, o sinal de interesse será próximo a uma onda quadrada de período $60 \mathrm{~s}$. O filtro temporal buscará remover as componentes na série temporal que variam mais lentamente do que o sinal de período $60 \mathrm{~s}$ (filtro passa alta) e também remover componentes que variam mais rapidamente (filtro passa baixa).

A filtragem temporal, ao invés de trabalhar com cada volume separadamente, como o filtro espacial, trabalha com cada série temporal de voxels separadamente. Devido à maioria das bases de análises estatísticas operarem diretamente nas séries temporais dos voxels, de regra a realização dessa etapa é realizada após todos os estágios de pré-processamento descritos anteriormente.

\section{Filtro passa alta}

O filtro passa alta remove as componentes lentas dos sinais, muitas vezes indesejáveis, i.e., aqueles que possuem freqüência abaixo de um determinado valor. Tais perturbações podem ser provenientes de efeitos fisiológicos, como batimento cardíaco e respiração, ou devido flutuações associadas ao tomógrafo. Se os sinais de baixa freqüência não estão relacionados ao estímulo, será, então, lucrativo removêlos. Isso irá resultar em um melhor ajuste do modelo derivado da estimulação dos 
dados e maior significância de ativação. É importante, contudo, que o filtro passa alta não corrompa o sinal relacionado ao estímulo.

\section{Filtro passa baixa}

O filtro passa baixa reduz ruídos de alta freqüência das séries temporais dos voxels. Como no caso do filtro passa alta, é importante escolher um filtro que remova os ruídos sem corromper os sinais subjacentes relacionados ao estímulo.

É comum realizar o filtro passa baixa através de uma simples convolução com uma função Gaussiana. Contudo, ao invés da variável da função Gaussiana ser espacial, ela é temporal. Devido à utilização comum do filtro Gaussiano estreito, que realiza um borramento pequeno, no fundo a operação de convolução com a série nada mais é do que substituir cada ponto temporal da série pelo seu valor original mais uma pequena fração da vizinhança.

Um risco para o filtro passa baixa pode aparecer com experimentos que envolvam paradigmas de evento-relacionados, os quais geralmente contêm componentes de alta freqüência. Por exemplo, uma estimulação breve pode conter picos estreitos na série temporal resultante. O filtro passa baixa pode suprir esses sinais, reduzindo portanto a eficiência das análises estatísticas [Smith 2001].

\subsection{Análise Estatística das Imagens}

Após a etapa de pré-processamento, são realizadas análises estatísticas para determinar quais voxels são estatisticamente significativos, indicando uma alta probabilidade de estarem respondendo à estimulação específica. Vários são os métodos de análise. Dentre eles podemos citar a correlação entre todos os voxels da série temporal e um modelo da resposta hemodinâmica. Outros métodos, mais complexos, podem ser efetivamente elaborados, possibilitando a inferência de características interessantes dos exames de fMRI. Dentre eles, podemos citar o modelo geral linear [Friston et al. 1995] ou a análise de componentes independentes.

A maioria dos testes estatísticos utilizados em fMRI possui três pontos em comum. Primeiro, eles expressam a significância como a probabilidade do resultado ocorrer sobre a hipótese nula (no caso da técnica de fMRI, a hipótese nula é o caso 
em que a diferença entre as condições não possuem efeito nos dados de fMRI) e utilizam mapas coloridos para expressar essa probabilidade. Segundo, os voxels cujo nível de probabilidade está abaixo de um limiar, conhecido como valor alfa, são marcados como significativos, enquanto os voxels cuja probabilidade está acima do limiar estatístico é marcado como não significativo. $O$ valor alfa proporciona a probabilidade do erro do Tipo I. Em termos da análise de fMRI o erro do Tipo I significa que um voxel é marcado como ativo quando na verdade não é (i.e., falso positivo). Terceiro, as aproximações são geralmente conservativas, no qual enfatizam excluir voxels ativos, resultando no erro do Tipo II, ou seja, um voxels é marcado como sendo não ativo quando, na verdade ele é ativo (i.e., falso negativo). Dentre os algoritmos mais utilizados podemos citar o GLM, sigla para General Linear Model, o qual será descrito em seguida.

\subsubsection{Modelo Linear Geral}

O método linear utiliza a sessão experimental como uma única série temporal, e a compara a uma série temporal preditora composta por várias respostas hemodinâmicas individuais. A equação para o modelo é dada por:

$$
y=a_{0}+a_{1} x_{1}+a_{2} x_{2}+\ldots+a_{n} x_{n}+\varepsilon
$$

A idéia básica por trás de um modelo linear é que o dado observado ( $y$ ) é igual à combinação de pesos de vários fatores modelos $\left(x_{i}\right)$ (o fator modelo representa componentes hipotéticas dos dados), mais um termo de erro $(\varepsilon)$. Os parâmetros de peso $\left(a_{i}\right)$ indicam quanto cada fator contribui para os dados absolutos. O termo $a_{0}$ reflete a contribuição de todos os fatores que são tomados como constantes durante o experimento como, por exemplo, os valores brutos de T2* gravados em um voxel particular na ausência da ativação BOLD. Resolvendo a equação do modelo linear, possuímos apenas uma quantidade conhecida, os dados experimentais. Dado os dados experimentais e uma série específica dos fatores modelo, podemos, então, calcular qual combinação de pesos serve para minimizar o termo de erro. O termo de erro mínimo, após resolver o modelo linear, é conhecido como erro residual. Quando há apenas uma variável dependente, a equação 3.6 é 
conhecida como um modelo de regressão múltipla univariada. Mas a mesma equação pode ser estendida para incluir um grande número de variáveis dependentes, como os vários pontos temporais de um estudo fMRI, por meio do modelo linear geral (GLM).

No GLM os dados experimentais são representados como uma matriz bidimensional constituída de $n$ pontos temporais por $\mathrm{V}$ voxels. Nesse método os valores dos parâmetros de peso e o termo de erro são calculados independentemente para todos os voxels. Os voxels são organizados ao longo de uma dimensão para tornar o cálculo mais simples. A design matrix, a qual especifica o modelo linear geral a ser estimado, consiste de $\mathrm{M}$ fatores modelos. A matriz parâmetro contém $n$ linhas, de tal foram que cada célula indica a amplitude de um fator modelo para um dado voxel. Finalmente, o termo de erro é um vetor com $n$ linhas. Em alguns sistemas de notação, a design matrix é denominada como X e a matriz parâmetro é denominada como $\beta$, podemos então expressá-los como forma matricial:

$$
\left(\begin{array}{c}
y_{1} \\
\vdots \\
y_{n}
\end{array}\right)=\left(\begin{array}{ccc}
x_{11} & \cdots & x_{n 1} \\
\vdots & \ddots & \vdots \\
x_{1 V} & \cdots & x_{n V}
\end{array}\right)\left(\begin{array}{c}
a_{1} \\
\vdots \\
a_{n}
\end{array}\right)+\left(\begin{array}{c}
\varepsilon_{1} \\
\vdots \\
\varepsilon_{n}
\end{array}\right) \text {, }
$$

ou na notação matricial:

$$
Y=X \beta+\varepsilon
$$

Após estabelecer o modelo linear geral para um dado experimento, calculamos quais as combinações dos pesos, quando multiplicados pela design matrix, nos dá o menor termo de erro. Para entender esse processo, considere em experimento simples onde um voluntário fecha a sua mão a cada 20 s enquanto os dados de fMRI são adquiridos com um TR de $1 \mathrm{~s}$ ao longo de 60 pontos temporais. Podemos supor que os valores ativos deveriam mostrar três respostas hemodinâmicas distintas, uma para cada fechada de mão. Assim, entramos com essa hipótese como uma única coluna na design matrix. O GLM avalia quanto essa série temporal hipotética contribui para os dados reais, comparando a variabilidade fora do modelo. Como os dados de fMRI consistem de vários pontos temporais, o erro residual para um dado voxel deve ser combinado através de todos os pontos 
temporais em um único valor. A equação para combinar vários erros em uma estatística resumida é conhecida como função custo. No GLM, o padrão de uma função custo é a determinação do erro por mínimos quadrados, ou a soma de todos os quadrados residuais. Para testar a significância do fator modelo para um dado voxel, a amplitude do parâmetro associado é dividido pelo erro residual. A significância é baseada em quão bem os dados experimentais ajustam uma resposta hemodinâmica preditiva. Então, o sucesso da análise do modelo linear geral depende somente da validade de criar a design matrix.

\subsection{Apresentação dos Mapas Estatísticos}

Os resultados estatísticos fornecidos pelas diferentes técnicas de análise dos sinais de fMRI devem ser visualizados de alguma forma. Usualmente, cada pixel que compõe a imagem recebe uma cor que varia de acordo com a sua significância estatística, formando um mapa de cores. Dentre os padrões mais adotados, seguindo a coloração do arco-íris, pixels cuja significância estatística é elevada recebem uma coloração mais próxima ao vermelho, enquanto que aqueles de significância estatística desprezível têm coloração azulada. Um exemplo típico de um exame funcional de regiões primárias motoras é apresentado na figura 3.5a. Nela observamos uma espécie de aglomerado de pontos avermelhados, indicando uma alta probabilidade de ser aquela a região ativa pelo paradigma motor.

Em um segundo momento, esses mapas devem ser apresentados em superposição a imagens que tragam informações anatômicas das estruturas funcionais envolvidas naquele processo cerebral específico. A primeira possibilidade é atribuir uma coloração específica, na própria imagem que gerou os mapas estatísticos (por exemplo, EPI), pintando regiões da imagem que apresentem significância superior a um certo limiar. $\mathrm{Na}$ figura $3.5 \mathrm{~b}$, apresentamos um desses exemplos. O mapa gerado em um paradigma motor, o mesmo apresentado na figura 3.5a, é superposto a sua respectiva imagem EPI. Note que apenas regiões mais significativas são apresentadas. No caso dessa figura, em que a origem dos resultados provém de uma análise de correlação, somente regiões cujos coeficientes de correlação foram superiores a 0.75 são mostradas. 
As imagens EPIs tem uma resolução espacial baixa. Por outro lado, é interessante que os resultados sejam mostrados sobre imagens anatômicas de boa resolução, como as ponderadas em T1. Nesse caso, uma transformação de coordenadas é realizada, encontrando-se os pontos cerebrais ativos nos mapas estatísticos, e superpondo-os às imagens anatômicas. Um exemplo desse procedimento é observado na figura 3.5c. Ali vemos a atividade motora bilateral de um voluntário normal superposta ao seu respectivo plano anatômico, de uma imagem ponderada em T1 [de Araújo 2002].

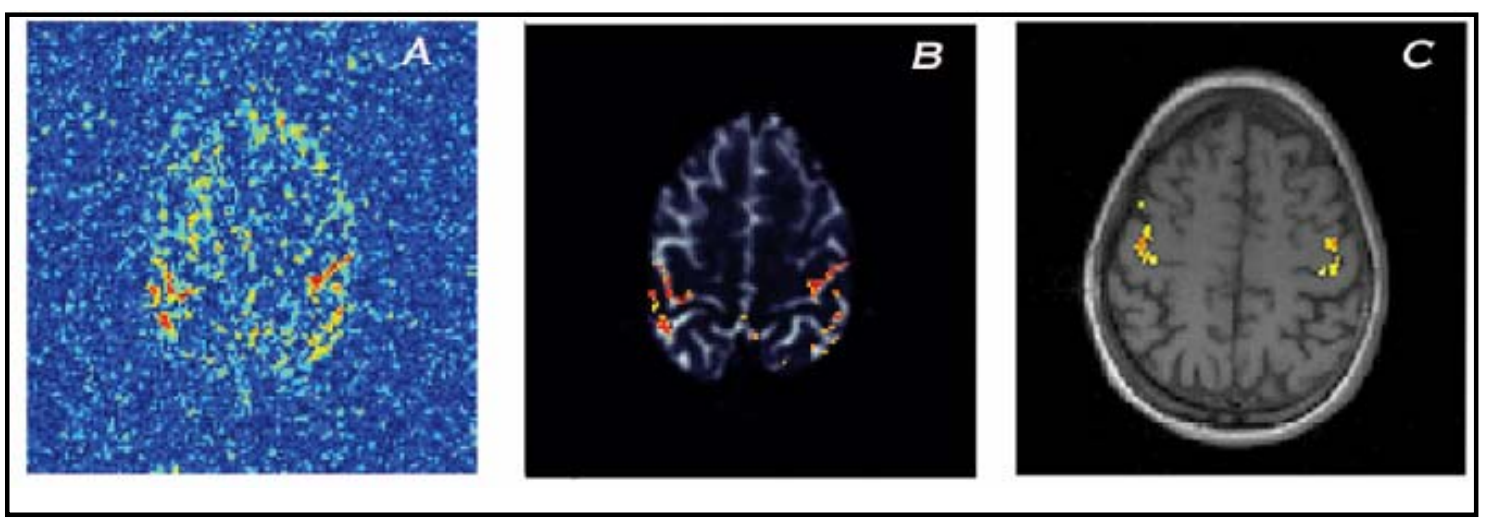

Figura 3.5 - Possíveis apresentações de exames de fMRI. (a) Mapas estatísticos originários de um paradigma motor em um voluntário assintomático, analisados por correlação cruzada. (b) Superposição dos mapas estatísticos à respectiva imagem EPI de um paradigma motor. (c) Superposição dos resultados a um plano axial de imagem ponderada em T1 [de Araújo 2002].

\subsection{Atlas Cerebral}

Neste ponto, vale a pena comentar a necessidade, que muitas vezes aparece, da normalização dos resultados. Atualmente, as formas mais utilizadas são os Atlas Talairach [Talairach \& Tournoux 1988], o qual estabelece um padrão espacial com a finalidade de mapear as estruturas do cérebro. Um Atlas estabelece um sistema de coordenadas ao qual as estruturas cerebrais são referenciadas.

O interesse da comunidade de neuroimagem é a apresentação dos resultados de estudos populacionais. Para efeito de comparação entre indivíduos, é necessário que, inicialmente, os mapas de ativação sejam transformados para um espaço comum de coordenadas [Talairach \& Tournoux, 1988]. Esses sistemas de coordenadas normalizados, além de facilitarem a comparação direta entre resultados 
de localização funcional, também servem como uma ferramenta de correção das variações anatômicas cerebrais entre indivíduos.

O sistema de coordenadas Talairach está baseado no plano entre duas formações anatômicas típicas: a comissura anterior (AC) e a comissura posterior (PC), o qual é chamado plano AC-PC. Após a definição do novo plano de coordenadas são geradas quatro linhas de referências que formam o sistema de grade Talairach, as quais são: a linha AC-PC, a linha AC vertical (ACV), a linha PC vertical (PCV) e a linha média (Figura 3.6).

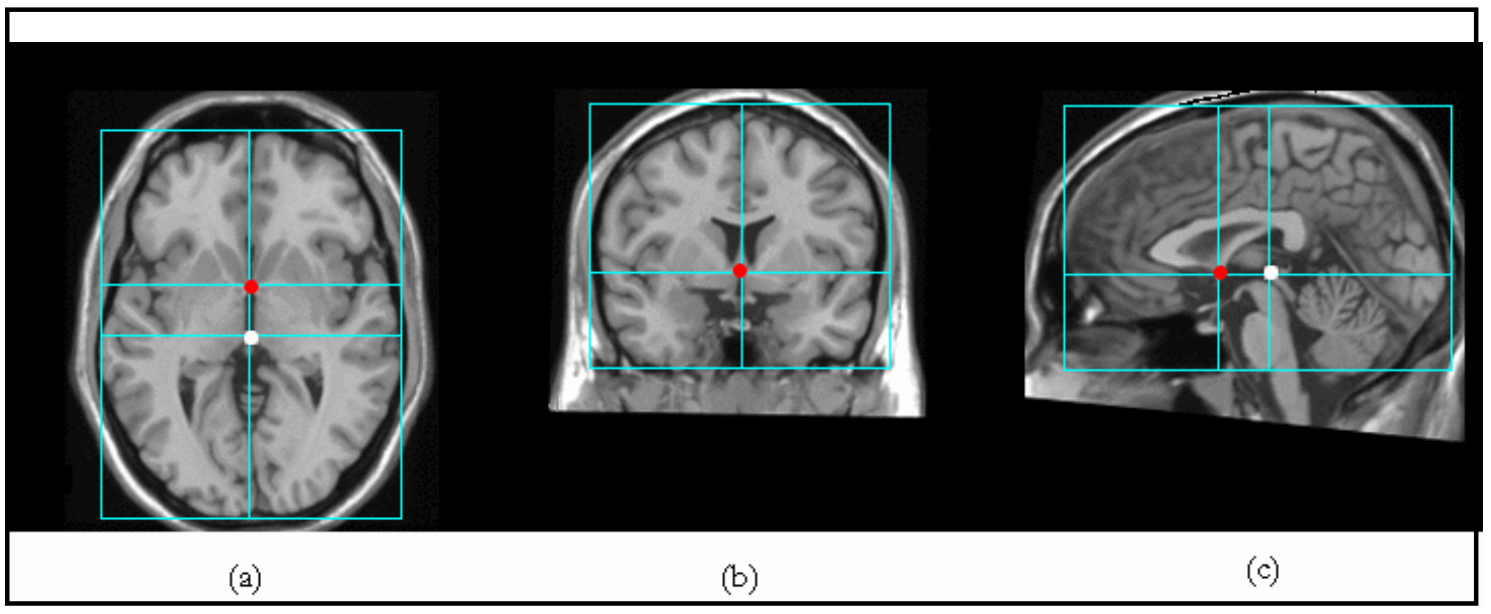

Figura 3.6 - Representação, nos planos axial (a), coronal (b) e sagital (c), das linhas utilizadas para definir o sistema de coordenadas Talairach. (a) Linha AC-PC. (b) Plano ACPC. (c) Linhas AC vertical e PC vertical e plano AC-PC. O cículo vermelho indica a localização anatômica da comissura anterior e o círculo branco indica a localização anatômica da comissura posterior.

As definições seguintes são utilizadas para delimitar o sistema de coordenadas: 1. A linha AC-PC passa pela borda superior da comissura anterior e pela borda inferior da comissura posterior. 2. A ACV é uma linha vertical perpendicular a linha AC-PC que atravessa a margem posterior da comissura anterior. 3. A PCV é uma linha que atravessa a margem anterior da comissura posterior é, também, perpendicular a linha AC-PC. 4. A linha média é a fissura interhemisférica. O sistema de grade Talairach é estabelecido baseado nas máximas dimensões do cérebro. O passo seguinte, de demarcação, é utilizado para definir a periferia cortical, no qual são definidos 6 pontos: o ponto mais superior do córtex parietal, a porção mais posterior do córtex occipital, o ponto mais inferior do córtex 
temporal, o ponto mais anterior do lobo frontal, e os pontos mais laterais (direito e esquerdo) do córtex parieto-temporal (figura 3.7).

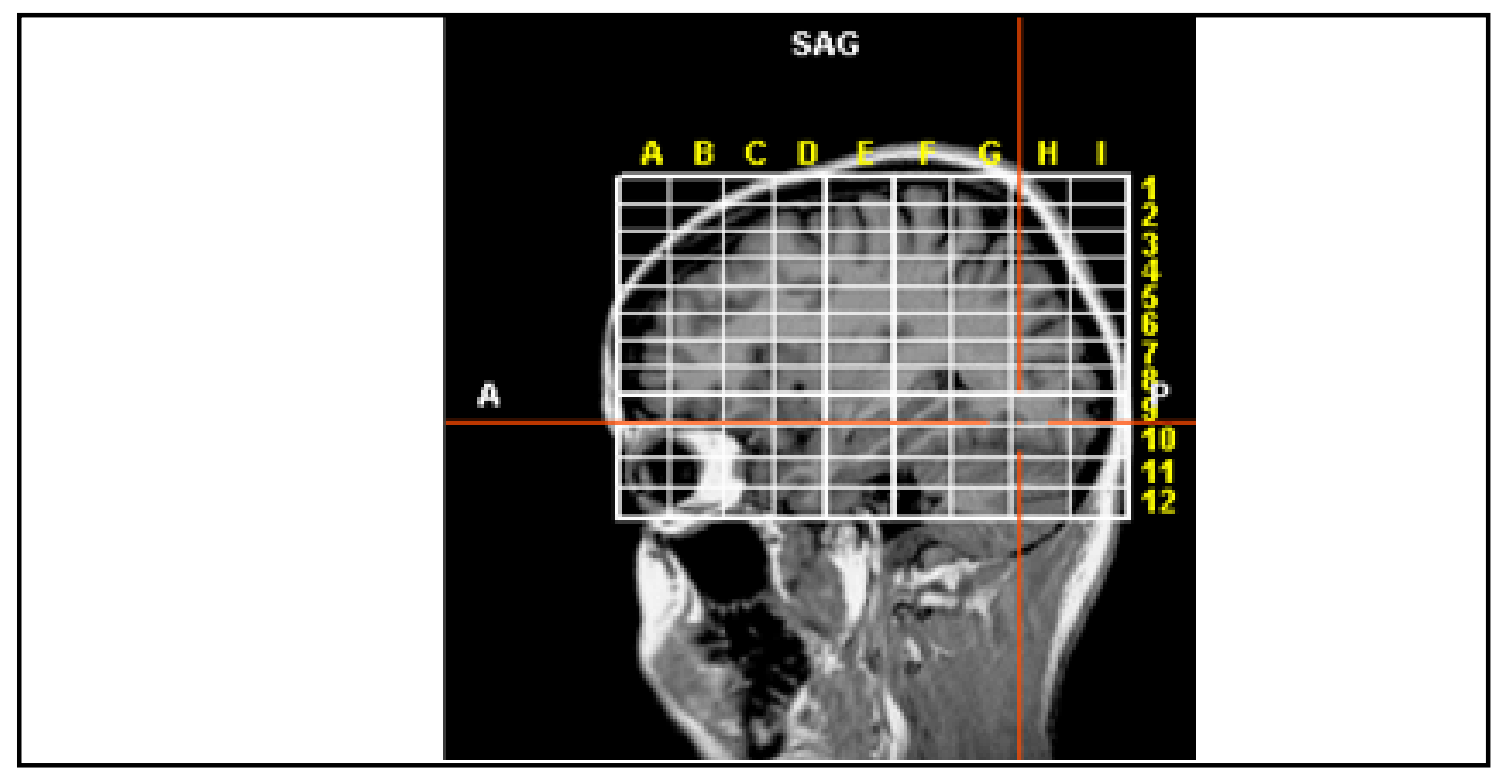

Figura 3.7 - Representação das linhas utilizadas para definir o sistema de coordenadas Talairach. Também está representada a grade delimitada pelos seis pontos.

Após as dimensões máximas de cada cérebro serem demarcadas são realizadas contrações e expansões do cérebro para que ele preencha o sistema de grade Talairach. E então, podemos extrair suas coordenadas $x, y, z$. Através desses processos conseguimos normalizar cada cérebro por uma estrutura padrão. 


\section{Capítulo 4}

\section{MATERIAL E MÉTODOS}

\subsection{Voluntários}

Participaram desse estudo 23 voluntários (15 homens e 8 mulheres). Nenhum voluntário possuía histórico de doença neurológica ou psiquiátrica e também nenhum distúrbio oculomotor.

\subsection{Estímulos}

Foram realizados três experimentos. No primeiro, imagens por ressonância magnética funcional foram adquiridas enquanto os voluntários (treze no total) realizavam uma estimulação do tipo Nistagmo Optocinético (NOC). No segundo, dez voluntários foram submetidos a um estímulo que induzia um movimento de rastreio puro. Por fim, os mesmos 10 voluntários foram submetidos a um paradigma que induzia um movimento puro de sacade do olho.

Para os três experimentos, um paradigma em bloco foi desenhado com 11 blocos, de 27,5 segundos cada, alternando períodos de repouso com períodos de atividade. Para os intervalos de repouso os voluntários foram instruídos a concentrar sua atenção em um ponto fixo, o qual aparecia no centro da tela.

A estimulação NOC foi realizada projetando-se um padrão de barras pretas e brancas, com velocidade de $5 \%$ s. Durante a indução do nistagmo, o ponto de fixação era retirado, mantendo, contudo, o movimento das barras. Nesse experimento foram realizados dois estudos: primeiro as barras moviam-se para a direita e no segundo, para a esquerda.

Para a estimulação do movimento de rastreio, os voluntários foram instruídos a seguir um quadrado vermelho que aparecia no centro da tela e movimentava-se num padrão oscilatório horizontal de amplitude constante, com uma freqüência de $0.1 \mathrm{~Hz}$. 
Para a estimulação do movimento sacádico o voluntário foi induzido a realizar movimentos sacádicos, pelo acompanhamento de um quadrado vermelho, que aparecia primeiramente no centro da tela e depois aparecia em uma posição à direita, e em seguida, em uma posição à esquerda, com uma freqüência constante de $1 \mathrm{~Hz}$.

Os estímulos apresentados foram desenvolvidos em um programa específico para geração de estímulos para exames de fMRI (Presentation ${ }^{\circledR} 0.55$ 03.10.03). O alvo visual foi gerado por um computador (Pentium 4, $2.4 \mathrm{GHz}$ ) e projetado por um canhão de projeção (Infocus Systems, modelo LitePro 210) em uma tela translúcida, localiza próxima aos pés do voluntário. O voluntário era capaz de enxergar o estímulo pela utilização de um espelho acoplado à bobina de cabeça.

\subsection{Aquisição dos Dados por MRI}

Para aquisição das imagens, utilizamos um scanner de $1.5 \mathrm{~T}$ Siemens (Magneton Vision) com uma bobina de quadratura transmissora/receptora de cabeça. Uma seqüência do tipo EPI foi utilizada para produzir continuamente, 66 volumes de aquisição, sendo cada um constituído por 16 fatias axiais, com $6 \mathrm{~mm}$ de espessura cada (ISI = $3540 \mathrm{~ms}$; TE $=60 \mathrm{~ms}$; ângulo flip 90 ; matriz 64 x 64; FOV = $220 \mathrm{~mm}$; dimensão do voxel $=3.44 \times 3.44 \times 6.00 \mathrm{~mm}$ ). Cada voluntário realizou cinco séries de atividade permanecendo por seis blocos em repouso. As imagens anatômicas foram adquiridas, após as imagens funcionais, utilizando uma seqüência do tipo GRE, MPR ponderada em T1 $\left(\mathrm{TR}=9.7 \mathrm{~ms}\right.$; TE $=4 \mathrm{~ms}$; ângulo flip $12^{\circ}$; matriz $256 \times 256 ; \mathrm{FOV}=256 \mathrm{~mm}$; espessura da fatia $=1 \mathrm{~mm}$; dimensão do voxels $=1 \times 1 \times 1 \mathrm{~mm})$. A duração total de cada experimento foi de aproximadamente 20 minutos.

\subsection{Análise dos Dados}

Os mapas estatísticos foram processados no programa Brain Voyager $^{\mathrm{TM}}$ (versão 4.9), utilizando o método GLM. Na etapa de pré-processamento foram realizadas a correção de movimento, a correção do tempo entre fatia, a suavização 
espacial (através de um Filtro Gaussiano com FWHM de $4 \mathrm{~mm}$ ) e também a filtragem temporal, na qual utilizamos um filtro passa alta de $3 \mathrm{~Hz} / \mathrm{s}$. Após a análise dos dados individuais, os mapas estatísticos foram normalizados no espaço Talairach.

Os dados foram primeiramente analisados de modo a indicarem as principais regiões envolvidas em cada um dos estímulos. Para tanto, obtivemos uma média, no espaço Talairach, da atividade de todos os voluntários.

Em seguida, gostaríamos de ter uma primeira idéia da variabilidade da localização dessas ativações entre os diferentes voluntários. Dessa forma, encontramos as coordenadas no espaço Talairach de cada indivíduo, separadamente, das áreas que responderam aos estímulos. Sobre essas coordenadas, então, calculamos sua média e desvio padrão, o que nos forneceu uma idéia dessa variabilidade.

Para acessarmos a variabilidade inter-individual, realizamos um estudo da freqüência de ocorrência para cada região observada [Vandenbroucke et al. 2004], ou seja, para um dado grupo, quantas vezes uma dada região foi ativada em cada um dos três estudo.

Para acessarmos a evolução da lateralização das funções vestibular e oculomotora, calculamos o índice de lateralização (IL) através de dois métodos: primeiramente por um método ( $\mathrm{IL}_{1}$ ) descrito anteriormente em estudos de lateralização da linguagem [Binder et al. 1996; Hinke et al. 1993] e, segundo, através de um método $\left(\mathrm{IL}_{2}\right)$ que leva em consideração a influência do limiar estatístico [Nagata et al. 2001].

Método $\mathbf{I L}_{1}$. Para a realização desse método, mantivemos um valor estatístico uniforme $(\mathrm{p}<0.0002$ para o estudo NOC para direita e $\mathrm{p}<0.0006$ para o estudo NOC para esquerda; $\mathrm{p}<0.00001$ para o estudo rastreio e $\mathrm{p}<0.00004$ para o estudo sacade) para todos os voluntários e, então, medimos o número de pixels ativados em cada ROI (Região de Interesse, Region of Interest - ROI). Para a delimitação da ROI foi construída uma máscara do córtex para cada hemisfério, essa máscara continha informações apenas da substância cinzenta, excluindo a contribuição do cerebelo e da substância branca. Assim, determinamos uma ROI 
para o hemisfério esquerdo e uma ROI para o hemisfério direito. A partir da definição das ROIs, calculamos o IL 1 utilizando a seguinte equação:

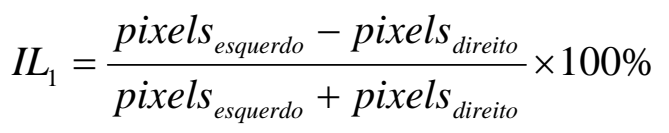

O IL $\mathrm{IL}_{1}$ varia de $+100 \%$ (para lateralização absoluta no hemisfério esquerdo) a $-100 \%$ (para lateralização absoluta no hemisfério direito).

Método IL2. Esse segundo método visa avaliar a relação entre a lateralização das funções vestibular e oculmotora e o valor de limiar estatístico escolhido. Para a utilização desse método, primeiramente obtivemos a correlação entre o valor estatístico z (valor-z) e o número de pixels ativados em cada hemisfério. Ou seja, fizemos um diagrama no qual o eixo- $x$ representa o valor-z e o eixo- $y$ representa o número de pixels ativos (figura 4.1).

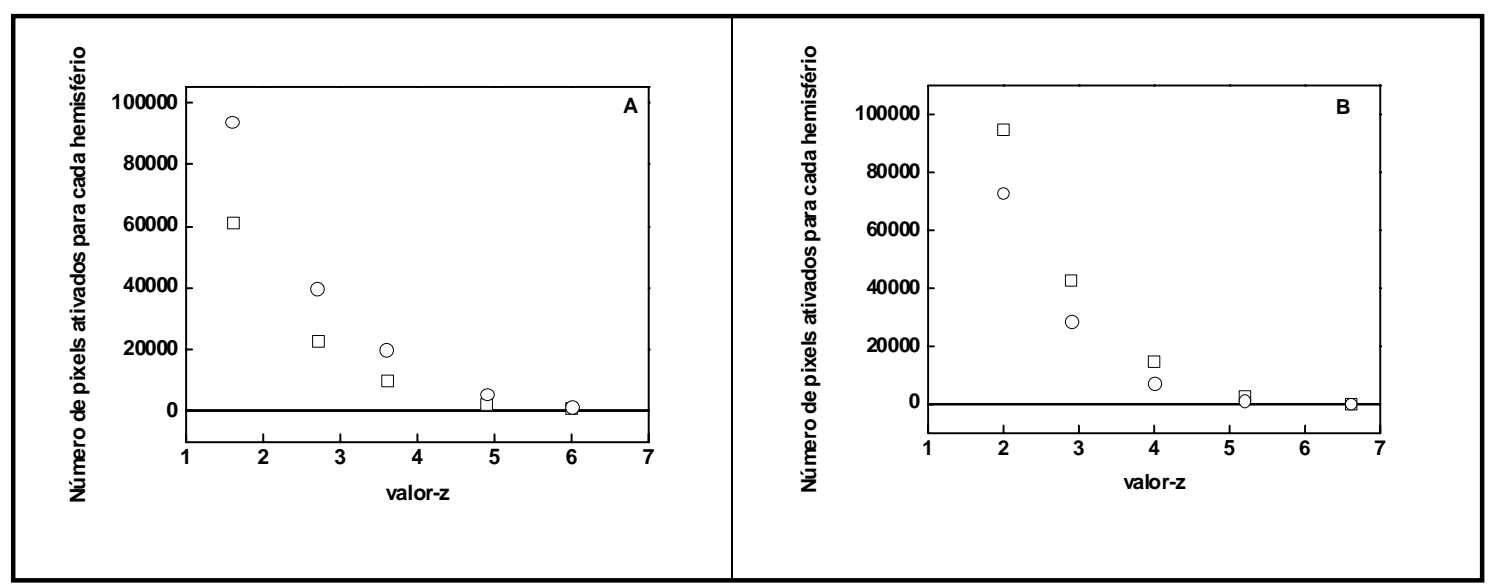

Figura 4.1 - Diagrama do número de pixels ativados versus o valor-z para os voluntários 3 do estudo NOC para esquerda (A) e 5 para o estudo NOC para direita (B). Os círculos indicam os valores para os pixels ativados no hemisfério direito e os quadrados, os pixels ativados no hemisfério esquerdo.

Note que o índice de lateralização varia entre um valor próximo de 1, para um valor-z em torno de 1,6, até um valor próximo de 0 , em um valor-z em torno de 6,6. Isso se deve a uma saturação no número de pixels ativados a valores altos e baixos de z. Ou seja, para valores altos de z fica difícil distinguir qual hemisfério contribui mais para o índice de lateralização, acontecendo o mesmo para valores pequenos de z. Desse modo, buscamos avaliar matematicamente a maneira com a qual o IL varia com o valor-z. Para tanto, ajustamos a curva dos pixels ativados a uma função de regressão. A função mais apropriada é uma expressão polinomial sendo assim, utilizamos uma função particular do tipo $\left(\frac{1}{\text { valor }-z}\right)^{n}$, encontrando 
para cada estudo o valor de $n$ que melhor ajustava os pontos. Em seguida, verificamos a correlação entre a função de regressão e o número de pixels ativados.

A partir da função de correlação encontrada, calculamos a equação de regressão para as duas curvas da figura 4.1, em que o número de pixels ativados no hemisfério esquerdo é dado por:

$$
R O I_{\text {esq }}=A \times\left(\frac{1}{\text { valor }-\mathrm{z}}\right)^{n}
$$

e o número de pixels ativados no hemisfério direito é dado por uma equação análoga a equação (4.2):

$$
R O I_{d i r}=B \times\left(\frac{1}{\text { valor }-\mathrm{z}}\right)^{n},
$$

sendo,

$n=2$ para os estudos NOC para direita e sacade; $n=3$ para os estudos NOC para esquerda e rastreio; e $A$ e $B$ são os coeficientes angulares calculados a partir da função de regressão. Então, $\mathrm{IL}_{2}$ foi calculado utilizando a equação:

$$
\begin{aligned}
I L_{2}= & {\left[\frac{F e(z)-F d(z)}{F e(z)+F d(z)}\right] \times 100 \%=} \\
= & \frac{A \times\left(\frac{1}{\text { valor }-z}\right)^{n}-B \times\left(\frac{1}{\text { valor }-z}\right)^{n}}{A \times\left(\frac{1}{\text { valor }-z}\right)^{n}+B \times\left(\frac{1}{\text { valor }-z}\right)^{n}} \times 100 \%= \\
= & \frac{A-B}{A+B} \times 100 \%,
\end{aligned}
$$

em que $\mathrm{Fe}(\mathrm{z})$ é a equação de regressão calculada para a curva dos pixels da esquerda e a $F d(z)$ é a equação de regressão calculada para a curva dos pixels da direita e, o valor $n$ tem os mesmos valores das equações (4.2) e (4.3). 


\section{Capítulo 5}

\section{RESULTADOS E DISCUSSÃO}

\subsection{Resultados}

Dos 23 voluntários 17 foram incluídos nesta análise, devido a problemas na aquisição das imagens, em especial pela presença de artefatos de movimento (4 voluntários para o paradigma NOC e 2 voluntários para os estudos Rastreio e Sacade). Os mapas estatísticos estão todos apresentados no espaço Talairach, mas possuem uma significância estatística específica para cada estudo, baseados em artigos prévios da literatura. Utilizamos uma significância de $\mathrm{p}<0.001$ para os estudos NOC para direita e NOC para esquerda e uma significância de $\mathrm{p}<0.003$ para os estudos Rastreio e Sacade.

A seguir apresentamos as principais estruturas que responderam seletivamente a cada um dos estímulos. Esses resultados dizem respeito à ativação média, no Atlas Talairach, entre todos os voluntários estudados.

\subsubsection{Estruturas Ativadas Durante o Estudo NOC para Direita}

Foram encontradas regiões com atividades estatisticamente significativas no giro occipital médio e inferior, no cúneus e pré-cúneus, no giro lingual, no giro temporal médio, superior e inferior, no giro fusiforme, no giro pós- e pré-central, no giro frontal inferior, superior e médio, no giro orbital, no giro subcaloso, no giro parahipocampal, no hipotálamo, no giro supramarginal, no lobo parietal superior e inferior, na ínsula anterior e posterior, no giro do cíngulo anterior e posterior, no uncus, no putamen, no globo pálido, na cabeça do núcleo caudado, no tronco encefálico, na substância negra, no corpo caloso, no tálamo e no cerebelo.

As figuras 5.1 e 5.2 indicam exemplos de regiões com mapas estatísticos no campo frontal do olho, no campo suplementar do olho e no córtex frontal dorsolateral, respectivamente. 

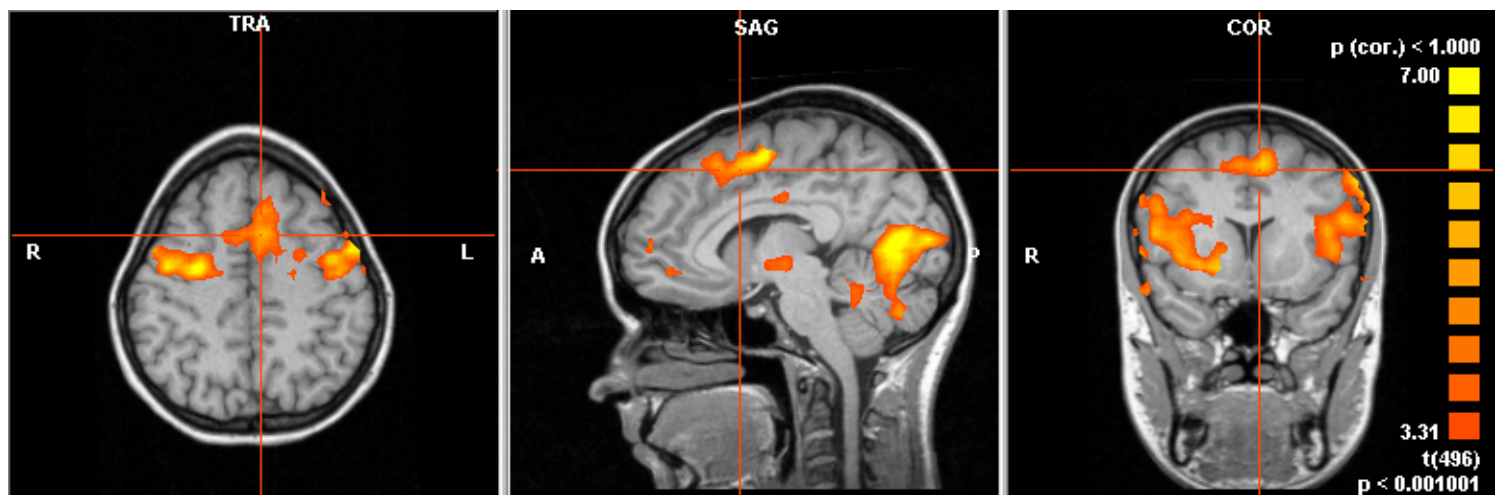

Figura 5.1 - Mapa estatístico ( $\mathrm{p}<0.001)$ indicando atividade bilateral no campo frontal do olho e atividade no campo suplementar do olho em resposta ao estímulo NOC para direita. A cor amarela indica uma significância estatística maior em comparação a cor vermelha.
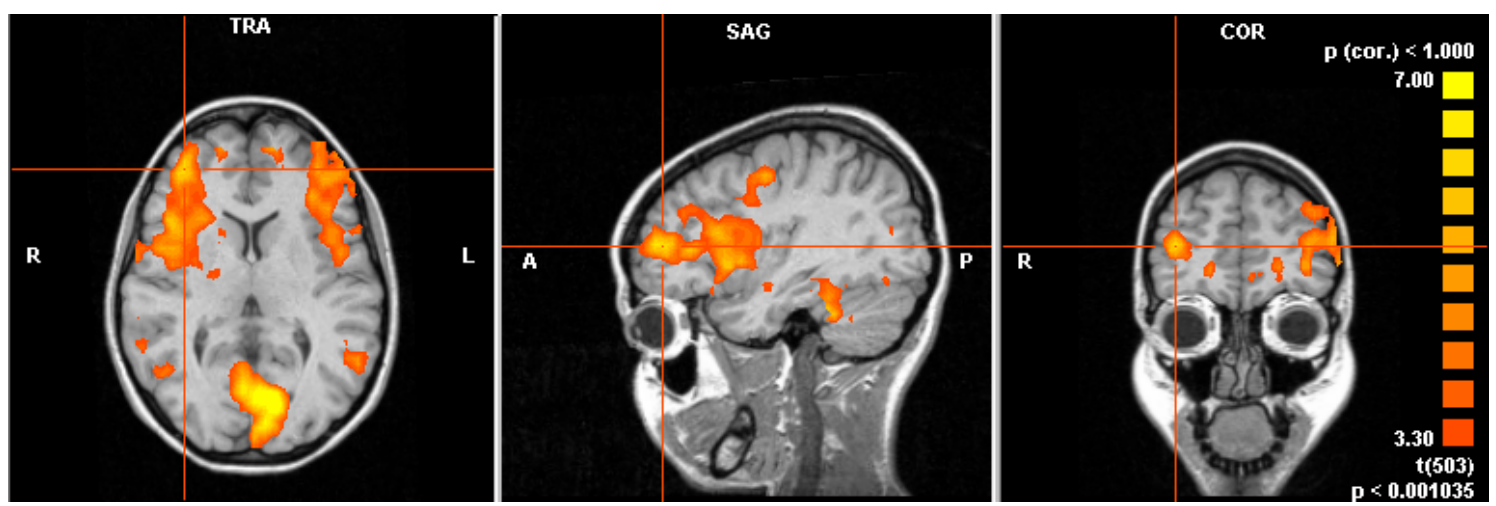

Figura 5.2 - Mapas estatísticos $(\mathrm{p}<0.001)$ indicando atividade bilateral no córtex préfrontal dorsolateral em resposta ao estímulo NOC para direita.

\subsubsection{Estruturas Ativadas Durante o Estudo NOC para Esquerda}

Além do giro occipital superior e médio, a atividade cerebral respondeu seletivamente ao estímulo no cúneus e pré-cúneus, no giro lingual, no giro temporal médio, superior, inferior e transverso, no giro fusiforme, no giro angular, no giro pós- e pré-central, no giro frontal inferior, superior e médio, no giro subcaloso, no giro parahipocampal, no hipotálamo, no giro supramarginal, no lobo parietal superior e inferior, na ínsula anterior e posterior, no giro do cíngulo anterior e posterior, no fastigium, no uncus, no putamen, no globo pálido, no corpo do núcleo caudado, no tronco encefálico, na substância negra, no corpo caloso, no tálamo, nos núcleos subtalâmicos e no cerebelo.

A figura 5.3 e 5.4 mostram os mapa estatístico em reposta ao NOC para esquerda mostrando a atividade bilateral na ínsula e atividade no córtex visual primário e também no cerebelo. 

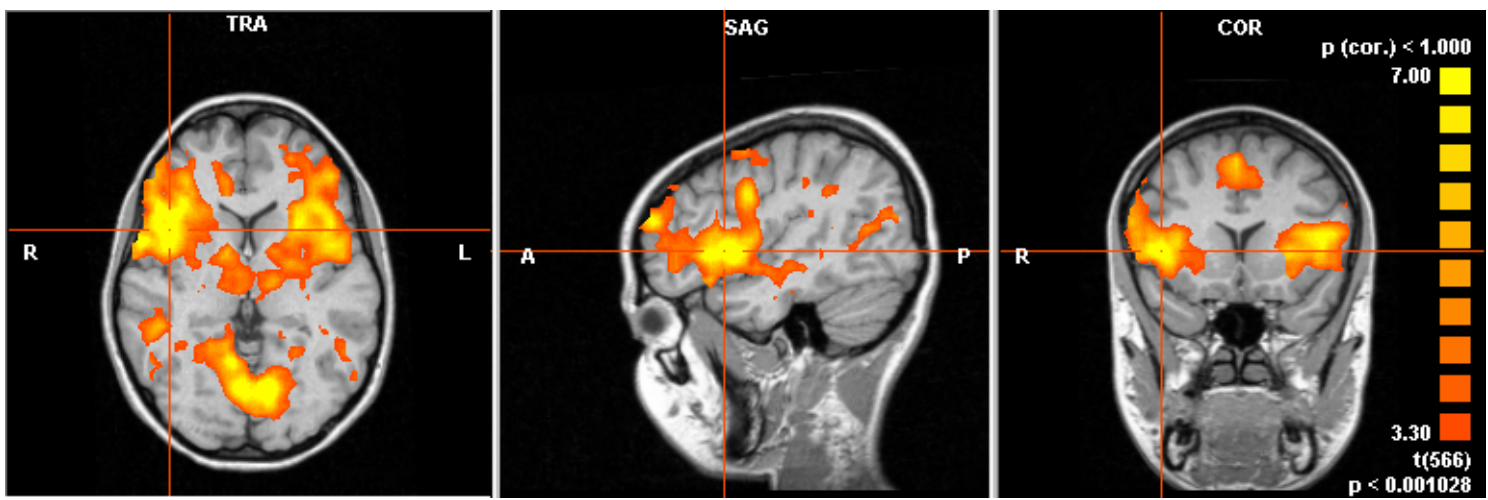

Figura 5.3 - Mapa estatístico $(\mathrm{p}<0.001)$ indicando atividade bilateral na ínsula durante o estudo NOC para esquerda.
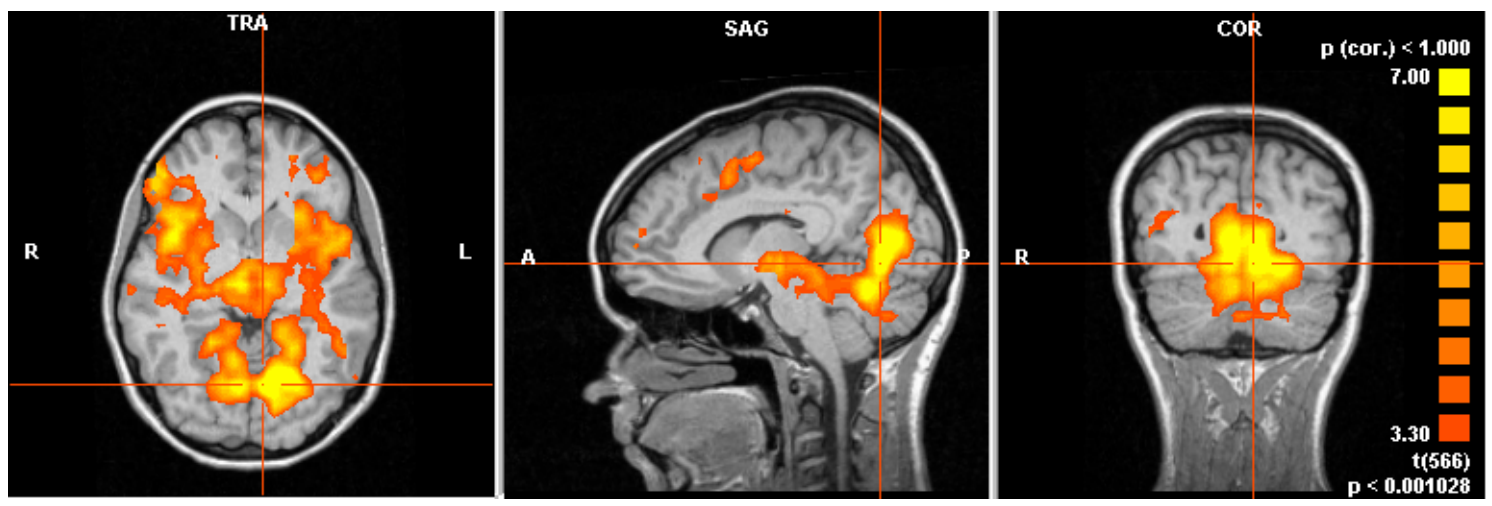

Figura 5.4 - Mapa estatístico ( $\mathrm{p}<0.001$ ) indicando atividade no córtex occipital e no cerebelo durante o estudo NOC para esquerda. A cor amarela indica uma significância estatística maior.

\subsubsection{Estruturas Ativadas Durante o Estudo Rastreio}

A atividade cerebral respondeu seletivamente ao estímulo de rastreio no giro occipital médio e inferior, no cúneus e pré-cúneus, no giro lingual, no giro temporal médio, superior e inferior, no giro fusiforme, no giro angular, no giro pós- e précentral, no giro frontal inferior, superior e médio, no giro subcaloso, no giro parahipocampal, no giro supramarginal, no lobo parietal superior e inferior, a ínsula anterior e posterior, no giro do cíngulo anterior e posterior, no uncus, no putamen, no globo pálido, no corpo do núcleo caudado, no tronco encefálico, nos núcleos vermelhos, no corpo caloso, no tálamo e no cerebelo.

As figuras 5.5 demonstra o mapa estatístico da região MT/MST região esta ativada durante o estudo Rastreio. 

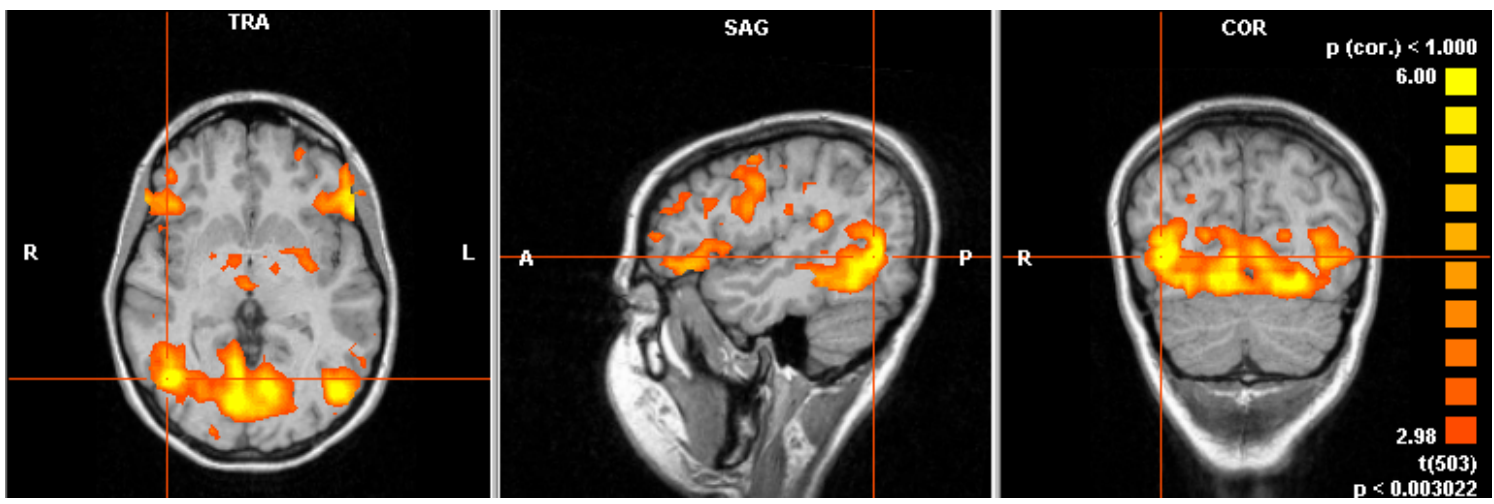

Figura 5.5 - Mapa estatístico ( $\mathrm{p}<0.003$ ) indicando atividade bilateral na área MT/MST durante o estudo Rastreio. A cor amarela indica uma significância estatística maior.

\subsubsection{Estruturas Ativadas Durante o Estudo Sacade}

Encontramos atividade significativa no giro occipital médio, superior e inferior, no cúneus, no giro lingual, no giro temporal médio, superior e inferior, no giro fusiforme, no giro angular, no giro pós- e pré-central, no giro frontal inferior, superior e médio, no giro parahipocampal, na amídala, no giro supramarginal, no pré-cúneus, no lobo parietal superior e inferior, na ínsula anterior e posterior, no giro do cíngulo anterior e posterior, no uncus, no putamen, no globo pálido, no corpo do núcleo caudado, no tronco encefálico, no corpo caloso, no tálamo e no cerebelo.

As figuras 5.6 e 5.7 indicam os mapas estatísticos durante o estudo Sacade, mostrando atividade no campo parietal do olho e no giro do cíngulo, respectivamente.
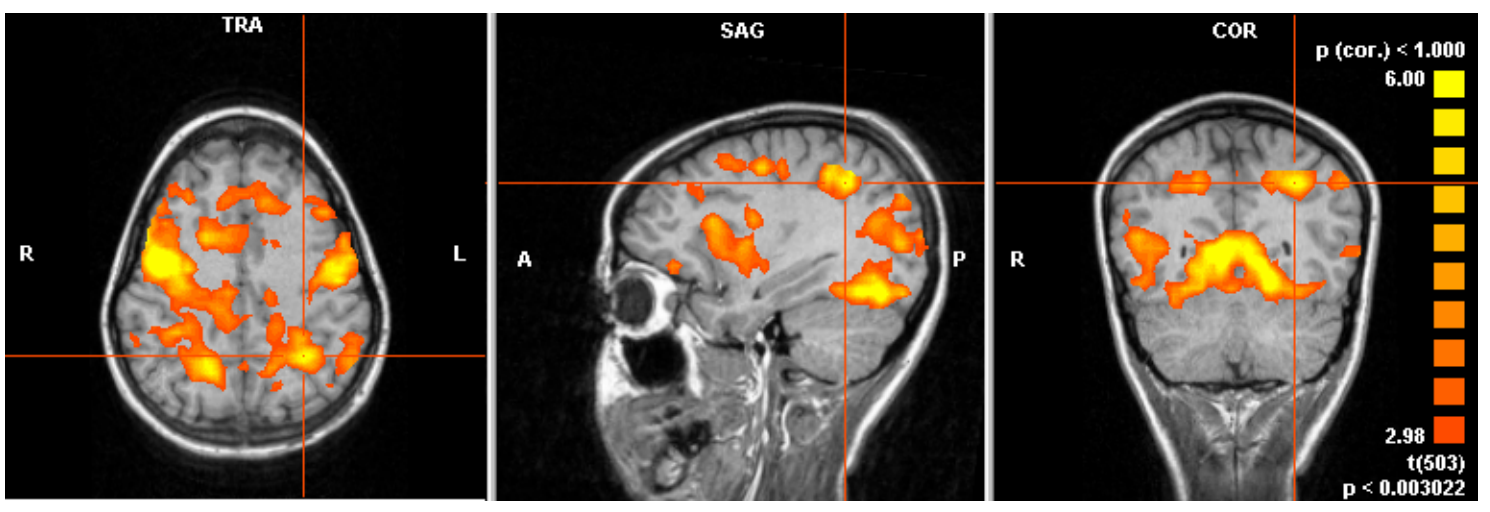

Figura 5.6 - Mapa estatístico ( $\mathrm{p}<0.003$ ) indicando atividade bilateral no PEF durante o estudo Sacade. A cor amarela indica uma significância estatística maior. 

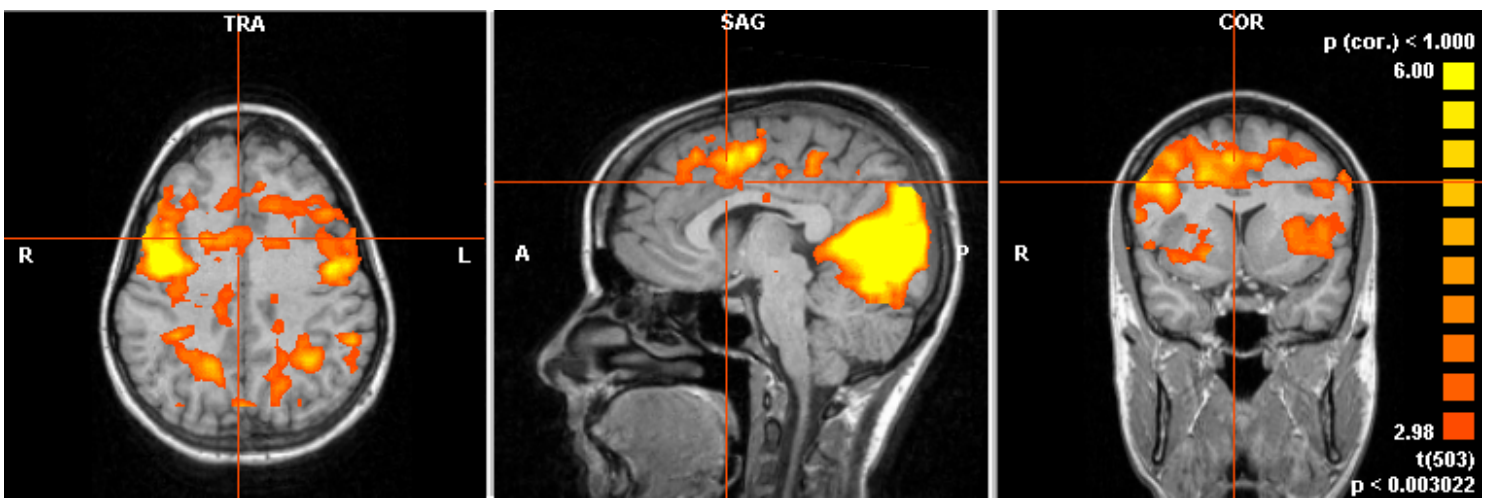

Figura 5.7 - Mapa estatístico ( $\mathrm{p}<0.003$ ) indicando atividade no giro do cíngulo durante o estudo Sacade. A cor amarela indica uma significância estatística maior.

\subsubsection{Diferenças entre os Estudos}

As Tabelas I e II mostram as coordenadas médias $x, y$ e $z$, no sistema Talairach, obtidas com base nas respostas individuais das principais regiões ativadas durante o estudo NOC para direita e NOC para esquerda, respectivamente. Além das coordenadas Talairach de cada região, indicamos a área de Brodmann correspondente.

Essas coordenadas sugerem que apesar de uma considerável superposição entre as ativações nos estudos NOC para direita e NOC para a esquerda, a maioria dessas regiões exibem diferenças espaciais. A menor diferença espacial das regiões ativadas foi encontrada no putamen, dada sua coordena média e desvio padrão para o estudo NOC para direita (D: $22 \pm 2,6 ; 3,3 \pm 6,8 ;-0,7 \pm 5,5 ; \mathrm{E}:-20,5 \pm 0,7 ; 7,5 \pm$ $3,4 ;-0,5 \pm 9,2)$ e para o estudo NOC para esquerda (D: 21,3 $\pm 5,7 ; 2,5 \pm 7 ; 0 \pm 6,5$; E: $-22,8 \pm 3,1 ; 6,2 \pm 10 ; 1,6 \pm 6)$. A região ativada com maior diferença espacial foi o corpo caloso, onde sua coordenada média e desvio padrão tanto no estudo NOC para direita (D: $1,5 \pm 0,7 ;-9,5 \pm 10,6 ; 24,5 \pm 0,7 ; \mathrm{E}:-5,3 \pm 2,5 ; 12,3 \pm 20,8 ; 13 \pm$ 10,5) como para o estudo NOC para esquerda (D: $5 \pm$ 6,7; -10,2 \pm 20,8; 18,2 \pm 6,3; $\mathrm{E}:-3,7 \pm 2,7 ;-18,5 \pm 21,8 ; 21 \pm 4,2)$.

Durante os estudos Rastreio e Sacade (Tabelas III e IV) verificamos, também, uma considerável sobreposição entre as ativações. Além disso, as regiões ativadas com maior e menor diferenças espaciais concordam com as encontradas para o estudo NOC, i.e., o putamen com o menor desvio e corpo caloso com o maior. 
Note que algumas estruturas, como o Tálamo, não apresentam desvio padrão, uma vez que só se mostraram ativas em um único voluntário.

Tabela I. Principais áreas ativadas, e sua área de Brodmann correspondente, com suas coordenadas médias ( \pm desvio padrão) $x, y$ e $z$ durante a estimulação NOC para direita.

\begin{tabular}{|c|c|c|c|c|c|}
\hline Áreas Cerebrais & \multicolumn{4}{|c|}{ Coordenadas Talairach $(x ; y ; z)$} & BA \\
\hline FEF & $\begin{array}{l}\mathrm{D} \\
\mathrm{E}\end{array}$ & $\begin{array}{l}30,5 \pm 7,4 \\
-46,7 \pm 5,9\end{array}$ & $\begin{array}{l}-7,7 \pm 2,3 \\
-5,7 \pm 6,4\end{array}$ & $\begin{array}{l}50,8 \pm 7,2 \\
44,4 \pm 8,8\end{array}$ & $4 / 6$ \\
\hline SEF & & $-3,1 \pm 3,4$ & $1,2 \pm 11,5$ & $52 \pm 5,4$ & 6 \\
\hline PEF & $\begin{array}{l}\mathrm{D} \\
\mathrm{E}\end{array}$ & $\begin{array}{c}44 \pm 13,4 \\
-44,7 \pm 16,5\end{array}$ & $\begin{array}{c}-37,6 \pm 8,5 \\
-35,7 \pm 10,3\end{array}$ & $\begin{array}{c}36,8 \pm 12,4 \\
35,2 \pm 13\end{array}$ & $40 / 7$ \\
\hline DLPFC & $\begin{array}{l}D \\
E\end{array}$ & $\begin{array}{c}32 \pm 7,6 \\
-31,6 \pm 10,5\end{array}$ & $\begin{array}{l}41,4 \pm 9,9 \\
53,3 \pm 4,4\end{array}$ & $\begin{array}{c}10,1 \pm 14,2 \\
5,9 \pm 7,8\end{array}$ & $46 / 10$ \\
\hline MT/MST & $\begin{array}{l}D \\
E\end{array}$ & $\begin{array}{l}49,6 \pm 5,6 \\
-52,3 \pm 3,2\end{array}$ & $\begin{array}{l}-57,9 \pm 14,6 \\
-44,5 \pm 16,4\end{array}$ & $\begin{array}{l}10 \pm 4,1 \\
8,8 \pm 7,9\end{array}$ & $19 / 39$ \\
\hline V1 & $\begin{array}{l}D \\
E\end{array}$ & $\begin{array}{c}3,8 \pm 1 \\
-9,6 \pm 3,4\end{array}$ & $\begin{array}{l}-82,2 \pm 10,1 \\
-84,7 \pm 8,6\end{array}$ & $\begin{array}{c}2,2 \pm 7,5 \\
4 \pm 6\end{array}$ & $17 / 18$ \\
\hline Paraestriado & $\begin{array}{l}\mathrm{D} \\
\mathrm{E}\end{array}$ & $\begin{array}{c}7 \pm 5,3 \\
-8,1 \pm 4,8\end{array}$ & $\begin{array}{l}-78 \pm 12,9 \\
-79,7 \pm 9,2\end{array}$ & $\begin{array}{c}-1,7 \pm 4 \\
0,8 \pm 9,1\end{array}$ & 18 \\
\hline Ínsula Anterior & $\begin{array}{l}\mathrm{D} \\
\mathrm{E}\end{array}$ & $\begin{array}{c}39 \pm 3 \\
-38,7 \pm 4,5\end{array}$ & $\begin{array}{c}10,8 \pm 8,7 \\
8 \pm 6,2\end{array}$ & $\begin{array}{l}2,3 \pm 5,1 \\
4,5 \pm 6,2\end{array}$ & 13 \\
\hline Ínsula Posterior & $\begin{array}{l}\mathrm{D} \\
\mathrm{E}\end{array}$ & $\begin{array}{c}39,7 \pm 3 \\
-44\end{array}$ & $\begin{array}{c}-5,7 \pm 3,8 \\
-6\end{array}$ & $\begin{array}{c}5,2 \pm 4,6 \\
12\end{array}$ & 13 \\
\hline Cíngulo Anterior & $\begin{array}{l}D \\
E\end{array}$ & $\begin{array}{l}6,5 \pm 2,1 \\
-5,3 \pm 2,1\end{array}$ & $\begin{array}{l}29 \pm 14,1 \\
32,7 \pm 7,5\end{array}$ & $\begin{array}{c}-8,5 \pm 0,7 \\
6 \pm 8\end{array}$ & $24 / 32$ \\
\hline Cíngulo Posterior & $\begin{array}{l}\mathrm{D} \\
\mathrm{E}\end{array}$ & $\begin{array}{c}6 \pm 1 \\
-\end{array}$ & $\begin{array}{c}-59,7 \pm 0,6 \\
-\end{array}$ & $\begin{array}{c}8,7 \pm 3,8 \\
-\end{array}$ & $30 / 31$ \\
\hline $\begin{array}{c}\text { Giro } \\
\text { Parahipocampal }\end{array}$ & $\begin{array}{l}\mathrm{D} \\
\mathrm{E}\end{array}$ & $25,5 \pm 10,8$ & $-22 \pm 19,6$ & $-11 \pm 4,7$ & $19 / 36$ \\
\hline
\end{tabular}




\begin{tabular}{c|cccc}
\hline \multirow{2}{*}{ Cerebelo } & & $-18 \pm 3,8$ & $-27,7 \pm 27,2$ & $-10,7 \pm 7,3$ \\
Putamen & $\mathrm{D}$ & $25 \pm 8,3$ & $-50,9 \pm 8,1$ & $-29,1 \pm 8,1$ \\
$\mathrm{E}$ & $-26,3 \pm 13,8$ & $-54,4 \pm 9,1$ & $-25 \pm 8,4$ \\
Tálamo & $22 \pm 2,6$ & $3,3 \pm 6,8$ & $-0,7 \pm 5,5$ \\
E & $-20,5 \pm 0,7$ & $7,5 \pm 3,5$ & $-0,5 \pm 9,2$ \\
Corpo Caloso & $\mathrm{D}$ & $11 \pm 7$ & $-22 \pm 2$ & $7,7 \pm 8,6$ \\
$\mathrm{E}$ & -13 & -8 & 6 \\
Globo Pálido & $\mathrm{D}$ & $1,5 \pm 0,7$ & $-9,5 \pm 10,6$ & $24,5 \pm 0,7$ \\
$\mathrm{E}$ & $-5,3 \pm 2,5$ & $12,3 \pm 20,8$ & $13 \pm 10,5$ \\
& $\mathrm{D}$ & $13,7 \pm 4$ & $-3 \pm 5,6$ & $-3,3 \pm 2,5$ \\
$\mathrm{E}$ & $-19,7 \pm 4,7$ & $-6,7 \pm 4,1$ & $-5 \pm 1,7$
\end{tabular}

As coordenadas foram calculadas no espaço Talairach, para cada uma das regiões, com base na localização da resposta individual.

Tabela II. Principais áreas ativadas, e sua área de Brodmann correspondente, com suas coordenadas médias $x, y$ e $z$ ( \pm desvio padrão) durante a estimulação NOC para esquerda.

\begin{tabular}{|c|c|c|c|c|c|}
\hline Áreas Cerebrais & \multicolumn{4}{|c|}{ Coordenadas Talairach $(x ; y ; z)$} & BA \\
\hline FEF & $\begin{array}{l}\mathrm{D} \\
\mathrm{E}\end{array}$ & $\begin{array}{l}36,7 \pm 9,7 \\
-45,9 \pm 6,6\end{array}$ & $\begin{array}{l}-5,3 \pm 6,3 \\
-2,9 \pm 7,6\end{array}$ & $\begin{array}{l}48,6 \pm 6,7 \\
44,7 \pm 8,3\end{array}$ & $4 / 6$ \\
\hline SEF & & $5,3 \pm 4,2$ & $4 \pm 9$ & $49 \pm 4,4$ & 6 \\
\hline PEF & $\begin{array}{l}D \\
E\end{array}$ & $\begin{array}{c}48,6 \pm 12 \\
-46,2 \pm 18,8\end{array}$ & $\begin{array}{c}-40 \pm 7,1 \\
-38,8 \pm 10,7\end{array}$ & $\begin{array}{c}39 \pm 11,1 \\
39,8 \pm 10,9\end{array}$ & $40 / 7$ \\
\hline DLPFC & $\begin{array}{l}D \\
E\end{array}$ & $\begin{array}{c}38,7 \pm 7,2 \\
-29,8 \pm 7,8\end{array}$ & $\begin{array}{l}49,3 \pm 6,6 \\
52,4 \pm 4,7\end{array}$ & $\begin{array}{l}8,6 \pm 8,4 \\
7,5 \pm 6,7\end{array}$ & $46 / 10$ \\
\hline MT/MST & $\begin{array}{l}\mathrm{D} \\
\mathrm{E}\end{array}$ & $\begin{array}{c}53 \pm 6,2 \\
-52,3 \pm 7,1\end{array}$ & $\begin{array}{c}-48,7 \pm 19 \\
-56 \pm 13\end{array}$ & $\begin{array}{c}4,6 \pm 7 \\
5,5 \pm 11,6\end{array}$ & $19 / 39$ \\
\hline V1 & $\begin{array}{l}\mathrm{D} \\
\mathrm{E}\end{array}$ & $\begin{array}{c}6 \pm 1,1 \\
-8,7 \pm 4,6\end{array}$ & $\begin{array}{l}-75,7 \pm 3,7 \\
-81,1 \pm 7,8\end{array}$ & $\begin{array}{l}8,2 \pm 5,2 \\
5,1 \pm 9,2\end{array}$ & $17 / 18$ \\
\hline
\end{tabular}




\begin{tabular}{|c|c|c|c|c|c|}
\hline \multirow{2}{*}{ Paraestriado } & $\mathrm{D}$ & $8,7 \pm 5,3$ & $-73,4 \pm 8,5$ & $11,4 \pm 11$ & \multirow{2}{*}{18} \\
\hline & $\mathrm{E}$ & $-9,9 \pm 9,2$ & $-75,3 \pm 6,5$ & $2,3 \pm 9,1$ & \\
\hline \multirow{2}{*}{ Ínsula Anterior } & $\mathrm{D}$ & $37,6 \pm 4,1$ & $9 \pm 5,9$ & $4,7 \pm 4,1$ & \multirow{2}{*}{13} \\
\hline & $\mathrm{E}$ & $-37,4 \pm 1,7$ & $6 \pm 6,1$ & $8,2 \pm 6,5$ & \\
\hline \multirow{2}{*}{ Ínsula Posterior } & $\mathrm{D}$ & $38,2 \pm 2$ & $-5,4 \pm 7$ & $5,6 \pm 11$ & \multirow{2}{*}{13} \\
\hline & $\mathrm{E}$ & $-38 \pm 1$ & $0,3 \pm 3,8$ & $-3,7 \pm 2,1$ & \\
\hline \multirow{2}{*}{ Cíngulo Anterior } & $\mathrm{D}$ & $4 \pm 1,4$ & $39 \pm 10$ & $9 \pm 21,2$ & \multirow{2}{*}{$24 / 32$} \\
\hline & $\mathrm{E}$ & -3 & 42 & 10 & \\
\hline \multirow{2}{*}{ Cíngulo Posterior } & $\mathrm{D}$ & $8,6 \pm 3,2$ & $-62 \pm 6,6$ & $12,6 \pm 2,8$ & \multirow{2}{*}{$30 / 31$} \\
\hline & $\mathrm{E}$ & $-12 \pm 6,3$ & $-64,5 \pm 3,7$ & $15 \pm 1,4$ & \\
\hline Giro & $\mathrm{D}$ & $27,2 \pm 7$ & $-26,3 \pm 11,2$ & $-14,2 \pm 7,7$ & \multirow{12}{*}{$19 / 36$} \\
\hline Parahipocampal & $\mathrm{E}$ & $-24,5 \pm 6,6$ & $-18,3 \pm 15,6$ & $-13,3 \pm 6$ & \\
\hline \multirow{2}{*}{ Cerebelo } & $\mathrm{D}$ & $26,9 \pm 12,7$ & $-53,4 \pm 8,8$ & $-24,4 \pm 5,8$ & \\
\hline & $\mathrm{E}$ & $-25 \pm 12,6$ & $-58,6 \pm 9$ & $-28,3 \pm 6,7$ & \\
\hline \multirow{2}{*}{ Putamen } & $\mathrm{D}$ & $21,3 \pm 5,7$ & $2,5 \pm 7$ & $0 \pm 6,5$ & \\
\hline & $\mathrm{E}$ & $-22,8 \pm 3,1$ & $6,2 \pm 10$ & $1,6 \pm 6$ & \\
\hline \multirow{2}{*}{ Tálamo } & $\mathrm{D}$ & 5 & -19 & 3 & \\
\hline & $\mathrm{E}$ & $-8,5 \pm 2,1$ & $-14,5 \pm 5$ & $4,5 \pm 2,1$ & \\
\hline \multirow{2}{*}{ Corpo Caloso } & $\mathrm{D}$ & $5 \pm 6,7$ & $-10,2 \pm 20,8$ & $18,2 \pm 6,3$ & \\
\hline & $\mathrm{E}$ & $-3,7 \pm 2,7$ & $-18,5 \pm 21,8$ & $21 \pm 4,2$ & \\
\hline \multirow{2}{*}{ Globo Pálido } & $\mathrm{D}$ & $12,3 \pm 1,5$ & $0,3 \pm 3,2$ & $1,3 \pm 2,1$ & \\
\hline & $\mathrm{E}$ & $-14,3 \pm 2,9$ & $-1,7 \pm 4,6$ & $-1,3 \pm 3,2$ & \\
\hline
\end{tabular}

As coordenadas foram calculadas no espaço Talairach, para cada uma das regiões, com base na localização da resposta individual.

Tabela III - Principais áreas ativadas, e sua área de Brodmann correspondente, com suas coordenadas médias ( \pm desvio padrão) $x, y$ e $z$ durante o estudo Rastreio.

\begin{tabular}{l|ll}
\hline Áreas Cerebrais & Coordenadas Talairach $(x ; y ; z)$ & BA \\
\hline & &
\end{tabular}




\begin{tabular}{|c|c|c|c|c|c|}
\hline FEF & $\begin{array}{l}\mathrm{D} \\
\mathrm{E}\end{array}$ & $\begin{array}{r}40,3 \pm 14,6 \\
-41,3 \pm 11,8\end{array}$ & $\begin{array}{l}-8,5 \pm 6,6 \\
-9,6 \pm 10,3\end{array}$ & $\begin{array}{l}46,4 \pm 6,7 \\
46,7 \pm 9,1\end{array}$ & $4 / 6$ \\
\hline SEF & & $1,7 \pm 7,1$ & $-4,7 \pm 4,8$ & $52,8 \pm 5,4$ & 6 \\
\hline \multirow{2}{*}{ PEF } & $\mathrm{D}$ & $38,7 \pm 10,7$ & $-45,5 \pm 12,2$ & $37,8 \pm 12,2$ & \multirow{2}{*}{$40 / 7$} \\
\hline & $\mathrm{E}$ & $-46,5 \pm 11,7$ & $-37,5 \pm 15,5$ & $28,5 \pm 18,7$ & \\
\hline \multirow{2}{*}{ DLPFC } & $\mathrm{D}$ & $33,8 \pm 3,8$ & $45,4 \pm 11,8$ & $9,8 \pm 6,5$ & \multirow{2}{*}{$46 / 10$} \\
\hline & $\mathrm{E}$ & $-27 \pm 8,8$ & $50,5 \pm 8,2$ & $3,3 \pm 6$ & \\
\hline \multirow{2}{*}{ MT/MST } & $\mathrm{D}$ & $44,8 \pm 6,6$ & $-61,4 \pm 9,2$ & $3,9 \pm 8$ & \multirow{2}{*}{$19 / 39$} \\
\hline & $\mathrm{E}$ & $-45,6 \pm 5,2$ & $-64,6 \pm 7,9$ & $2,4 \pm 3,9$ & \\
\hline \multirow{2}{*}{ V1 } & $\mathrm{D}$ & $10,7 \pm 3,8$ & $-86,5 \pm 6,2$ & $-1,8 \pm 8,4$ & \multirow{2}{*}{$17 / 18$} \\
\hline & $\mathrm{E}$ & $-6,5 \pm 6$ & $-87,8 \pm 4,6$ & $1,5 \pm 9,3$ & \\
\hline \multirow{2}{*}{ Paraestriado } & $\mathrm{D}$ & $8,8 \pm 6,7$ & $-76,6 \pm 8,2$ & & \multirow{2}{*}{18} \\
\hline & $\mathrm{E}$ & $-16,2 \pm 16,2$ & $-74,2 \pm 6,3$ & $5,8 \pm 12,3$ & \\
\hline \multirow{2}{*}{ Ínsula Anterior } & $\mathrm{D}$ & $41 \pm 4,4$ & $2,7 \pm 2,1$ & $4,7 \pm 4,7$ & \multirow{2}{*}{13} \\
\hline & $\mathrm{E}$ & $-40 \pm 2,6$ & $1,3 \pm 4$ & $4 \pm 4,4$ & \\
\hline \multirow{2}{*}{ Ínsula Posterior } & $\mathrm{D}$ & $38,4 \pm 4,5$ & $-12 \pm 8,8$ & $8,8 \pm 9$ & \multirow{2}{*}{13} \\
\hline & $\mathrm{E}$ & $-40,5 \pm 3,5$ & $-12 \pm 4,2$ & $7 \pm 11,3$ & \\
\hline \multirow{2}{*}{ Cíngulo Anterior } & $\mathrm{D}$ & $4,5 \pm 2,1$ & $16 \pm 11,3$ & $27 \pm 12,7$ & \multirow{2}{*}{$24 / 32$} \\
\hline & $\mathrm{E}$ & $-4,5 \pm 2,6$ & $21,8 \pm 16,7$ & $11,3 \pm 18,4$ & \\
\hline \multirow{2}{*}{ Cíngulo Posterior } & $\mathrm{D}$ & $11,3 \pm 3$ & $-49,3 \pm 13$ & $19 \pm 16,1$ & \multirow{2}{*}{$30 / 31$} \\
\hline & $\mathrm{E}$ & $-3,5 \pm 24,7$ & $-64,5 \pm 0,7$ & $14 \pm 4,2$ & \\
\hline Giro & $\mathrm{D}$ & $22,3 \pm 7,2$ & $-34,3 \pm 10$ & $-5,9 \pm 7$ & \multirow{2}{*}{$19 / 36$} \\
\hline Parahipocampal & $\mathrm{E}$ & $-33 \pm 4,2$ & $-14 \pm 8,5$ & $-16 \pm 5,7$ & \\
\hline \multirow{2}{*}{ Cerebelo } & $\mathrm{D}$ & $18,7 \pm 8,4$ & $-67,2 \pm 9,3$ & $-24,8 \pm 7,2$ & \\
\hline & $\mathrm{E}$ & $-23,2 \pm 9,8$ & $-50,7 \pm 15,5$ & $-24 \pm 11,5$ & \\
\hline \multirow{2}{*}{ Putamen } & $\mathrm{D}$ & $20,3 \pm 3,8$ & $11,3 \pm 4,2$ & $1 \pm 3$ & \\
\hline & $\mathrm{E}$ & $-22,5 \pm 3,5$ & $-0,5 \pm 6,4$ & $5,5 \pm 2,1$ & \\
\hline
\end{tabular}




\begin{tabular}{c|cccc}
\hline Tálamo & $\mathrm{D}$ & 4 & -14 & 1 \\
& $\mathrm{E}$ & $-9 \pm 2,8$ & $-12 \pm 8,5$ & $8 \pm 2,8$ \\
Corpo Caloso & $\mathrm{D}$ & $6 \pm 1,4$ & $-3,5 \pm 41,7$ & $12,5 \pm 4,9$ \\
& $\mathrm{E}$ & -13 & 31 & 3 \\
Globo Pálido & $\mathrm{D}$ & 15 & -1 & 4 \\
As coordenadas foram calculadas no espaço Talairach, para cada uma das regiões, com
\end{tabular}
base na localização da resposta individual.

Tabela IV. Principais áreas ativadas, e sua área de Brodmann correspondente, com suas coordenadas médias ( \pm desvio padrão) $x, y$ e $z$ durante o estudo Sacade.

\begin{tabular}{|c|c|c|c|c|c|}
\hline Áreas Cerebrais & \multicolumn{4}{|c|}{ Coordenadas Talairach $(x ; y ; z)$} & BA \\
\hline FEF & $\begin{array}{l}\mathrm{D} \\
\mathrm{E}\end{array}$ & $\begin{array}{c}41 \pm 4,9 \\
-41,3 \pm 11,2\end{array}$ & $\begin{array}{c}-6 \pm 5,9 \\
-10,3 \pm 4,3\end{array}$ & $\begin{array}{l}46,1 \pm 5,7 \\
48,4 \pm 6,8\end{array}$ & $4 / 6$ \\
\hline SEF & & $-0,7 \pm 3,1$ & $-3,7 \pm 6,2$ & $53,6 \pm 5,2$ & 6 \\
\hline PEF & $\begin{array}{l}\mathrm{D} \\
\mathrm{E}\end{array}$ & $\begin{array}{c}37,7 \pm 11,9 \\
-42,3 \pm 10,2\end{array}$ & $\begin{array}{c}-44,7 \pm 12,2 \\
-43,9 \pm 9,1\end{array}$ & $\begin{array}{c}38,3 \pm 8,8 \\
37 \pm 7\end{array}$ & $40 / 7$ \\
\hline DLPFC & $\begin{array}{l}\mathrm{D} \\
\mathrm{E}\end{array}$ & $\begin{array}{c}36,5 \pm 7,3 \\
-32,8 \pm 8,6\end{array}$ & $\begin{array}{c}39 \pm 10,4 \\
40,5 \pm 13,4\end{array}$ & $\begin{array}{l}20,5 \pm 14,6 \\
17,7 \pm 19,1\end{array}$ & $46 / 10$ \\
\hline MT/MST & $\begin{array}{l}\mathrm{D} \\
\mathrm{E}\end{array}$ & $\begin{array}{c}44,6 \pm 3 \\
-44,9 \pm 3,7\end{array}$ & $\begin{array}{c}-65 \pm 5,4 \\
-71,1 \pm 6,5\end{array}$ & $\begin{array}{l}5,7 \pm 8,3 \\
5,3 \pm 8,5\end{array}$ & $19 / 39$ \\
\hline V1 & $\begin{array}{l}\mathrm{D} \\
\mathrm{E}\end{array}$ & $\begin{array}{l}7,2 \pm 4,1 \\
-10,5 \pm 8\end{array}$ & $\begin{array}{l}-86,6 \pm 4,6 \\
-91,2 \pm 6,5\end{array}$ & $\begin{array}{r}6,6 \pm 2,2 \\
-1,2 \pm 7,2\end{array}$ & $17 / 18$ \\
\hline Paraestriado & $\begin{array}{l}\mathrm{D} \\
\mathrm{E}\end{array}$ & $\begin{array}{l}17 \pm 10,9 \\
-17 \pm 13,2\end{array}$ & $\begin{array}{c}-71,3 \pm 10,2 \\
-74,7 \pm 8,9\end{array}$ & $\begin{array}{c}6 \pm 8,8 \\
1,1 \pm 12,6\end{array}$ & 18 \\
\hline Ínsula Anterior & $\begin{array}{l}\mathrm{D} \\
\mathrm{E}\end{array}$ & $\begin{array}{c}38,8 \pm 4,7 \\
-39,8 \pm 2,8\end{array}$ & $\begin{array}{c}5,5 \pm 9 \\
4,6 \pm 7,7\end{array}$ & $\begin{array}{l}6,8 \pm 2,2 \\
4,8 \pm 4,7\end{array}$ & 13 \\
\hline Ínsula Posterior & $\begin{array}{l}\mathrm{D} \\
\mathrm{E}\end{array}$ & - & - & - & 13 \\
\hline
\end{tabular}




\begin{tabular}{|c|c|c|c|c|c|}
\hline \multirow{2}{*}{ Cíngulo Anterior } & $\mathrm{D}$ & $11 \pm 6$ & $22 \pm 20,7$ & $16,7 \pm 25$ & \multirow{2}{*}{$24 / 32$} \\
\hline & $\mathrm{E}$ & $-6 \pm 4,4$ & $12,3 \pm 19,3$ & $23,3 \pm 29$ & \\
\hline \multirow{2}{*}{ Cíngulo Posterior } & $\mathrm{D}$ & $9 \pm 7,6$ & $-49,3 \pm 10,6$ & $20 \pm 15$ & \multirow{2}{*}{$30 / 31$} \\
\hline & $\mathrm{E}$ & $-4,3 \pm 4,6$ & $-50,5 \pm 10,4$ & $19,8 \pm 14,4$ & \\
\hline Giro & $\mathrm{D}$ & $28,8 \pm 3,9$ & $-26 \pm 22,8$ & $-12,8 \pm 8,2$ & \multirow{13}{*}{$19 / 36$} \\
\hline Parahipocampal & $\mathrm{E}$ & $-26 \pm 8,6$ & $-35,8 \pm 11,7$ & $-8,8 \pm 5,4$ & \\
\hline \multirow{3}{*}{ Cerebelo } & $\mathrm{D}$ & $16,6 \pm 9,4$ & $-64,9 \pm 13,2$ & & \\
\hline & $\mathrm{E}$ & $226+103$ & $550+164$ & 16,5 & \\
\hline & & $-22,0 \perp 10, \pi$ & $-50,10,4$ & $-24,9 \pm 9,7$ & \\
\hline \multirow{2}{*}{ Putamen } & $\mathrm{D}$ & $20,9 \pm 3,8$ & $4,8 \pm 6$ & $1,6 \pm 7$ & \\
\hline & $\mathrm{E}$ & $-23,8 \pm 2,9$ & $-0,7 \pm 5,5$ & $1,3 \pm 6,1$ & \\
\hline \multirow{2}{*}{ Tálamo } & $\mathrm{D}$ & $11,5 \pm 4,9$ & $-15,5 \pm 2,1$ & $7,5 \pm 10,6$ & \\
\hline & $\mathrm{E}$ & $-13 \pm 2,6$ & $-22 \pm 4,4$ & $7,3 \pm 9,6$ & \\
\hline \multirow{2}{*}{ Corpo Caloso } & $\mathrm{D}$ & 3 & -30 & 11 & \\
\hline & $\mathrm{E}$ & $-4,8 \pm 2,5$ & $-9,6 \pm 25,1$ & $17,2 \pm 6,7$ & \\
\hline \multirow{2}{*}{ Globo Pálido } & $\mathrm{D}$ & - & - & - & \\
\hline & $\mathrm{E}$ & $-15,3 \pm 0,6$ & $-1,3 \pm 4$ & $-0,7 \pm 1,1$ & \\
\hline
\end{tabular}

As coordenadas foram calculadas no espaço Talairach, para cada uma das regiões, com base na localização da resposta individual.

\subsubsection{Análise da Freqüência de Ocorrência}

A variabilidade da ativação entre os voluntários foi acessada pela determinação da freqüência de ativação em cada região. Devido ao fato de várias regiões aparecerem ativas nos três paradigmas, a comparação da freqüência de ativação para a mesma região, entre dois estudos (NOC para direita versus NOC para esquerda, e Rastreio versus Sacade), permitiu o acesso da variabilidade entre esses estudos. A análise da freqüência de ocorrência entre os estudos NOC para direita e NOC para esquerda, apresentados na Tabela V, mostra o envolvimento predominante das áreas frontais em ambos os estudos. Entretanto, para os estudos 
Rastreio e Sacade (Tabela VI) houve o envolvimento predominante das áreas frontais, além da área MT/MST.

Tabela V. Principais áreas ativadas, e sua área de Brodmann correspondente, com a freqüência de ativação para os estudos NOC para direita e NOC para esquerda.

\begin{tabular}{|c|c|c|c|}
\hline Áreas Cerebrais & BA & $\begin{array}{c}\text { f NOC direita } \\
(\%)\end{array}$ & $\begin{array}{c}\text { f NOC esquerda } \\
(\%)\end{array}$ \\
\hline FEF & $4 / 6$ & 100 & 100 \\
\hline SEF & 6 & 88 & 67 \\
\hline PEF & $40 / 7$ & 75 & 78 \\
\hline DLPFC & $46 / 10$ & 100 & 100 \\
\hline MT/MST & $19 / 39$ & 88 & 100 \\
\hline V1 & $17 / 18$ & 88 & 89 \\
\hline Paraestriado & 18 & 100 & 89 \\
\hline Ínsula Anterior & 13 & 88 & 89 \\
\hline Ínsula Posterior & 13 & 63 & 67 \\
\hline Cíngulo Anterior & $24 / 32$ & 50 & 25 \\
\hline Cíngulo Posterior & $30 / 31$ & 38 & 78 \\
\hline Giro Parahipocampal & $19 / 36$ & 75 & 78 \\
\hline Cerebelo & & 100 & 89 \\
\hline Putamen & & 63 & 56 \\
\hline Tálamo & & 38 & 25 \\
\hline Corpo Caloso & & 38 & 67 \\
\hline Globo Pálido & & 50 & 56 \\
\hline
\end{tabular}

Tabela VI. Principais áreas ativadas, e sua área de Brodmann (BA) correspondente, com a freqüência de ativação para os estudos Rastreio e Sacade.

\begin{tabular}{l|lll}
\hline Áreas Cerebrais & BA & f Rastreio (\%) & f Sacade (\%) \\
\hline & &
\end{tabular}




\begin{tabular}{|c|c|c|c|}
\hline$\overline{\text { FEF }}$ & $4 / 6$ & 100 & 100 \\
\hline SEF & 6 & 75 & 88 \\
\hline PEF & $40 / 7$ & 75 & 88 \\
\hline DLPFC & $46 / 10$ & 88 & 88 \\
\hline MT/MST & $19 / 39$ & 100 & 100 \\
\hline V1 & $17 / 18$ & 75 & 75 \\
\hline Paraestriado & 18 & 75 & 88 \\
\hline Ínsula Anterior & 13 & 38 & 75 \\
\hline Ínsula Posterior & 13 & 63 & 0 \\
\hline Cíngulo Anterior & $24 / 32$ & 50 & 63 \\
\hline Cíngulo Posterior & $30 / 31$ & 50 & 63 \\
\hline Giro Parahipocampal & $19 / 36$ & 100 & 63 \\
\hline Cerebelo & & 75 & 100 \\
\hline Putamen & & 50 & 88 \\
\hline Tálamo & & 38 & 38 \\
\hline Corpo Caloso & & 25 & 63 \\
\hline Globo Pálido & & 38 & 38 \\
\hline
\end{tabular}

\subsubsection{Análise Combinada da Freqüência}

Essa análise mostra quantas vezes uma dada região pode ser encontrada, no mesmo voluntário, em dois tipos de estudos e, quão freqüente uma dada região pode aparecer ativa em um estudo, no outro, ou em ambos.

Nas figuras 5.8 e 5.9, as barras pretas indicam as áreas que mostraram atividade para os dois estudos em um mesmo voluntário. As barras brancas indicam as áreas que mostraram atividade em pelo menos um dos estudos. A figura 5.8 mostra que as regiões FEF e DLPFC foram ativadas em todos os voluntários, para o caso dos estudos NOC. Notamos que, ao considerarmos o número de voluntários que ativaram a mesma área nos dois estudos, houve um decréscimo significativo da freqüência em quase todos os voluntários. As áreas que mostram um decréscimo maior na freqüência de ativação foram o putamen e o tálamo. Sendo que o tálamo 
não mostrou atividade quando consideramos a ativação dos dois estudos no mesmo voluntário.

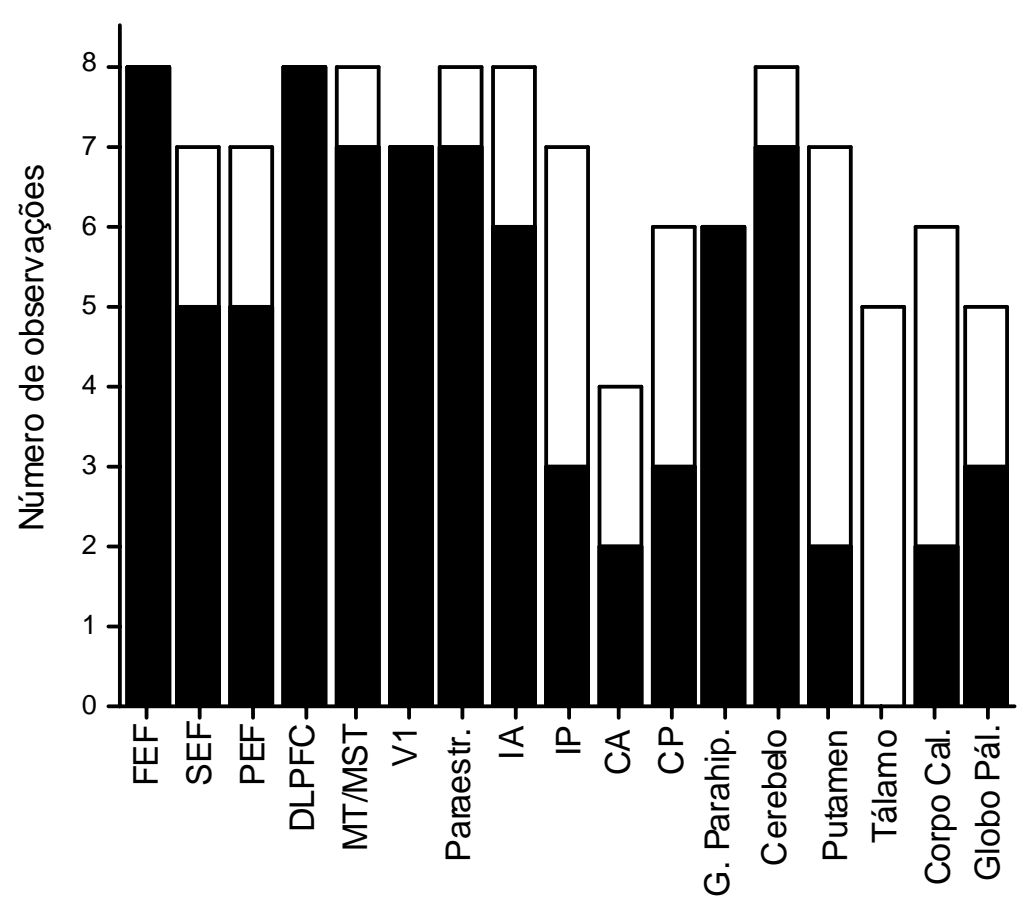

Figura 5.8 - Análise combinada da freqüência para os estudos NOC para direita e NOC para esquerda. As barras pretas indicam as áreas que mostraram atividade nos dois estudos para o mesmo voluntário. As barras brancas indicam as áreas que mostraram atividade no estudo NOC para direita ou no estudo NOC para esquerda.

Ao considerarmos os estudos Rastreio e Sacade (fig. 5.9) verificamos que as áreas FEF e MT/MST foram ativadas em todos os voluntários. Notamos que, como para o caso dos estudos NOC, ao considerarmos o número de voluntários que ativaram a mesma área nos dois estudos, houve um decréscimo significativo da freqüência em quase todos os voluntários. As áreas que mostraram um decréscimo maior na freqüência de ativação foram a ínsula posterior e o cíngulo anterior e posterior. Observamos, também, que a ínsula posterior não apresentou atividade ao consideramos a ativação dos dois estudos no mesmo voluntário, essa área apresentou atividade somente durante o estudo Rastreio (5 voluntários). 


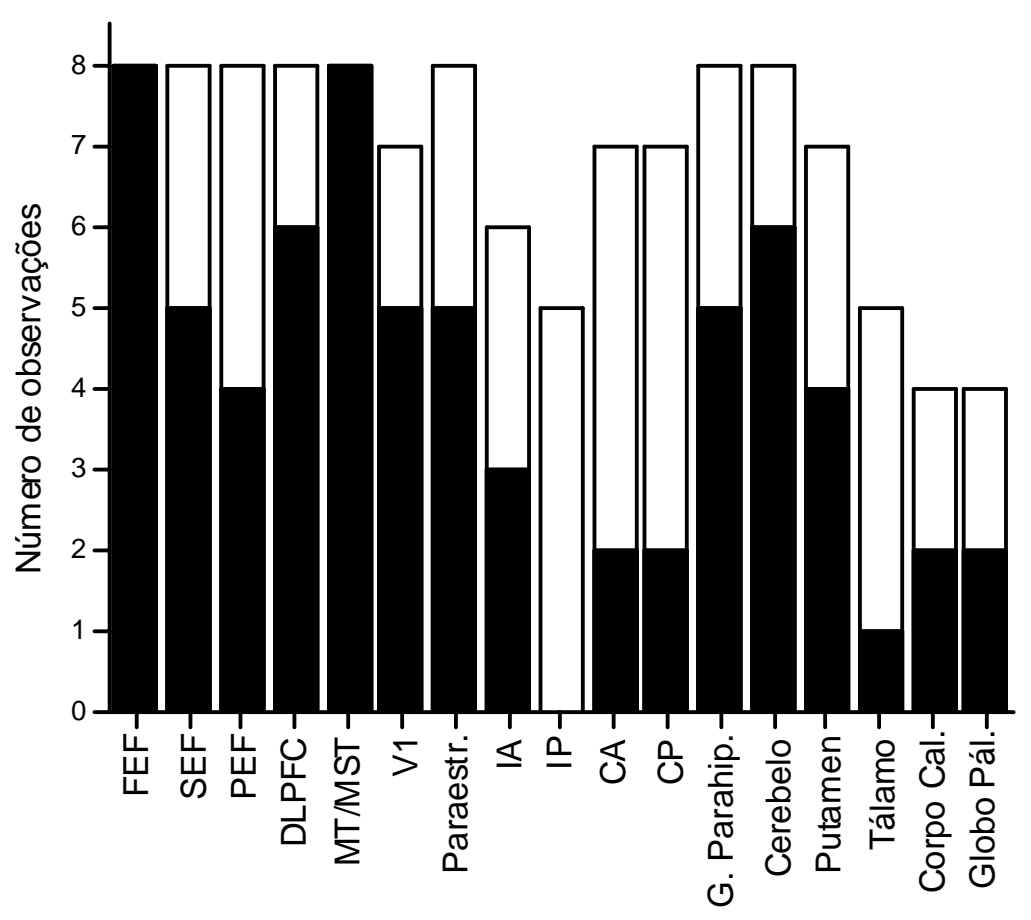

Figura 5.9 - Análise combinada da freqüência para os estudos Rastreio e Sacade. As barras pretas indicam as áreas que mostraram atividade no mesmo voluntário, durante os dois estudos. As barras brancas indicam as áreas que mostraram atividade no estudo Rastreio ou no estudo Sacade.

\subsection{8 Índice de Lateralização}

O número de pixels ativados em cada hemisfério variou significativamente com o valor-z, isto é, o número de pixels ativados depende do valor-z. O método $\mathrm{IL}_{1}$ foi obtido pelo número de pixels ativados nos hemisférios direito e esquerdo, considerando um valor fixo para o valor-z (valor-z $=4.0$ para o estudo NOC para direita e valor-z $=3.6$ para o estudo NOC para esquerda; valor- $z=4.8$ para o estudo Rastreio e valor-z $=4.4$ para o estudo Sacade). Esses valores foram determinados pela significância média encontrada entre os voluntários, mas nos mesmos voluntários, IL 1 variou com o valor-z. Devido ao fato de IL $_{1}$ ser influenciado pelo limiar estatístico, quantificamos esses índices pelo método $\mathrm{IL}_{2}$, lembrando que $\mathrm{IL}_{1}$ é calculado com um valor fixo de $z$ e $\mathrm{IL}_{2}$ tem como base a análise do índice de lateralização independentemente do valor estatístico.

O diagrama (no qual o eixo-x representa o valor-z e o eixo-y o número de pixels ativados) mostrou um padrão fixo exponencial para todos os voluntários (figura 5.10). 


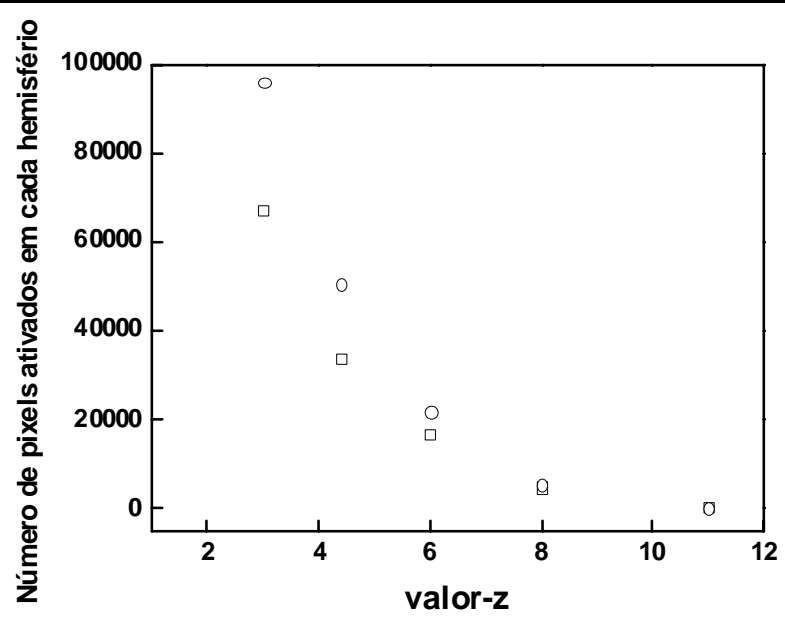

Figura 5.10 - Diagrama do número de pixels ativados versus o valor-z. Os círculos indicam os valores para os pixels ativados no hemisfério direito e os quadrados, os pixels ativados no hemisfério esquerdo.

Ajustamos, então, a curva dos pixels ativados a uma função particular do tipo $(1 / \text { valor }-z)^{n}$, a qual chamamos de função de regressão. Em seguida, calculamos o valor do coeficiente de correlação da regressão linear de cada voluntário, para cada um dos estudos. O coeficiente de correlação tanto para os dois hemisférios, como somente para o hemisfério esquerdo e somente para o hemisfério direito mostraram uma máxima correlação em $\mathrm{n}=2$ para o estudo NOC para direita (Figura 5.11) e para o estudo Sacade (Figura 5.14) e em n $=3$ para o estudo NOC para esquerda (Figura 5.12) e para o estudo Rastreio (Figura 5.13). Assim, calculamos os IL2 pela equação (4.4). Os valores calculados pelos diferentes métodos para o índice de lateralização estão representados nas Tabelas VII e VIII. 


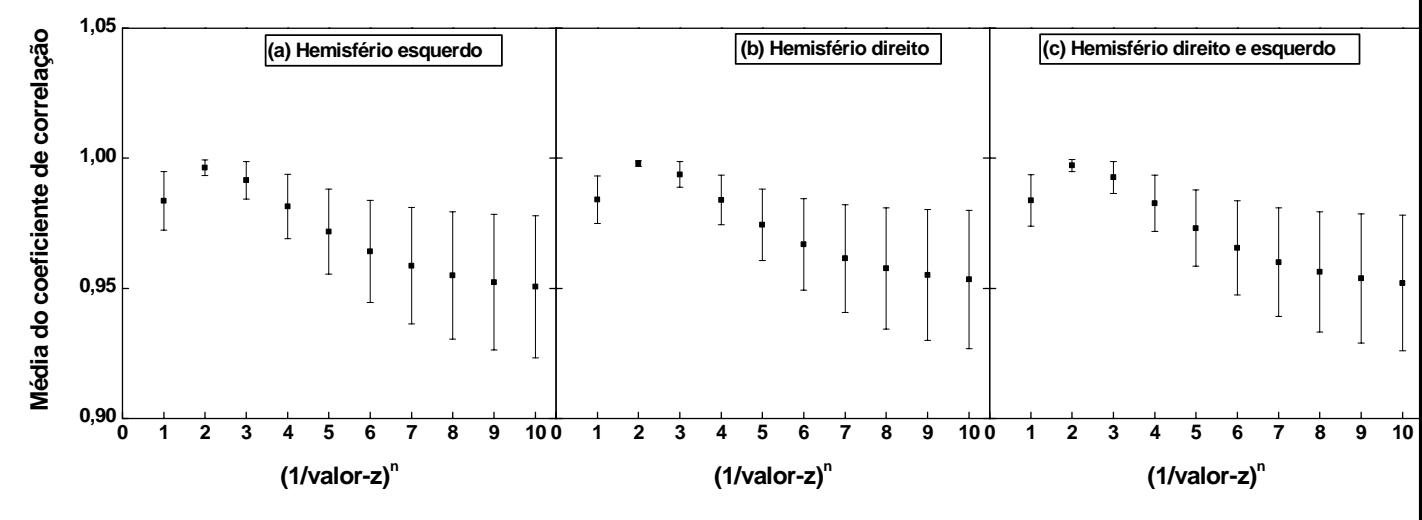

Figura 5.11 - Média do coeficiente de correlação entre (1/valor-z), (1/valor-z) $)^{2}, \ldots,(1 /$ valorz) ${ }^{10}$ e o número de pixels ativados no hemisfério esquerdo (a), no hemisfério direito (b) e no hemisfério direito e esquerdo (c) para o estudo NOC para direita.

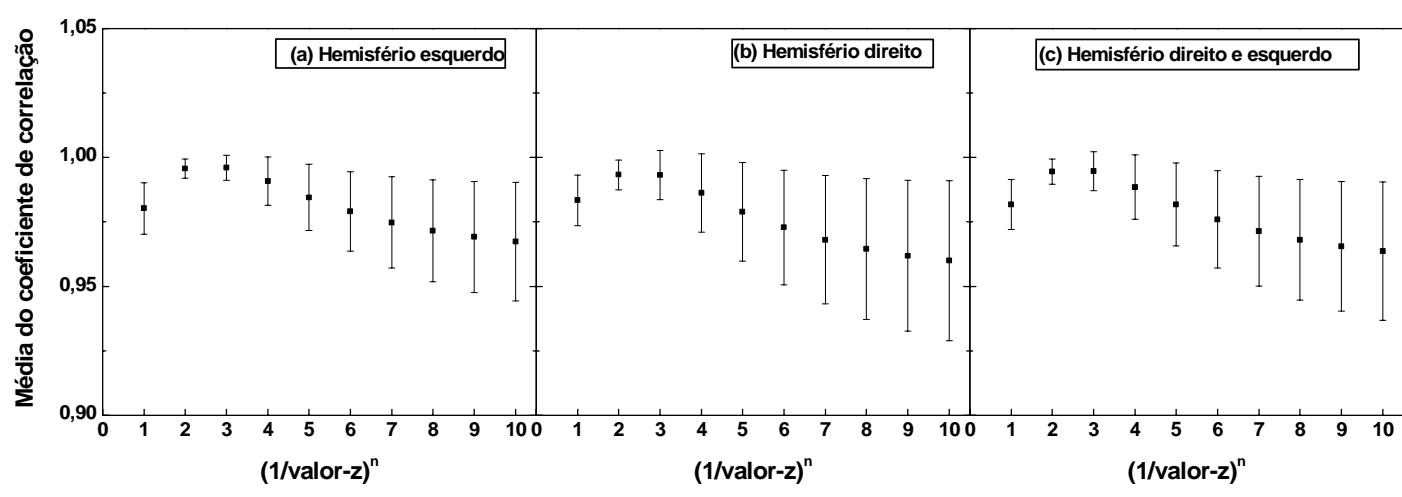

Figura 5.12 - Média do coeficiente de correlação entre (1/valor-z), (1/valor-z) ${ }^{2}, \ldots,(1 /$ valorz) ${ }^{10}$ e o número de pixels ativados no hemisfério esquerdo (a), no hemisfério direito (b) e no hemisfério direito e esquerdo (c) para o estudo NOC para esquerda.

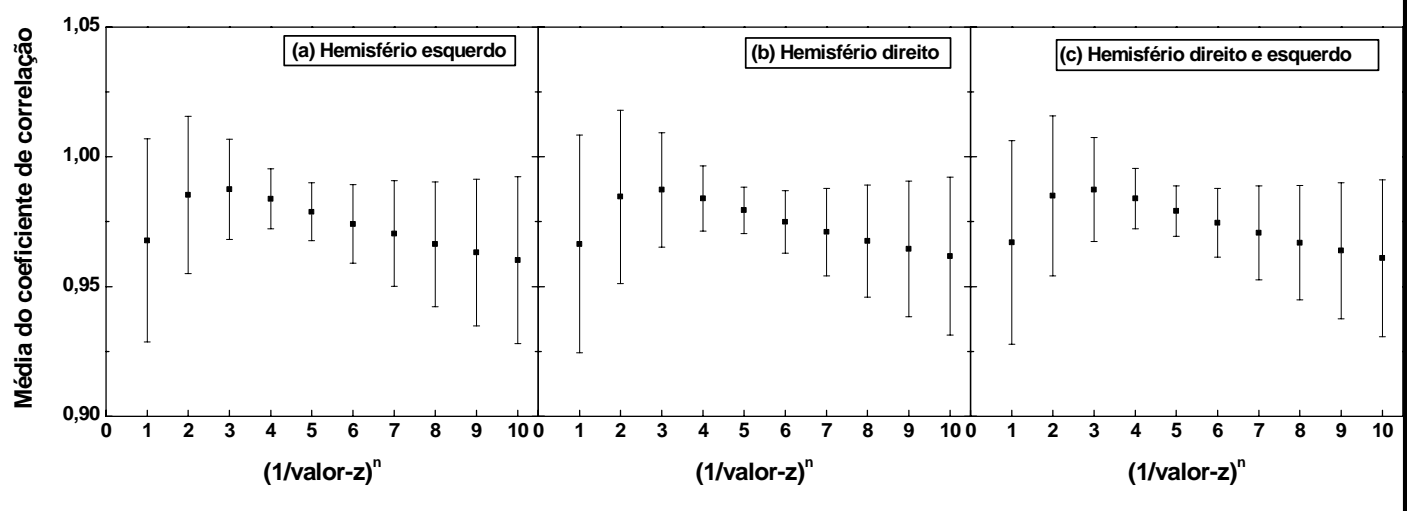

Figura 5.13 - Média do coeficiente de correlação entre (1/valor-z), (1/valor-z) $)^{2}, \ldots,(1 /$ valorz) ${ }^{10}$ e o número de pixels ativados no hemisfério esquerdo (a), no hemisfério direito (b) e no hemisfério direito e esquerdo (c) para o estudo Rastreio. 


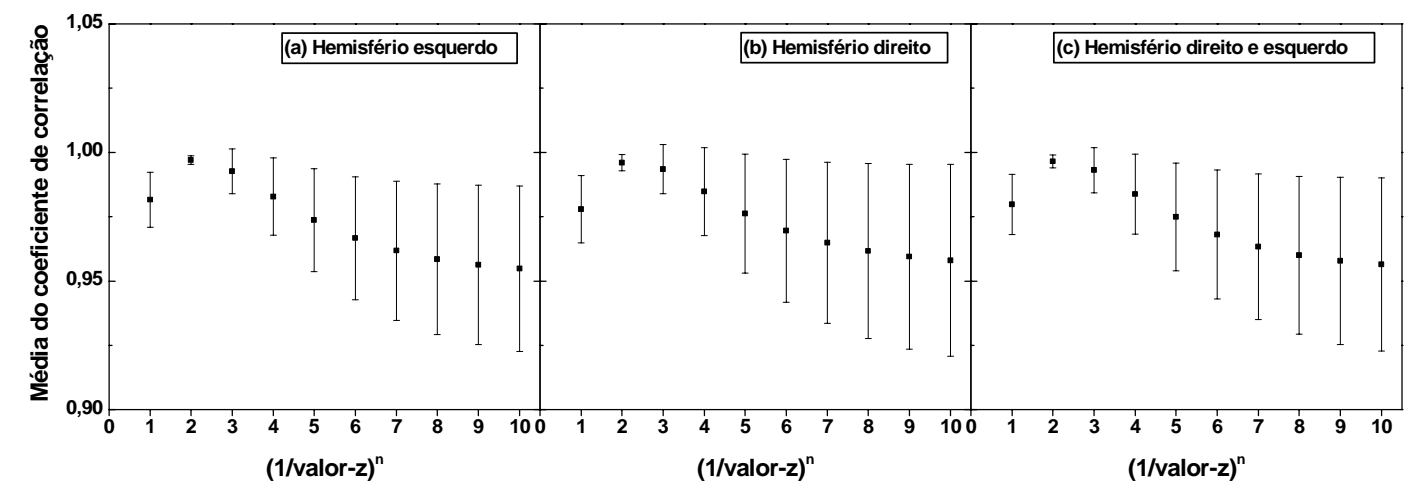

Figura 5.14. Média do coeficiente de correlação entre (1/valor-z), $(1 / \text { valor-z) })^{2}, \ldots,(1 /$ valorz) $)^{10}$ o número de pixels ativados no hemisfério esquerdo (a), no hemisfério direito (b) e no hemisfério direito e esquerdo (c) para o estudo Sacade.

As tabelas VII e VIII mostram os índices de lateralização encontrados para cada voluntário pelos diferentes métodos utilizados.

Tabela VII. Índice de Lateralização para os estudos NOC para direita e NOC para esquerda.

\begin{tabular}{c|cccc}
\hline Voluntário & \multicolumn{2}{|c}{ Estudo NOC direita } & \multicolumn{2}{c}{ Estudo NOC esquerda } \\
\hline & $\mathrm{IL}_{1}(\%)$ & $\mathrm{IL}_{2}(\%)$ & $\mathrm{IL}_{1}(\%)$ & $\mathrm{IL}_{2}(\%)$ \\
V1 & -3 & 7 & -93 & -4 \\
V2 & -67 & 12 & 24 & -6 \\
V3 & -16 & -17 & -33 & -19 \\
V4 & 29 & -1 & -73 & -39 \\
V5 & 34 & 13 & 8 & 13 \\
V6 & -28 & -5 & -15 & -12 \\
V7 & 76 & 29 & -9 & -2 \\
V8 & -13 & -9 & 9 & -2 \\
V9 & - & - & -8 & -8
\end{tabular}


Tabela VIII. Índice de Lateralização para os estudos Rastreio e Sacade.

\begin{tabular}{c|cccc}
\hline Voluntário & \multicolumn{2}{|c}{ Estudo Rastreio } & \multicolumn{2}{c}{ Estudo Sacade } \\
\hline V1 & $\mathrm{IL}_{1}(\%)$ & $\mathrm{IL}_{2}(\%)$ & $\mathrm{IL}_{1}(\%)$ & $\mathrm{IL}_{2}(\%)$ \\
V2 & 6 & 1 & 7 & -2 \\
V3 & -29 & 2 & 10 & 24 \\
V4 & 100 & -3 & 37 & 2 \\
V5 & 84 & 5 & 1 & -3 \\
V6 & -64 & -7 & -20 & -18 \\
V7 & -9 & -11 & 6 & 0 \\
V8 & 16 & 0 & -8 & -23 \\
& -30 & -15 & -15 & 4
\end{tabular}

No caso de $\mathrm{IL}_{1}$, percebemos uma ligeira predominância do hemisfério direito para os estudos NOC, sendo maior durante o estudo NOC para esquerda. O mesmo ocorreu ao considerarmos o método $\mathrm{IL}_{2}$ (Tabela VII). Se analisarmos, por exemplo, o caso do voluntário 1 (V1) para o estudo NOC para esquerda, notamos que o índice primeiramente considerado alto se apresenta menos significativos ao levarmos em consideração a influência do limiar estatístico.

Verificamos uma leve predominância do hemisfério esquerdo durante o estudo Sacade e nenhuma predominância durante o estudo Rastreio, ao considerarmos apenas o método IL1. Entretanto, ao utilizarmos o método $\mathrm{IL}_{2}$, a dominância do hemisfério esquerdo durante o estudo Sacade não é mais tão proeminente (Tabela VIII). Se considerarmos, por exemplo, o caso do voluntário 3 (V3) para o estudo Rastreio, notamos que, primeiramente poderíamos considerá-lo com uma total predominância do hemisfério esquerdo, mas ao levarmos em consideração a influência do limiar estatístico essa predominância desaparece.

\subsection{Discussão}

Nesse estudo utilizamos três tipos de paradigmas com o intuito de acessarmos a variabilidade de ativação das áreas relacionadas ao sistema vestibular e aos movimentos dos olhos do tipo rastreio e sacade, em voluntários normais. O 
estudo NOC utilizado nesse estudo mostrou uma leve dominância do hemisfério direito independente da direção do estímulo, concordando com outro estudo já realizado [Dieterich et al. 1998]. O estudo NOC para esquerda mostrou possuir uma maior probabilidade para essa dominância, pois dos nove voluntários analisados, apenas um não apresentou a dominância hemisférica direita. Entretanto, os estudos Rastreio e Sacade não apresentaram dominância alguma. Independente do método utilizado para encontrarmos o índice de lateralização, dos oito voluntários estudados quatro apresentaram dominância do hemisfério direito e quatro apresentaram dominância do hemisfério esquerdo.

Bucher et al. [Bucher et al. 1997] encontraram uma dominância do hemisfério direito para estimulação NOC apenas na região occipito-temporal. Além disso, um estudo envolvendo estimulação por movimento sacádico do olho mostrou possuir uma atividade mais pronunciada no hemisfério direito. Contudo não foi realizada uma análise quantitativa dessa assimetria [Muri et al. 1996]. A predominância do hemisfério direito no campo frontal do olho e no campo suplementar do olho também foi confirmada durante uma estimulação do tipo sacade guiado por memória após um período de atraso [Sweeney et al. 1996].

Um estudo envolvendo orientação visuo-espacial e a técnica PET também mostrou possuir uma dominância do hemisfério direito em três áreas: no córtex parietal posterior, no cíngulo anterior e no sulco temporal superior [Nobre et al. 1997]. Estudos relacionados em pacientes com lesões no córtex parietal posterior direito e/ou no córtex frontal dorsolateral direito indicam danos mais significativos comparados a lesões equivalentes no lado esquerdo [Lekwuwa \& Barnes 1996 ]. Além disso, um estudo com fMRI mostrou uma sobreposição de atividade durante dois estímulos (indicação da linha média e NOC) no córtex parietal posterior direto [Boileau et al. 2002].

Um estudo envolvendo uma tarefa de memória de trabalho (working memory), onde uma tarefa de abstração foi utilizada, mostrou o envolvimento predominante do córtex frontal dorsolateral médio direito [Petrides et al. 1993]. Pardo et al. realizaram um estudo com PET, no qual identificaram mudanças na atividade cerebral regional durante tarefas visual e somatosensorial de atenção relacionadas ao 
córtex pré-frontal e ao córtex parietal superior primeiramente no hemisfério direito, independente da modalidade de lateralidade do estímulo sensorial [Pardo et al. 1991].

Um estudo utilizando a técnica PET e estimulação calórica mostrou uma dominância do hemisfério não-dominante ipsilateral ao ouvido estimulado, isto é, dominância do hemisfério direito para voluntários destros durante estimulação do ouvido direito e dominância do hemisfério esquerdo para voluntários canhotos durante estimulação do ouvido esquerdo [Dieterich et al. 2003b].

É importante percebermos a diferença existente entre os valores dos índices devido ao método empregado neste estudo. Alguns critérios precisam ser estabelecidos para podermos dizer que um método é útil e apropriado. Primeiro, os resultado devem representar boas informações sobre os voluntários, segundo os resultados devem ser facilmente comparados e terceiro, o método deve possuir boa reprodutibilidade. Como os valores de $\mathrm{IL}_{1}$ mostraram uma alta variabilidade dependente do valor-z, o primeiro critério já não é preenchido. Além disso, o número de pixels ativados a um certo limiar varia entre os voluntários, então o método $\mathrm{IL}_{1}$ não possui uma confiabilidade, com isso não é possível comparar dois valores de $\mathrm{IL}_{1}$, então, o método $\mathrm{IL}_{1}$ não atinge o segundo critério. Entretanto, pudemos verificar que o método $\mathrm{IL}_{2}$ representa uma maneira qualitativa de determinar o índice de lateralização. Portanto, a comparação entre o padrão exponencial entre os dois hemisférios é mais exato e confiável comparado a comparação entre o número de pixels ativados somente em um limiar.

Como a dominância hemisférica não se mostrou tão evidente neste estudo e, além disso, nenhum dos estudos citados realizou uma análise quantitativa do índice de lateralização, ainda precisamos realizar outras análises envolvendo o índice de lateralização para que possamos determinar a dominância hemisférica das funções vestibular e oculomotora. Trataremos, portanto, desses possíveis estudos na seção de perspectivas.

\subsubsection{Campo Frontal do Olho}

O FEF está localizado na intersecção entre o sulco pré-central e o sulco frontal superior (figura 5.15) [Paus 1996]. O fato do FEF ter mostrado a maior freqüência de ativação nos três paradigmas demonstra a confiabilidade da ativação 
dessa área nesses tipo de paradigmas e indica que ela pode ser encontrada, com maior probabilidade, em voluntários normais mesmo quando apenas um desses paradigmas é utilizado [Darby et al. 1996; Bucher et al. 1997; Corbetta et al. 1998; Dieterich et al. 1998; O’Driscoll et al. 1998; Gaymard et al. 1999; O’Driscoll et al. 2000; Kimmig et al. 2001; Schmid et al. 2001; Petit \& Haxby 1999; Rosano et al. 2002; Tanabe et al. 2002; Blanke \& Seeck 2003; Dieterich et al. 2003a; Lencer et al. 2004; Pierrot-Deseilligny et al. 2004].

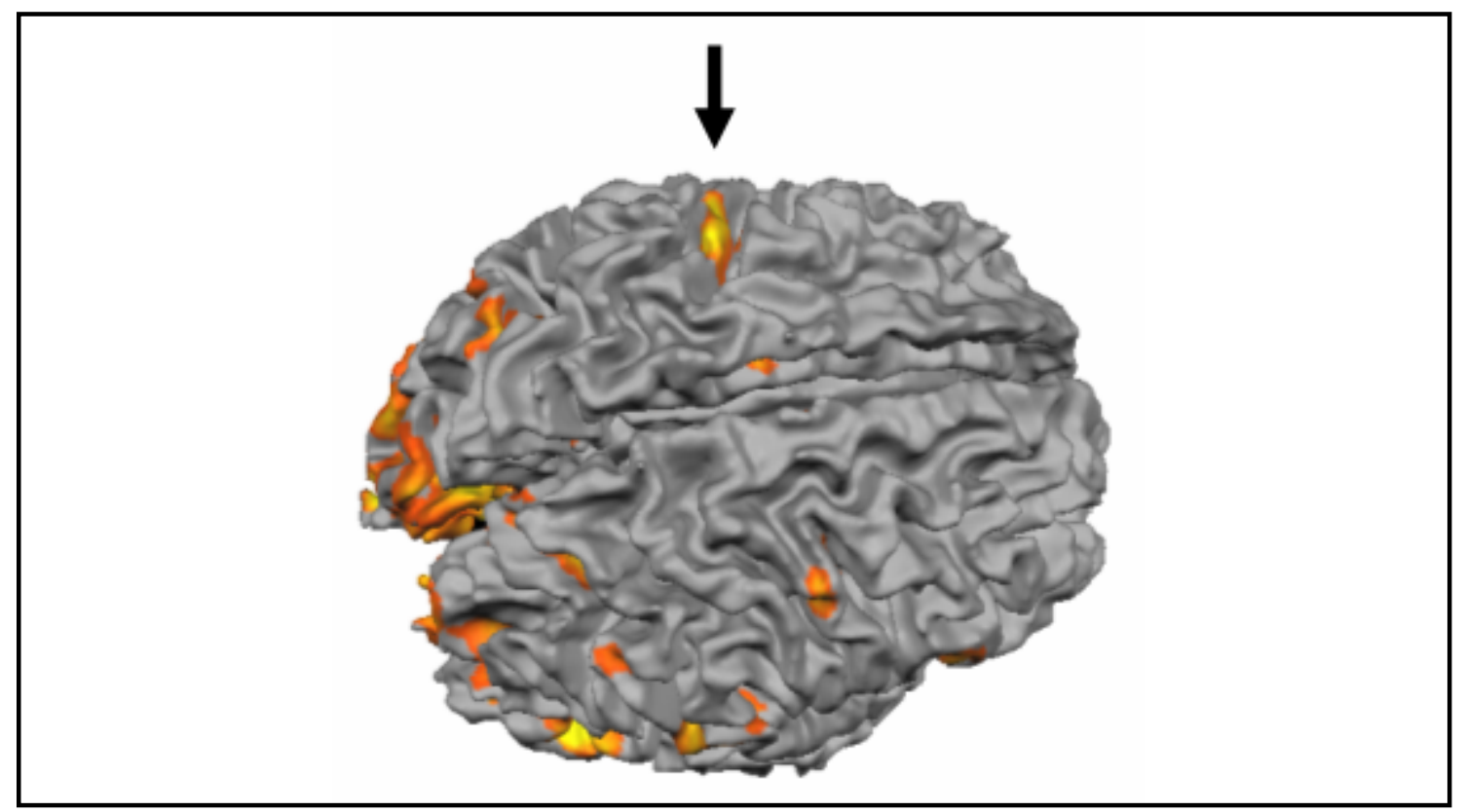

Figura 5.15 - Localização anatômica do campo frontal do olho (FEF) em uma representação 3D do cérebro humano.

A análise combinada da freqüência de ativação das regiões mostrou que a probabilidade de ativação chega a 100\% quando considerados os dois estudos juntos (tanto para o caso dos estudos NOC para direita e NOC para esquerda, quando para os estudos Rastreio e Sacade).

Estudos eletrofisiológicos demonstram claramente que o FEF é a maior área oculomotora cortical envolvida no controle do movimento sacádico. O FEF está envolvido na preparação e na facilitação do sacade intencional, o qual é internamente provocado pelo alvo já apresentado (sacade visualmente guiado), ainda não apresentado (sacade predito) e não visível (sacade guiado por memória) [PierrotDeseilligny et al. 2004]. 
O FEF está, também, envolvido na inibição do movimento sacádico. Células de fixação, em macacos, estão provavelmente envolvidas com a função de inibição. Essas células, que normalmente reduzem sua atividade durante a preparação do movimento sacádico, mostram um aumento na atividade imediatamente após a apresentação do sinal de cancelamento [Hanes et al. 1998].

Durante o movimento de perseguição lenta do olho o FEF reflete não apenas a execução, mas também a predição da perseguição lenta [Krauzlis 2004].

Ao analisarmos a variabilidade espacial da área FEF, comprovamos uma alta variância em termos das coordenadas $x, y$ e $z$. Isso está de acordo com um estudo citoarquitetônico envolvendo o giro pré-central. Nesse estudo encontrou-se uma grande variabilidade na localização do giro pré-central entre hemisférios e entre cérebros [Rademacher et al. 2001]. Além disso, Watkins et al. mostraram uma maior quantidade de matéria cinzenta no lobo frontal direito [Watkins et al. 2001]. Verificamos, também, que o FEF mostrou uma variabilidade maior durante o estudo NOC para esquerda, comparado ao estudo NOC para direita.

Dieterich e colaboradores [Dieterich et al. 2003a] sugerem uma diferenciação entre dois focos de ativação no giro pré-central nos dois hemisférios: um no giro infero-lateral (BA 9) e o outro no ântero-medial, na junção do sulco frontal superior com o sulco pré-central (BA 6). Um estudo com estimulação elétrica do FEF de humanos, mostrou desvios lentos contralaterais do olho, onde os locais de estimulação desses movimentos foram localizados no sulco pré-central, mais posterior ao local de estimulação do sacade [Blanke \& Seeck 2003].

Encontramos uma variabilidade maior para o estudo Rastreio comparado ao estudo Sacade. Estudos indicam duas sub-regiões para o FEF, na qual uma localização média para o rastreio é situada mais inferior e lateral do que a relacionada a atividade do Sacade [Paus 1996; Petit \& Haxby 1999; Rosano et al. 2002].

\subsubsection{Campo Suplementar do Olho}

O SEF (Suplementary Eye Field) está localizado na superfície medial do giro frontal superior, na parte superior do sulco pré-central [Grosbras et al. 1999]. Esta região está conectada com todas as áreas que envolvem o controle do olho - o FEF, 
o DLPFC (córtex pré-frontal dorsolateral), o córtex do cíngulo anterior e também com o PPC (Posterior Parietal Córtex) [Pierrot- Deseilligny et al. 2004].

Estudos envolvendo lesão do SEF mostraram que esta área está envolvida no programa motor compreendendo um movimento sacádico combinado com o movimento do corpo ou uma seqüência de vários sacades sucessivos [Gaymard et al. 1999]. No caso da seqüência de sacade, estudos com TMS (Estimulação Magnética Transcraniana, Transcanial Magnetic Stimulation - TMS) e fMRI também mostraram que uma região mais anterior está envolvida durante a apresentação de uma seqüência de estímulos visuais (aprendizado motor), onde o SEF está envolvido na execução da seqüência motora. No entanto, o SEF pode preparar todos os programas motores inicialmente, mesmo quando estão limitados a um único sacade [Pierrot- Deseilligny et al. 2004]. Além disso, o SEF participa do planejamento do movimento de perseguição do olho, similar ao papel que a área motora suplementar parece executar para outros tipos de movimento [Krauzlis 2004].

$\mathrm{Na}$ análise da variabilidade espacial, o SEF mostrou uma alta variância espacial [Watkins et al. 2001], tanto para os estudos NOC quanto para os estudos Rastreio e Sacade. No caso do paradigma NOC, o SEF mostrou uma freqüência de ativação inter-individual maior para o estudo NOC para direita (88\%). Entretanto, para os estudos Rastreio e Sacade, a freqüência de atividade inter-individual foi maior para o estudo Sacade (88\%). Isso pode estar relacionado ao fato da área correspondente ao movimento de rastreio no SEF ser menor quando comparada à encontrada durante o sacade [Petit \& Haxby 1999]. Um estudo envolvendo o movimento de rastreio do olho mostrou uma alta freqüência de atividade (12 dos 15 voluntários analisados) no SEF [Tanabe et al. 2002].

Finalmente, quando consideramos os dois estudos juntos, primeiramente no paradigma NOC, a probabilidade de encontrarmos ativação na área SEF é considerável (7/8 voluntários). Para os estudos Rastreio e Sacade chega a 100\%, o que sugere uma maior probabilidade de encontrarmos a área SEF em estudos que envolvam os estudos Rastreio e Sacade [Bucher et al. 1997; Corbetta et al. 1998; Dieterich et al. 1998; O’Driscoll et al. 1998; Gaymard et al. 1999; Petit \& Haxby 1999; O’Driscoll et al. 2000; Kimmig et al. 2001; Schmid et al. 2001; Tanabe et al. 2002; Dieterich et al. 2003a; Lencer et al. 2004; Pierrot-Deseilligny et al. 2004]. 


\subsubsection{Córtex Pré-Frontal Dorsolateral}

A figura 5.16 mostra a localização anatômica do DLPFC (Dorsolateral Prefrontal Cortex) em uma visão tri-dimensional. O papel central executado pelo córtex frontal e, especialmente, pelo DLPFC na supressão do sacade foi demonstrado por estudos de lesões em humanos e confirmado por estudos de neuroimagens [Muri et al. 1998; Pierrot-Deseilligny et al. 2003]. A região frontal envolvida na supressão de sacades reflexivos foi mais precisamente localizada no DLPFC.

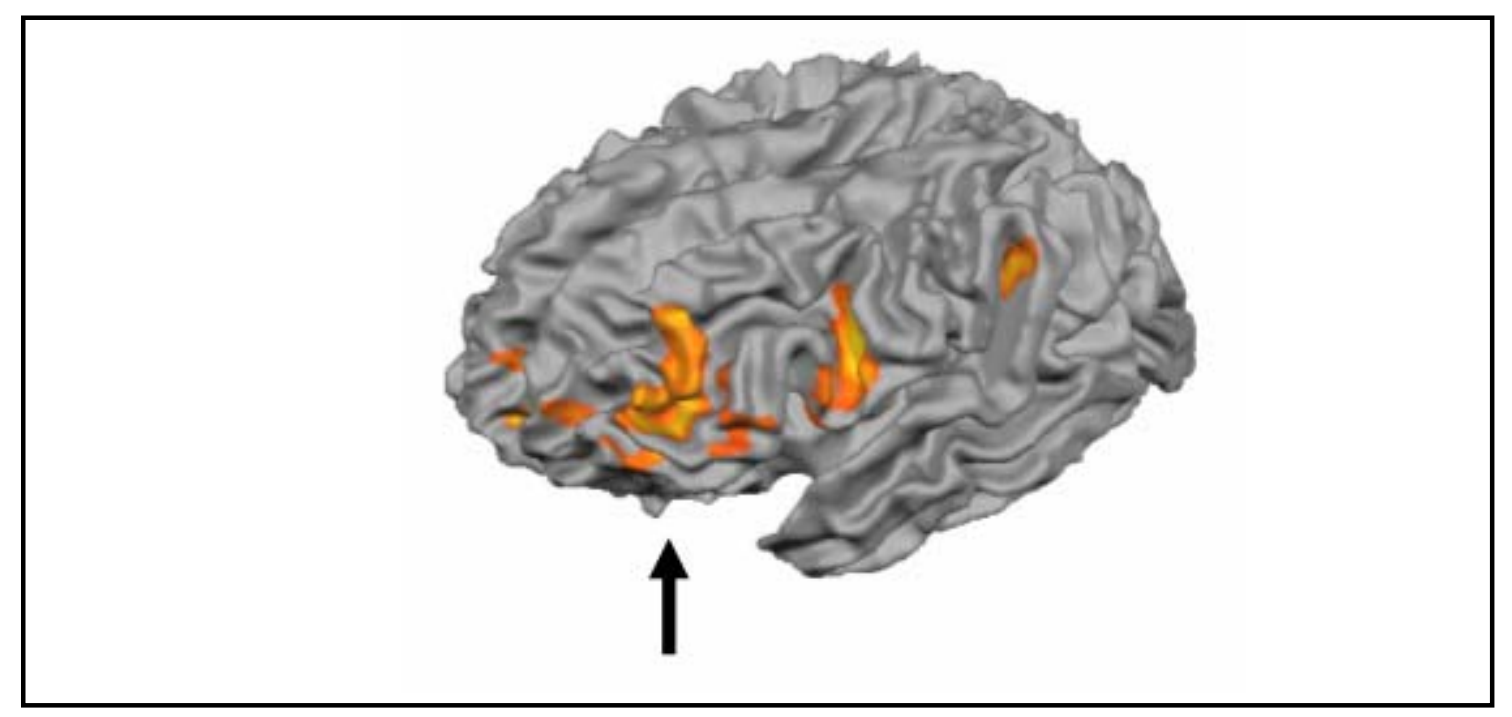

Figura 5.16 - Localização anatômica do córtex pré-frontal dorsolateral em uma visão 3D do cérebro humano.

O tálamo parece estar envolvido em alguns aspectos na atenção seletiva, desde que vários núcleos talâmicos estão diretamente conectados ao DLPFC, liberando sinais tanto do cerebelo ou dos núcleos da base. No entanto, evidências diretas que suportam um envolvimento dos núcleos da base ou do tálamo na supressão do sacade reflexivo não foram provadas até agora.

Resultados de um estudo com TMS em voluntários normais [Brandt et al. 1998] sugerem: (1) um controle da memória espacial pela área DLPFC durante os primeiros segundos de atraso; e (2) uma independência parcial do estado DLPFC existente durante esses primeiros segundos para a construção da informação da memória utilizada em longos atrasos.

O DLPFC mostra respostas de aspectos de seleção e monitoramento, especialmente com alvos não previsíveis [Schmid et al. 2001], indicando, seu 
envolvimento no controle de sacades preditivas. Após lesões limitadas ao DLPFC, a porcentagem de sacades preditivas decresce significativamente. Isso resulta na conjunção das sugestões referidas anteriormente, de que o DLPFC executa um papel crucial em processos de decisão governando o comportamento do movimento do olho, preparando o movimento sacádico intencional para a inibição do sacade reflexivo indesejável (inibição), mantendo a informação da memória do sacade intencional (memorização espacial) ou facilitando o sacade antecipatório intencional (predição), dependendo do ambiente externo e das circunstâncias internas. O DLPFC, além de estar envolvido na inibição do sacade, também está envolvido com a memória espacial em processos de decisão [Pierrot-Deseilligny et al. 2004].

Apesar da grande variabilidade espacial [Zilles et al. 1997; Watkins et al. 2001] apresentada nos três paradigmas, a freqüência de ativação da região DLPFC no paradigma NOC foi de 100\%. Essa freqüência também é encontrada para os dois tipos da análise combinada da freqüência, o que indica uma alta probabilidade de encontrarmos essa área em estudos que envolvam a estimulação optocinética em voluntários normais [Bucher et al. 1997; Dieterich et al. 1998; Dieterich et al. 2003a].

Já para os estudos Rastreio e Sacade a freqüência de ativação chegou a $88 \%$. Mas, se considerarmos a análise da freqüência combinada para os dois estudos, essa freqüência chega a 100\%. E, considerando o caso da área DLPFC ser encontrada no mesmo voluntário durante esses estudos, há um decréscimo significativo da freqüência de ativação (6/8 voluntários). Mesmo assim, vários estudos mostram atividade do DLPFC durante estimulações do movimento do olho do tipo rastreio e sacade [Corbetta et al. 1998; Gaymard et al. 1999; Schmid et al. 2001; Condy et al. 2004; Lencer et al. 2004]. Entretanto, um estudo de Pierrot-Deseilligny et al. mostra atividade do DLPFC apenas relacionada ao sacade [Pierrot-Deseilligny et al. 2003], que pode estar relacionada à variabilidade encontrada neste trabalho.

\subsubsection{Campo Parietal do Olho}

O sulco intraparietal (Intraparietal Sulcus - IPS) separa o lobo parietal superior (Superior Parietal Lobe - SPL), localizado medialmente (i.e. área 7 de Brodmann), do lobo parietal inferior, localizado lateralmente. O último compreende a área 40 de Brodmann (i. e. o giro supramarginal) e a área 39 de Brodmann (i. e., o giro angular). 
O Campo parietal do olho (Parietal Eye Field - PEF) está localizado na parede medial do IPS.

O lobo parietal, particularmente sua parte posterior, o PPC, está envolvido no controle do movimento sacádico e da atenção [Pierrot-Deseilligny et al. 2004]. O papel da integração espacial do PPC também foi confirmado por dois estudos envolvendo TMS, no qual a acurácia do sacade guiado por memória foi prejudicada durante a aplicação de um pulso magnético sobre uma região que cobria o PPC (isto é, durante a fase correspondente a integração visuo-espacial) [Muri et al. 1996; Brandt et al. 1998].

Estimulações leves do PEF, em macacos, resultam numa simples mudança de atenção visual (sem movimento dos olhos), enquanto estimulações intensas resultam em um sacade [Cutrell \& Marrocco 2002]. A ativação dessa área é também modulada pela posição da cabeça, um resultado que está provavelmente relacionado ao papel dessa área na integração visuo-espacial. Estudos com fMRI mostram que a atualização espacial da informação visual ocorre no PPC humano (incluindo a região PEF) após um movimento do olho [Medendorp et al. 2003; Merriam et al. 2003].

Há agora evidências acumuladas, com base em estudos utilizando a técnica de fMRI, sugerindo que a parte anterior do IPS está mais envolvida na coordenação do conjunto cabeça-olho e a parte posterior do SPL em processos de atenção [Simon et al. 2002; Yantis et al. 2002]. Neurônios do sulco intraparietal participam no mapa interno da representação sensorial, na localização de alvos visuais e na atenção espacial [Kimmig et al. 2001].

Além disso, o PEF contém células visuais que descarregam vigorosamente em resposta a novos estímulos inesperados. Devido essa área ser diretamente ligada ao colículo superior, esta pode ser a responsável pela rápida orientação do movimento dos olhos na direção do estímulo de início repentino [Gaymard et al. 1999].

Lesões no lobo parietal e occipital resultam em anormalidades do movimento de rastreio. Diferente do efeito de lesões no FEF e no colículo superior, os déficits do movimento dos olhos são feitos em direção ao lado da lesão. Por exemplo, uma lesão na região parieto-occipital esquerda resulta em uma inabilidade de rastrear um objeto movendo da direita para a esquerda. 
Boileau et al. mostraram que o PPC é o local anatômico onde os sinais multimodais sensoriais e motores são combinados e a informação espacial é construída. Lesões que afetam o PPC do hemisfério direito são freqüentemente relacionadas à síndrome de negligência, a qual é acompanhada por um desvio da linha média [Boileau et al. 2002].

O PEF apresentou uma freqüência de ativação maior durante o estudo NOC para a esquerda $(78 \%)$, sendo que, ao considerarmos os dois estudos juntos, a freqüência atinge $88 \%$. Mas essa freqüência decresce significantemente quando levamos em consideração apenas os voluntários que ativaram a região PEF nos dois estudos (5/8 voluntários), o que nos leva a crer que a ativação da área PEF certamente será encontrada em estudos com estimulação optocinética [Bucher et al. 1997; Dieterich et al. 1998; Boileau et al. 2002; Kleinschimdt et al. 2002; Dieterich et al. 2003a] com uma probabilidade maior de ocorrência durante a estimulação NOC para esquerda.

Já para o estudo Sacade a freqüência de ativação inter-individual é maior (88\%) quando comparada ao estudo Rastreio (75\%). Entretanto, se consideramos a análise da freqüência na qual o mesmo voluntário ativou o campo parietal do olho, a freqüência atinge somente $50 \%$. Apesar disso, pudemos encontrar uma freqüência de ativação para os dois estudos de 100\%, transformando essa região em uma provável região ativa nos estudos Rastreio e Sacade [Corbetta et al. 1998; O’Driscoll et al. 1998; Kimmig et al. 2001; Petit \& Haxby 1999; O’Driscoll et al. 2000; Schmid et al. 2001; Tanabe et al. 2002; Lencer et al. 2004; Krauzlis et al. 2004].

Apesar da alta probabilidade de ocorrência dessa área nos três paradigmas, observamos uma alta variância espacial. Este resultado está de acordo com Watkins et al. (2001) que demonstraram uma maior quantidade de matéria cinzenta no lobo parietal superior esquerdo, incluindo o giro angular e o sulco intraparietal [Watkins et al. 2001].

\subsubsection{Córtex do Cíngulo}

O córtex do cíngulo é dividido em córtex do cíngulo anterior (Anterior Cingulate Cortex - ACC) (área 24 de Brodmann) e córtex do cíngulo posterior (Posterior Cingulate Cortex - PCC) (área 23 de Brodmann). A parte posterior do ACC 
está envolvida no controle do movimento sacádico, mais precisamente no controle do sacade intencional, mas não no controle do sacade reflexivo. O limite entre as áreas 23 e 24 de Brodmann está envolvido no processo que preparar todas as áreas oculomotoras frontais envolvidas no controle do sacade intencional para agir no comportamento motor [Gaymard et al. 1999; Pierrot-Deseilligny et al. 2004]. O PCC também é ativado durante o movimento de perseguição [Tanabe et al., 2002]. Dois estudos com fMRI, no entanto, tem sugerido que o PCC é ativado durante paradigmas puramente de atenção [Hopfinger et al. 2000; Small et al. 2003].

A ativação do cíngulo anterior e posterior nos três paradigmas mostrou uma alta variabilidade espacial. O que está de acordo com um estudo envolvendo assimetria hemisférica, a qual mostra uma maior quantidade de matéria cinzenta no sulco do cíngulo direito [Watkins et al. 2001]. Fornito et al. (2004) mostraram que diferenças individuais nos giros cerebrais acarretam implicações em funções cognitivas, os voluntários com assimetria esquerda no sulco paracíngulo, comparado a um padrão simétrico ou de assimetria direita, demonstraram uma melhor performance nas tarefas verbal e espacial que estão envolvidas na execução de processos cognitivos.

Considerando a divisão do córtex do cíngulo, a região ACC mostrou uma freqüência de ativação maior comparada ao PCC durante o estudo NOC para direita (o PCC só mostrou atividade no hemisfério esquerdo). Entretanto, durante o estudo NOC para esquerda, o PCC mostrou uma maior freqüência de atividade. Para a análise da freqüência combinada à região PCC mostrou uma maior freqüência, tanto para os dois estudos $(75 \%)$ quanto para o caso dessa área apresentar atividade no mesmo voluntário (3/8 voluntários). Podemos considerar o ACC e PCC como regiões possivelmente ativas em estudos com estimulação optocinética, considerando, no entanto, a região PCC com uma maior probabilidade de ocorrência comparada ao ACC. Contudo, Dieterich et al. (1998) mostraram ativação na região ACC e desativação da região PCC. Um estudo envolvendo estimulação calórica mostrou ativação da região ACC, sendo que a ativação dessa região foi predominante no hemisfério contralateral ao ouvido estimulado [Dieterich et al. 2003b]. 
Considerando os estudos Rastreio e Sacade, a freqüência de ativação para as regiões ACC e PCC foi praticamente a mesma (50\% para o estudo Rastreio e 63\% para o estudo Sacade). Considerando a análise dos dois estudos juntos, as duas regiões mostraram uma freqüência de 88\%. Entretanto, se considerarmos a atividade dessas regiões nos mesmos voluntários a freqüência diminui significantemente (2/8 voluntários), indicando que podemos encontrar pelo menos uma dessas regiões em estudos que envolvam os paradigmas Rastreio e/ou Sacade [Gaymard et al. 1998a,b; Schmid et al. 2001; Mort et al. 2003; Pierrot-Deseilligny et al. 2004].

Uma maior freqüência de atividade no PCC também foi encontrada durante um estudo de fMRI com estimulação por movimento de rastreio, nesse dos 15 voluntários estudados apenas 9 mostraram atividade na região ACC e 14 desses voluntários mostraram atividade na região PCC [Tanabe et al. 2002].

\subsubsection{V1 e Paraestriado}

As áreas V1 e paraestriada estão localizadas no córtex occipital e representam as áreas visual primária e secundária, respectivamente (figura 5.17). O córtex estriado e paraestriado foram ativados durante os três paradigmas empregados, confirmando sua sensibilidade ao movimento visual [Darby et al. 1996; Corbetta et al. 1998; O’Driscoll et al. 1998; Petit \& Haxby 1999; O’Driscoll et al. 2000; Kimmig et al. 2001; Tanabe et al. 2002] e a estimulação optocinética [Bucher et al. 1997; Dieterich et al. 1998; Galati et al. 1999; Dieterich et al. 2003a]. Entretanto, a análise da freqüência de ativação dessas áreas mostrou uma freqüência baixa. Somente a área paraestriada apresentou 100\% de ativação para os estudos NOC, a qual era esperada para os três paradigmas e também para a área V1. Para a análise combinada a maior freqüência também ocorreu na área paraestriada $(100 \%)$, considerando o caso dos dois estudos juntos e, considerando a ativação dessas áreas no mesmo voluntário, a freqüência foi de $88 \%$ para as duas áreas. 


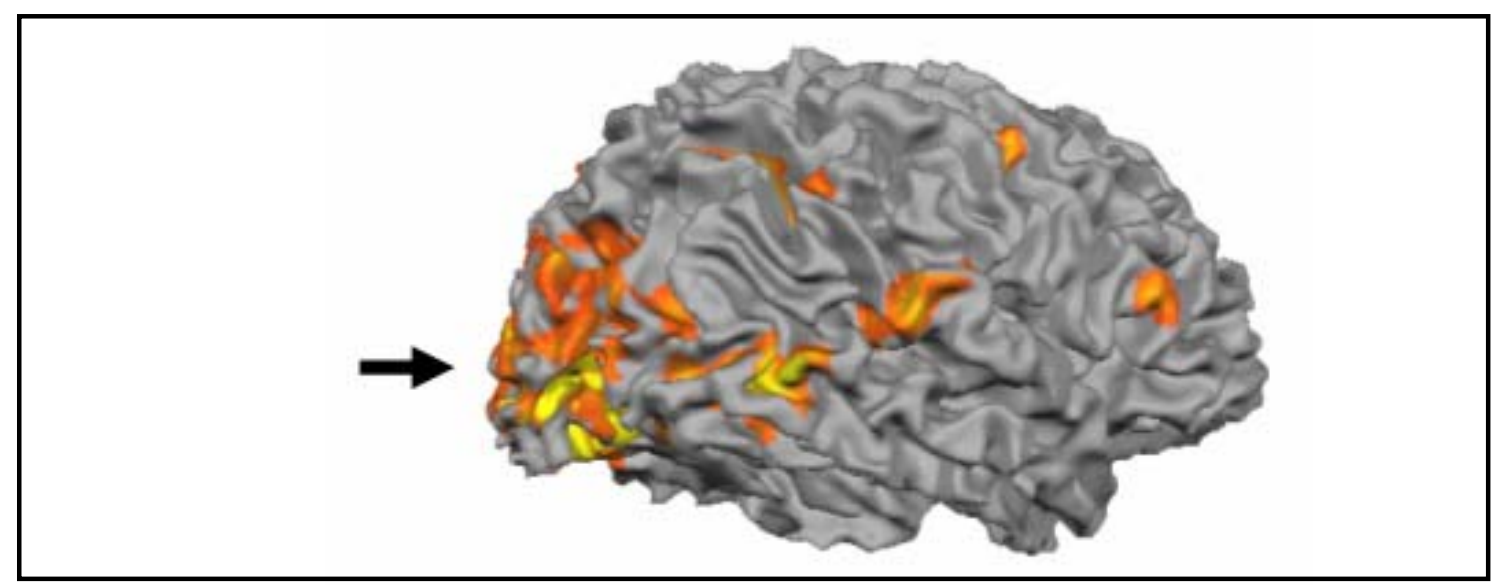

Figura 5.17 - Representação 3D da localização anatômica do córtex occipital.

As análises combinadas para os estudos de Rastreio e Sacade confirmaram uma maior freqüência de ativação da área paraestriada (100\%). Ao considerarmos a ativação dessas áreas no mesmo voluntário, ela decresceu significantemente (5/8 voluntários), tanto para o estudo Rastreio quanto para o estudo Sacade.

Tanto a área V1 quanto a área paraestriada mostraram uma alta variabilidade espacial para os três paradigmas [Zilles et al. 1997]. Essa alta variabilidade espacial encontrada, concorda com um estudo citoarquitetônico das áreas BA 17 e 18 [Amunts et al. 2000] que mostram uma alta variabilidade individual no tamanho e na forma dessas áreas em relação aos sulcos e, também, uma variabilidade interhemisférica. Concordando com Watkins et al. (2001), no qual mostraram uma maior quantidade de matéria cinzenta no lobo occipital esquerdo.

\subsubsection{MT/MST}

As duas áreas, temporal média (Middle Temporal - MT) e temporal média superior (Medial Superior Temporal - MST), estão localizadas no complexo V5, uma região no sulco temporal superior especializada em movimentação visual (figura 5.18). Nessas duas áreas, a maioria dos neurônios é sensível à direção e/ou a velocidade de uma movimentação visual [Lagae et al. 1993]. Kleinschmidt et al. (2002) sugerem uma subdivisão funcional desse complexo, com uma parte posterior, supostamente refletindo o comportamento funcional da área V5/MT e uma anterior, a área V5a/MSTd. Essa interpretação é compatível com um recente estudo de fMRI, no qual um movimento visual contralateral ativa toda a região MT/MST, 
sendo que o movimento visual ipsilateral produz uma resposta significativa na porção anterior do foco de ativação da área MT/MST, correspondente ao homólogo MSTd [Dukelow et al. 2001].

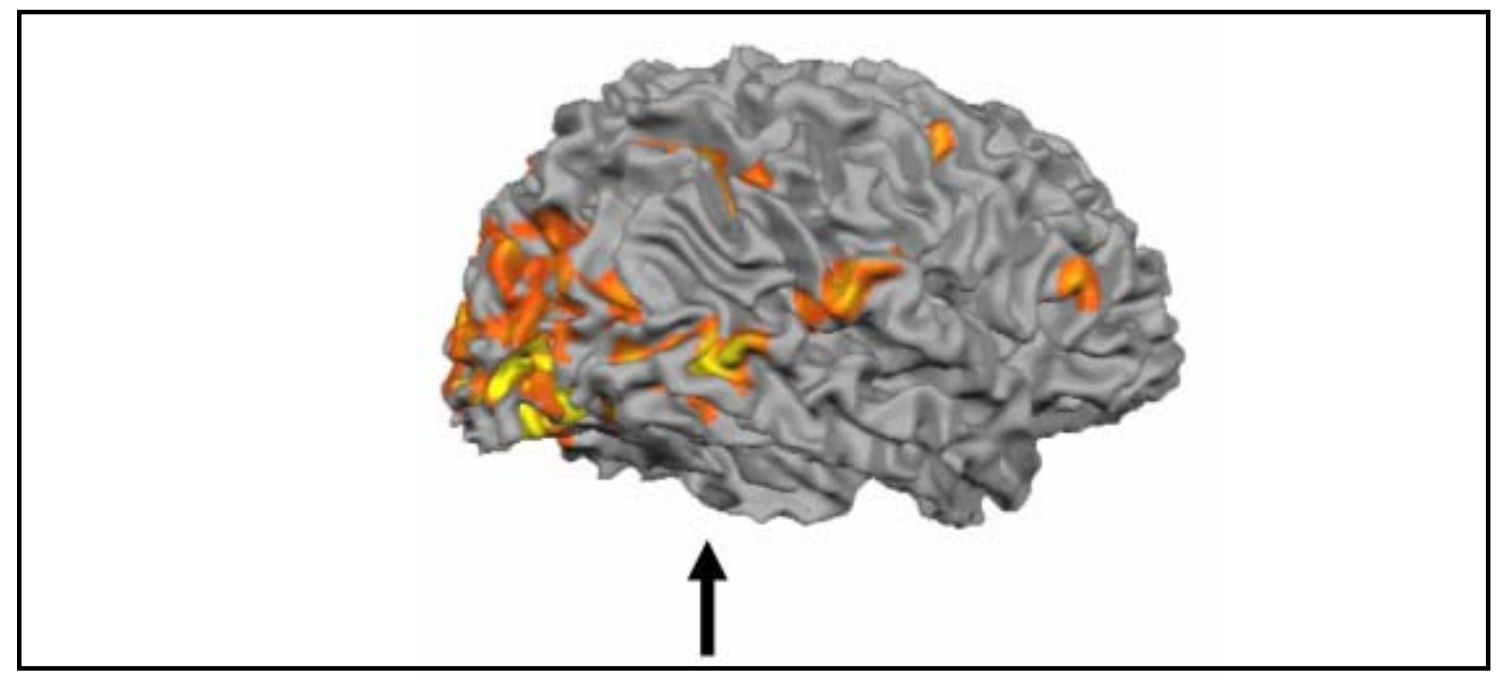

Figura 5.18 - Localização anatômica da região MT/MST em uma visão tri-dimensional do cérebro humano.

Um estudo com TMS mostrou que a estimulação sobre a área MT/MST faz crescer ipsilateralmente a aceleração do movimento de perseguição lenta e decrescer contralateralmente a desaceleração da perseguição lenta. Danos nas áreas MT/MST interrompem os movimentos de rastreio [Gaymard et al. 1999].

A região MT/MST apresentou uma alta variabilidade espacial para os três paradigmas. A coordenada $y$ mostrou uma grande variação do seu desvio padrão no estudo NOC, concordando com estudos de Hasnain e co-autores [Hasnain et al. 1998], no qual analisam a variabilidade entre voluntários para as áreas funcionais do córtex visual humano.

Para o caso dos estudos de Rastreio e Sacade, a coordenada z do hemisfério esquerdo, é a que apresenta maior variação no seu desvio padrão [Hasnain et al. 1998]. Watkins et al. (2001) mostraram uma maior quantidade de matéria cinzenta no sulco temporal superior esquerdo.

A área MT/MST mostrou uma freqüência de ativação maior para o estudo NOC para esquerda $(100 \%)$ comparada ao estudo NOC para direita (88\%). Se considerarmos a análise combinada da freqüência entre os dois estudos, também encontramos uma freqüência de $100 \%$, que diminui para $88 \%$ quando consideramos 
a freqüência de ativação da área MT/MST no mesmo voluntário, indicando, assim, uma alta probabilidade de encontrarmos essa área em estudos que apresentem estimulação optocinética [Bucher et al. 1997; Dieterich et al. 1998; Galati 1999; Dieterich et al. 2003a].

Já para os estudos Rastreio e Sacade a freqüência de ativação da área MT/MST é de 100\%, tanto para análise da freqüência combinada considerando os dois estudos, quanto consideramos a freqüência de atividade no mesmo voluntário, mostrando, assim, a importância dessa área em estudos que envolvam estimulações do tipo Rastreio e Sacade [Corbetta et al. 1998; O’Driscoll et al. 1998; Petit \& Haxby 1999; O’Driscoll et al. 2000; Dukelow et al. 2001; Schmid et al. 2001; Kimmig et al. 2001; Tanabe et al. 2002; Lencer et al. 2004]. Um estudo envolvendo percepção de movimento visual (tanto movimento de objetos como percepção de automovimento) também mostrou atividade nessa região [Kleinschmidt et al. 2002].

\subsection{8 Ínsula}

A ínsula está localizada no fundo do sulco lateral (figura 5.19). Esta é anatomicamente dividida em cinco giros, três curtos e dois longos, a região frontal do sulco ínsular central é conhecido como ínsula anterior e a região posterior ao sulco ínsular central é então definida como ínsula posterior [Bense et al. 2001]. Em estudos de fMRI foram encontradas áreas de atividades distintas nas partes anterior e posterior da ínsula [Bucher et al. 1997; Dieterich et al. 1998; Dieterich et al. 2003a]. A ínsula posterior é descrita como homóloga ao córtex parieto-insular vestibular. Guldin \& Grüsser (1998) descobriram neurônios multisensoriais que respondem a estímulos vestibular, somatosensorial e optocinético no córtex parieto-insular vestibular e neurônios que respondem especialmente o estímulo visual na área visual temporal (área de Sylvian). A ínsula posterior pode ser representada como a parte sensorial do sistema visual-vestibular, a qual integra-se com a orientação espacial. 


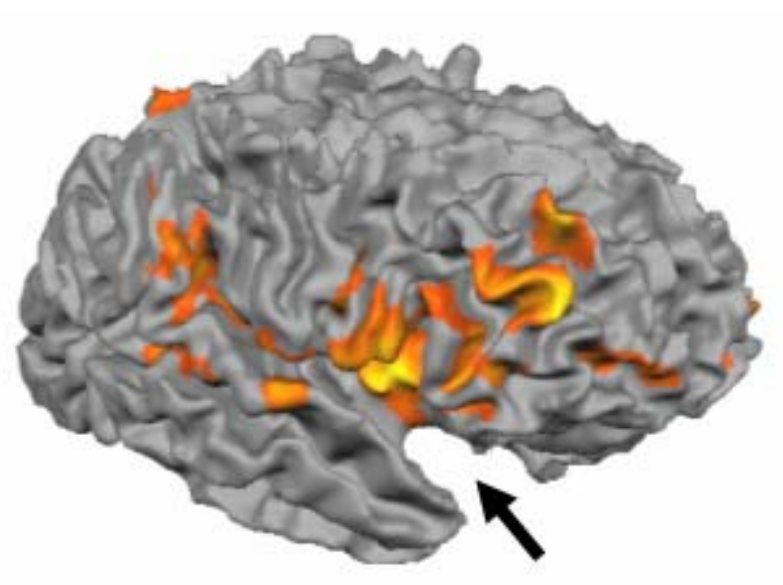

Figura 5.19 - Localização anatômica da ínsula em uma visão tri-dimensional do cérebro humano.

Entretanto, a ínsula anterior em cooperação com os centros sacádicos e de rastreio, pode estar envolvida com a geração e o controle do movimento do olho, especialmente com a orientação espacial do movimento do olho e sua estrutura temporal [Dieterich et al. 1998]. Alguns autores concluíram que a ínsula anterior é uma área motora secundária [Anderson et al. 1994].

Um estudo, em humanos, mostrou que lesões na área da ínsula posterior proporcionam um distúrbio significativo da percepção de verticalidade, isto é, distúrbio das entradas vestibulares (otólitos) [Brandt et al. 1995]. A mesma área na ínsula posterior foi ativada num estudo de PET com estimulação calórica em humanos. Isto sugere que neurônios multisensorias na ínsula posterior recebem uma entrada vestibular em humanos e primatas [Bottini et al. 1994 ; Dieterich et al. 1996].

Tanto a ínsula anterior como a ínsula posterior mostraram uma alta variabilidade espacial sendo que a variância da ínsula posterior foi maior quando considerados os estudos NOC para direita e NOC para esquerda. No caso dos estudos Rastreio e Sacade a variabilidade espacial para a ínsula anterior também foi alta. Como a ínsula posterior não apresentou atividade no estudo Sacade, podemos perceber apenas a sua variabilidade inter-hemisférica. Watkins et al. (2001) mostraram uma maior quantidade de matéria cinzenta no córtex insular direito.

Ao analisarmos a freqüência de ativação para os estudos NOC, verificamos uma maior freqüência da ínsula anterior, que também se mostrou mais ativa no caso da analise combinada da freqüência (100\% quando consideramos os dois estudos 
juntos e 75\% quando consideramos a atividade dessa área no mesmo voluntário). Podemos concluir, então, que tanto a ínsula anterior como a posterior possuem uma alta probabilidade de serem ativadas em estudos que envolvam estimulação optocinética. Além dos estudos citados anteriormente, um estudo realizado por estimulação calórica também mostrou atividade nas áreas da ínsula anterior e posterior [Dieterich et al. 2003b].

Considerando os estudos Rastreio e Sacade a freqüência de ativação para a ínsula anterior foi maior para o estudo Sacade (75\%), e para o Rastreio (63\%) se comparado à região da ínsula posterior. A análise combinada da freqüência para os estudos Rastreio e Sacade mostram uma freqüência de 75\% para a ínsula anterior e de 63\% para a ínsula posterior. Se considerarmos a atividade na ínsula anterior nos mesmos voluntários, a freqüência diminui para 38\%. Isso indica uma maior probabilidade da ativação da ínsula anterior em estudos que envolvam o movimento sacade. Um estudo envolvendo percepção de movimento visual (tanto movimento de objetos como percepção de auto-movimento) mostrou atividade na ínsula posterior [Kleinschmidt et al. 2002]. Alguns estudos envolvendo movimentos de rastreio e sacade do olho mostram ativação bilateral da ínsula [Barton et al. 1996; Petit et al. 1993; Anderson et al. 1994]. Os estudos de Petit et al. e Anderson et al., os quais envolviam apenas movimentos sacádicos do olho, mostraram atividade apenas na ínsula anterior [Petit et al. 1993; Anderson et al. 1994], indicando, novamente, que a ínsula anterior representa uma área motora secundária [Anderson et al. 1994] e que a ínsula posterior está envolvida somente com o sistema vestibular [Dieterich et al. 1998].

\subsubsection{Cerebelo}

O cerebelo executa um papel importante no comando de todos os tipos de movimentos, incluindo os movimentos dos olhos. Tanabe et al. (2002) apresentaram a primeira evidência, utilizando fMRI, que o cerebelo faz parte de um caminho significante para o movimento de rastreio. A identificação das estruturas cerebelares específicas responsáveis pelo rastreio é complicada devido à grande quantidade das entradas córtico-cerebelares. Embora o vermis cerebelar oculomotor tenha sido primeiramente reconhecido pelo seu papel na modulação do comando motor para o 
sacade [Noda \& Fujikado 1987], esta estrutura está também envolvida no controle do rastreio. As células de Pukinje dessa área respondem a uma combinação de sinais visuais, velocidade do olho e velocidade da cabeça [Suzuki \& Keller 1988; Shinmei et al. 2002]. A micro-estimulação do vermis pode provocar tanto movimento de rastreio como de sacade. Esse efeito pode ser explicado considerando que o vermis e os núcleos fastigiais regulam um sinal motor que contribui, tanto para o rastreio quanto para o sacade [Krauzlis \& Miles 1998]. Portanto, esses estudos suportam a idéia de que essa região do cerebelo executa um papel similar no controle do rastreio e do sacade - ela dá forma à trajetória do rastreio e do sacade, talvez modificando os comandos de aceleração e desaceleração do olho. Em humanos, a TMS ao longo do vermis aumenta ipsilateralmente a aceleração do rastreio e decresce contralateralmente a sua desaceleração [Ohtsuka \& Enoki 1998].

Outras estruturas cerebelares, como o flóculo, possuem neurônios específicos envolvidos no movimento de rastreio [Tanabe et al. 2002]. Um estudo recente envolvendo lesões mais seletivas mostrou que o paraflóculo ventral é uma estrutura crítica para o controle de perseguição [Rambold et al. 2002]. As células de Purkinje no paraflóculo ventral possuem potencial de disparo proporcional à velocidade do olho, indicando que esta atividade está relacionada ao comando motor [Stone \& Lisberger 1990].

Os hemisférios cerebelares estão envolvidos no processo da percepção visual e de atenção, e a estrutura vermal está envolvida no controle do movimento do olho, pois utiliza informações vestibulares dos canais semicirculares e dos otólitos [Barmack et al. 1995]. A discussão sobre a atividade nos hemisférios cerebelares não deve estar restrita à atenção, mas deve envolver percepção de movimento visual e o tempo do controle sensoriomotor do movimento dos olhos, a qual é conhecida como uma função típica do cerebelo. Entretanto, o vermis não está apenas envolvido no controle do movimento do olho e da cabeça, mas também executa um importante papel no controle postural [Ouchi et al. 1999]. Além disso, Ettinger et al. (2002) acreditam em um parâmetro volumétrico no controle do ganho sacádico pelo vermis cerebelar.

Apesar da alta variabilidade espacial encontrada nos três paradigmas, o cerebelo mostrou uma freqüência de ativação inter-individual significativa, sendo 
maior para o estudo NOC para direita $(100 \%)$ e maior para o estudo Sacade $(100 \%)$ [O’Driscoll et al. 2000]. Quando consideramos os dois estudos juntos, a freqüência de ativação chega a 100\% tanto para os estudos Rastreio e Sacade quanto para os estudos NOC, indicando uma alta probabilidade de encontrarmos atividade nessa área tanto para estudos que envolvam estimulação optocinética [Dieterich et al. 2000] quanto para estudos envolvendo movimentos de rastreio e sacade [Corbetta et al. 1998; Gaymard et al. 1999; O’Driscoll et al. 2000; Ettinger et al. 2002; Tanabe et al. 2002; Lencer et al. 2004]. Se considerarmos a atividade no cerebelo no mesmo voluntário durante o paradigma NOC, a freqüência diminui para $88 \%$ e para os estudos Rastreio e Sacade ela diminui para 75\%. 


\section{Capítulo 6}

\section{CONCLUSÕES E PERSPECTIVAS}

\subsection{Conclusões}

A técnica de fMRI foi capaz de demonstrar a localização das regiões cerebrais envolvidas nas tarefas de estimulação optocinética e dos movimentos de rastreio e sacade do olho. As principais regiões ativadas durante estas estimulações correspondem às áreas corticais e subcorticais envolvidas nos sistemas visual, oculomotor e vestibular. Além disso, pudemos verificar quais as regiões que apresentaram maior freqüência de ativação, sendo estas as áreas frontais (campo frontal do olho e córtex pré-frontal dorsolateral), relacionadas à execução, predição, inibição, seleção e monitoramento do movimento dos olhos, e a área que compreende o giro temporal médio e médio superior, responsável pela percepção de movimento. A ínsula posterior mostrou possuir um envolvimento maior com o sistema vestibular pois, das treze áreas corticais analisadas, a única área que não apresentou atividade durante o estudo sacade foi a ínsula posterior.

A técnica de fMRI permitiu, também, acessarmos a alta variabilidade anatômica existente entre os hemisférios e também entre sujeitos [Zilles et al. 1997; Watkins et al. 2001]. A simples média das coordenadas do Atlas Talairach, como é comumente utilizada em estudos de fMRI, não nos possibilita essa acessibilidade. Neste trabalho buscamos examinar, ainda que de forma preliminar, as diferenças existentes entre indivíduos da localização de funções vestibular e oculomotor. Notamos que essa variabilidade existe e é, de fato, importante.

Por fim, dentre os dois métodos utilizados para obtermos os índices de lateralização, o método $\mathrm{IL}_{2}$ apresentou maior confiabilidade. Isso se deve a sua independência do limiar estatístico. Portanto, encontramos um padrão bastante interessante relacionado aos índices de lateralização mostrando uma leve dominância do hemisfério direito para os estudos NOC independente da direção do estímulo. Esse possível padrão da dominância direita encontrada sugere uma relação 
com a dominância hemisférica da orientação espacial. No entanto, precisamos realizar mais estudos para que essa hipótese seja confirmada.

A combinação dos estímulos empregados constituiu uma importante ferramenta para determinar a lateralização de suas funções e mapear as maiores áreas corticais e subcorticais envolvidas nos sistemas oculomotor e vestibular.

\subsection{Perspectivas}

Além dos métodos utilizados para encontrarmos o índice de lateralização seria interessante realizar outros tipos de análises para determinar a influência de cada lobo nesse índice. Por exemplo, determinando um índice de dominância frontal, o qual englobaria todos os pixels ativados no lobo frontal, poderíamos compará-lo ao restante do cérebro e assim verificar sua influência na dominância hemisférica. Outro método seria a simples comparação entre o número de pixels presentes em cada lobo. Nesse caso, seria realizada a comparação entre os índices do lobo parietal e temporal, ou entre os índices do lobo parietal e occipital etc. Além de uma possível análise que envolva somente o cerebelo. Ainda, seria interessante verificar se algumas estruturas específicas em cada um desses lobos se apresenta mais lateralizada.

Alguns estudos foram realizados visando a relação de áreas corticais com o sistema vestibular por diferentes vias, um desses estudos envolve a estimulação calórica juntamente com a técnica de fMRI. A resposta calórica, no caso de utilização de água fria, reflete a inibição unilateral do canal semicircular e é extremamente aceita para examinar a função vestibular. A estimulação calórica é realizada através da aplicação tanto de água quente [Dieterich et al. 2003b] como fria [Suzuki et al. 2001], ou também, através da aplicação de nitrogênio [Fasold et al. 2002] no canal externo do ouvido. No trabalho de Suzuki et al. (2001) encontraram ativação no giro insular (com um padrão contralateral ao ouvido estimulado), no sulco intraparietal (com dominância hemisférica direita), no giro superior temporal, no hipocampo, no giro do cíngulo e no tálamo. Áreas de ativação nos lobos parietal, temporal e frontal também foram encontradas no trabalho de Fasold et al. (2002), além de regiões como os córtices parieto-insular e occipital. Assim como nos 
trabalhos descritos anteriormente, Dieterich et al. (2003) encontraram atividade em áreas corticais homólogas às maiores áreas corticais que recebem entradas vestibulares em várias espécies de primatas [Guldin \& Grüsser 1998]. No entanto, a máxima ativação encontrada foi quando o hemisfério não-dominante era ipsilateral ao ouvido estimulado, indicando que o sistema vestibular e seu hemisfério dominante determinam a predominância destra ou canhota [Dieterich et al. 2003b].

Um outro tipo de estimulação possível é a galvânica vestibular, que atua no disparo dos neurônios vestibulares primários atingindo principalmente aferências otolíticas [Watson et al. 1998] ou fibras dos canais semicirculares [Schneider et al. 2000], diferente da estimulação calórica que afeta principalmente os canais semicirculares horizontal. O primeiro trabalho que utilizou esse tipo de estimulação juntamente com a fMRI foi realizado por Lobel et al. (1998), este mostrou ativação na junção temporo-parietal, no sulco central e no sulco intraparietal, correspondendo as áreas envolvidas com o circuito multisensorial do sistema vestibular em macacos, além da ativação do lobo frontal e da desativação da parte anterior desse lobo. Bense et al. (2001) utilizaram a estimulação galvânica vestibular e a estimulação galvânica cutânea a fim de diferenciar as funções vestibulares oculomotora e nociceptiva. Encontraram atividade relacionada às funções multisensoral vestibulares e oculomotoras, além de um padrão inibitório entre a interação visual-vestibular.

Seria interessante se pudéssemos realizar os métodos empregados na análise da freqüência e no índice de lateralização, além dos sugeridos, em exames de fMRI envolvendo os estímulos calórico e galvânico vestibular. Para tanto, necessitamos do desenvolvimento de estimuladores específicos que possam ser utilizados juntos com a técnica de fMRI.

Por fim, este trabalho abre a possibilidade de aplicarmos estímulos de nistagmo optocinético e dos movimentos de rastreio e sacade dos olhos em pacientes com distúrbios vestibulares, para que possamos encontrar padrões relacionados a esses danos e também como forma de auxílio no diagnostico dessas doenças. 


\section{REFERÊNCIAS BIBLIOGRÁFICAS}

ALLEN, G., BUXTON, R.B., WONG, E.C., \& COURCHESNE, E. Attentional activation of the cerebellum independent of motor involvement. Science. 275(5308):1940-1943, 1997.

AMUNTS, K., MALIKOVIC, A., MOHLBERG, H., SCHORMANN, T., \& ZILLES, K. Brodmann's areas 17 and 18 brought into stereotaxic space-where and how variable? Neuroimage. 11(1): 66-84, 2000.

ANDERSON, T.J., JENKINS, I.H., BROOKS, D.J., HAWKEN, M.B., FRACKOWIAK, R.S., \& KENNARD, C. Cortical control of saccades and fixation in man. A PET study. Brain. 117: 1073-1084, 1994.

APKARIAN, A.V., DARBAR, A., KRAUSS, B.R., GELNAR, P.A., \& SZEVERENYI N.M. Differentiating cortical areas related to pain perception from stimulus identification: temporal analysis of fMRI activity. J. Neurophysiol 81(6): 2956-2963, 1999.

AUGUSTINE, J.R. Circuitry and functional aspects of the insular lobe in primates including humans. Brain Res. Rev. 22(3): 229-44, 1996.

AZIZ, Q., FURLONG, P.L., BARLOW, J., HOBSON, A., ALANI, S., BANCEWICZ, J., RIBBANDS, M., HARDING, G.F., \& THOMPSON, D.G. Topographic mapping of cortical potentials evoked by distension of the human proximal and distaloesophagus. Electroencephalogr. Clin. Neurophysiol. 96(3): 219-228, 1995.

BANDETTINI, P.A., WONG, E.C., HINKS, R.S., TIKOFSKY, R.S., \& HYDE, J.S. Time course EPI of human brain function during task activation. Magn. Reson. Med. 25(2): 390-397, 1992.

BARMACK, N.H. \& SHOJAKU, H. Vestibular and visual climbing fiber signals evoked in the uvula-nodulus of the rabbit cerebellum by natural stimulation. J. Neurophysiol. 74(6): 2573-2589, 1995.

BARTON, J.J., SIMPSON, T., KIRIAKOPOULOS, E., STEWART, C., CRAWLEY, A., GUTHRIE, B., WOOD, M., \& MIKULIS, D. Functional MRI of lateral occipitotemporal cortex during pursuit and motion perception. Ann. Neurol. 40(3): 387-398, 1996.

BENSE, S., STEPHAN, T., YOUSRY, T.A., BRANDT, T., \& DIETERICH, M. Multisensory cortical signal increases and decreases during vestibular galvanic stimulation (fMRI). J. Neurophysiol. 85(2): 886-899, 2001.

BERTHOZ, A. The role of inhibition in the hierarchical gating of executed and imagined movements. Cogn. Brain Res. 3(2): 101-113, 1996.

BERTHOZ, A., ISRAEL, I., GEORGES-FRANCOIS, P., GRASSO, R., \& TSUZUKU, T. Spatial memory of body linear displacement: what is being stored? Science. 269(5220): 95-98, 1995. 
BINDER, J.R.., SWANSON, S.J., HAMMEKE, T.A., MORRIS, G.L., MUELLER, W.M., FISCHER, M., BENBADIS, S., FROST, J.A., RAO, S.M., \& HAUGHTON, V.M. Determination of language dominance using functional MRI: a comparison with the Wada test. Neurology. 46(4): 978-984, 1996.

BISLEY, J.W. \& GOLDBERG, M.E. Neuronal activity in the lateral intraparietal area and spatial attention. Science. 299(5603): 81-86, 2003.

BLANKE, O. \& SEECK, M. Direction of saccadic and smooth eye movements induced by electrical stimulation of the human frontal eye field: effect of orbital position. Exp. Brain Res. 150(2): 174-183, 2003.

BOILEAU, I., BEAUREGAR, M., BEUTER, A., BREAULT, C., \& LECOURS, A.R. Optokinetic stimulation and the egocentred midsagittal plane: an fMRI study. Neuroreport. 13(1): 61-65, 2002.

BOR, D., DUNCAN, J., WISEMAN, R.J., \& OWEN, A.M. Encoding strategies dissociate prefrontal activity from working memory demand. Neuron. 37(2): 361-367, 2003.

BOTTINI, G., STERZI, R., PAULESU, E., VALLAR, G., CAPPA, S.F., ERMINIO, F., PASSINGHAM, R.E., FRITH, C.D., \& FRACKOWIAK, R.S. Identification of the central vestibular projections in man: a positron emission tomography activation study. Exp. Brain Res. 99(1): 164-169, 1994.

BRANDT, T. \& STRUPP, M. General vestibular testing. Clin. Neurophysiol. 116(2): 406426, 2005.

BRANDT, S.A., PLONER, C.J., MEYER, B.U., LEISTNER, S., \& VILLRINGER, A. Effects of repetitive transcranial magnetic stimulation over dorsolateral prefrontal and posterior parietal cortex on memory-guided saccades. Exp. Brain Res. 118(2): 197-204, 1998.

BRANDT, T., BOTZEL, K., YOUSRY, T., DIETERICH, M., \& SCHULZE, S. Rotational vertigo in embolic stroke of the vestibular and auditory cortices. Neurology. 45(1): 42-44, 1995.

BRANDT, T., DIETERICH, M., \& DANEK, A. Vestibular cortex lesions affect the perception of verticality. Ann. Neurol. 35(4): 403-412, 1994.

BUCHER, S.F., DIETERICH, M., SEELOS, K.C., \& BRANDT, T. Sensorimotor cerebral activation during optokinetic nystagmus. A functional MRI study. Neurology. 49(5): 1370-1377, 1997.

CHOLLET, F., DIPIERO, V., WISE, R.J., BROOKS, D.J., DOLAN, R.J., \& FRACKOWIAK, R.S. The functional anatomy of motor recovery after stroke in humans: a study with positron emission tomography. Ann. Neurol. 29(1): 63-71, 1991.

CONDY, C., RIVAUD-PECHOUX, S., OSTENDORF, F., PLONER, C.J., \& GAYMARD, B. Neural substrate of antisaccades: role of subcortical structures. Neurology. 63(9): 1571-1578, 2004. 
COOLS, R., CLARK, L., OWEN, A.M., \& ROBBINS, T.W. Defining the neural mechanisms of probabilistic reversal learning using event-related functional Magnetic Resonance Imaging. The Journal of Neuroscience. 22(11): 4563-4567, 2002.

CORBETTA, M., AKBUDAK, E., CONTURO, T.E., SNYDER, A.Z., OLLINGER, J.M., DRURY, H.A., LINENWEBER, M.R., PETERSEN, S.E., RAICHLE, M.E., VAN ESSEN, D.C., \& SHULMAN, G.L. A common network of functional areas for attention and eye movements. Neuron. 21(4): 761-773, 1998.

CORBETTA, M., SHULMAN, G.L., MIEZIN, F.M., \& PETERSEN, S.E. Superior parietal cortex activation during spatial attention shifts and visual feature conjunction. Science. 270(5241): 802-805, 1995.

COSTA S.S., CRUZ O.L.M., OLIVEIRA, J.A. Otorrinolaringologia: princípios e prática. Porto Alegre: Artes Médicas, 1994.

COURTNEY S. M., PETIT, L., HAXBY, J.V. \& UNGERLEIDER, L; G. The role of prefrontal cortex in working memory: examining the contents of consciousness. Phil. Trans. R. Soc. Lond. 353(1377): 1819-1828, 1998.

COURTNEY, S.M., UNGERLEIDER \& K.K., HAXBY, J.V. Transient and sustained activity in a distributed neural system for human working memory. Nature. 386(6625): 608-611, 1997.

CULHAM, J.C., \& KANWISHER, N.G. Neuroimaging of cognitive functions in human parietal cortex. Curr. Opin. Neurobiol. 11(2): 157-163, 2001.

CUTRELL, E.B. \& MARROCCO, R.T. Electrical microstimulation of primate posterior parietal cortex initiates orienting and alerting components of covert attention. Exp. Brain Res. 144(1): 103-113, 2002.

DARBY, D.G., NOBRE, A.C., THANGARAJ, V., EDELMAN, R., MESULAM, M.M., \& WARACH, S. Cortical activation in the human brain during lateral saccades using EPISTAR functional magnetic resonance imaging. Neuroimage. 3(1):53-62, 1996.

DAVIES P.M. Steps to Follow: A Guide to the treatment of adult hemiplegia. New York, NY: Springer; 1985.

DE ARAÚJO, D.B. Sobre neuroimagens funcionais por magnetoencefalografia e ressonância magnética: novos métodos e aplicações. Tese (Doutorado). Universidade de São Paulo. FFCLRP, 2002.

DEIBER, M.P., PASSINGHAM, R.E., COLEBATCH, J.G., FRISTON, K.J., NIXON, P.D., FRACKOWIAK, R.S. Cortical areas and the selection of movement: a study with positron emission tomography. Exp. Brain Res. 84(2): 393-402, 1991.

DELGADO-GARCIA, J.M. Structure and function of the cerebellum. Rev. Neurol. 33(7): 635-642, 2001. 
DI SALLE, F.,FORMISANO, E., LINDEN, D.E.J., GOEBEL, R., BONAVITA, S., PEPINO, A., SMALTINO, F. \& TEDESCHI, G. Exploring brain function with magnetic resonance imaging. European Journal of Radiology. 30(2): 84-94, 1999.

DIETERICH, M., BENSE, S., STEPHAN, T., YOUSRY, T.A., \& BRANDT, T. fMRI signal increases and decreases in cortical areas during small-field optokinetic stimulation and central fixation. Exp. Brain Res. 148(1): 117-127, 2003a.

DIETERICH, M., BENSE, S., LUTZ, S., DRZEZGA, A., STEPHAN, T., BARTENSTEIN, P., \& BRANDT, T. Dominance for vestibular cortical function in the nondominant hemisphere. Cereb. Cortex. 13(9): 994-1007, 2003b.

DIETERICH, M., BUCHER, S.F, SEELOS, K.C., \& BRANDT, T. Cerebellar activation during optokinetic stimulation and saccades. Neurology. 54(1): 148-155, 2000.

DIETERICH, M., BUCHER, S.F, SEELOS, K.C. \& BRANDT T. Horizontal or vertical optokinetic stimulation activates visual motion-sensitive, ocular motor and vestibular cortex areas with right hemispheric dominance. An fMRI study. Brain. 121:1479-95, 1998.

DIETERICH, M., BRANDT, T., BARTENSTEIN, P., WENZEL, R., DANEK, A., LUTZ S., et al. Different vestibular cortex areas activated during caloric irrigation: a PET study [abstract]. J. Neurol. 243(suppl. 2):S40, 1996.

DUKELOW, S.P., DESOUZA, J.F., CULHAM, J.C., VAN DEN BERG, A.V., MENON, R.S., \& VILIS, T. Distinguishing subregions of the human MT+ complex using visual fields and pursuit eye movements. J. Neurophysiol. 86(4): 1991-2000, 2001.

ELLIOTT, R., FRISTON, K.J., \& DOLAN R, J. Dissociable neural responses in human reward systems. The Journal of Neuroscience. 20(16): 6159-6165, 2000.

ETTINGER, U., KUMARI, V., CHITNIS, X.A., CORR, P.J., SUMICH, A.L., RABEHESKETH, S., CRAWFORD, T.J., \& SHARMA, T. Relationship between brain structure and saccadic eye movements in healthy humans. Neurosci. Lett. 328(3): 225-228, 2002.

FASOLD, O., VON BREVERN, M., KUHBERG, M., PLONER, C.J., VILLRINGER, A., LEMPERT, T., \& WENZEL, R. Human vestibular cortex as identified with caloric stimulation in functional magnetic resonance imaging. Neuroimage. 17(3): 1384-1393, 2002.

FORNITO, A., YUCEL, M., WOOD, S., STUART, G.W., BUCHANAN, J.A., PROFFITT, T., ANDERSON, V., VELAKOULIS, D., \& PANTELIS, C. Individual differences in anterior cingulate/paracingulate morphology are related to executive functions in healthy males. Cereb. Cortex. 14(4): 424-431, 2004.

FOX P.T., MINTUN, M.A., RAICHLE, M.E., MIEZIN, F.M., ALLMAN, J.M., \& VAN ESSEN D.C. Mapping human visual cortex with positron emission tomography. Nature. 323(6091): 806-809, 1986. 
FOX, P.T. \& RAICHLE, M.E. Focal physiological uncoupling of cerebral blood flow and oxidative metabolism during somatosensory stimulation in human subjects. Proc. Natl. Acad. Sci. U.S.A. 83(4): 1140-1144, 1986.

FRISTON, K.J., WILLIAMS, S., HOWARD, R., FRACKOWIAK, R.S., \& TURNER, R. Movement-related effects in fMRI time-series. Magn. Reson. Med. 35(3): 346-355, 1996.

FRISTON, K.J., HOLMES, A.P., WORSLEY, K.J., POLINE, J.P., FRITH, C.D., \& FRACKOWIAK, R.S.J. Statistical Parametric Maps in Functional Imaging: A General Linear Approach. Human Brain Mapping. 2: 189-210, 1995.

FRISTON, K.J., JEZZARD, P., \& TURNER, R. Analysis of functional MRI time series. Human Brain Mapping, 1: 153-171, 1994.

GALATI, G., PAPPATA, S., PANTANO, P., LENZI, G.L., SAMSON, Y., \& PIZZAMIGLIO, L. Cortical control of optokinetic nystagmus in humans: a positron emission tomography study. Exp. Brain Res. 126(2): 149-159, 1999.

GARAVAN, H., ROSS, T.J., \& STEIN, EA. Right hemispheric dominance of inhibitory control: an event-related functional MRI study. Proc. Natl. Acad. Sci. 96(14): 8301-8306, 1999.

GAYMARD, B. \& PIERROT-DESEILLIGNY, C. Neurology of saccades and smooth pursuit. Curr. Opin. Neurol. 12(1): 13-19, 1999.

GAYMARD, B., RIVAUD, S., CASSARINI, J.F., DUBARD, T., RANCUREL, G., AGID, Y., \& PIERROT-DESEILLIGNY, C. Effects of anterior cingulate cortex lesions on ocular saccades in humans. Exp. Brain Res. 120(2): 173-183, 1998a.

GAYMARD, B., PLONER, C.J., RIVAUD, S., VERMERSCH, A.I., \& PIERROTDESEILLIGNY, C. Cortical control of saccades. Exp. Brain Res. 123: 159-63, 1998 b.

GOT'TFRIED, J.A., O'DOHERTY, J., \& DOLAN, R.J. Appetitive and Aversive Olfactory Learning in Humans Studied Using Event-Related Functional Magnetic Resonance Imaging. The Journal of Neuroscience. 22(24): 10829-10837, 2002.

GROSBRAS, M.H., LOBEL, E., VAN DE MOORTELE, P.F., LEBIHAN, D., \& BERTHOZ, A. An anatomical landmark for the supplementary eye fields in human revealed with functional magnetic resonance imaging. Cereb. Cortex. 9(7): 705-711, 1999.

GRÜSSER, O.J., PAUSE, M., \& SCHREITER, U. Localization and responses of neurones in the parieto-insular vestibular cortex of awake monkeys (Macaca fascicularis). J. Physiol. 430: 537-557, 1990a.

GRÜSSER, O.J., PAUSE, M., \& SCHREITER, U. Vestibular neurones in the parietoinsular cortex of monkeys (Macaca fascicularis): visual and neck receptor responses. J. Physiol. 430: 559-583, 1990b.

GULDIN, W.O. \& GRÜSSER, O.J. Is there a vestibular cortex? Trends. Neurosci. 21(6): 254-259, 1998. 
HAMDY, S., MIKULIS, D.J., CRAWLEY, A., XUE, S., LAU, H., HENRY, S., \& DIAMANT, N.E. Cortical activation during human volitional swallowing: an event-related fMRI study. Am. J. Physiol. 277 (1): 219-225, 1999.

HANES, D.P., PATTERSON, W.F II, SCHALL, J.D. Role of frontal eye fields in countermanding saccades: visual, movement, and fixation activity. J. Neurophysiol. 79(2): 817834, 1998.

HASNAIN, M.K., FOX, P.T., \& WOLDORFF, M.G. Intersubject variability of functional areas in the human visual cortex. Hum. Brain Mapp. 6(4): 301-315, 1998.

HEIDE, W., BINKOFSKI, F., SEITZ, R.J., POSSE, S., NITSCHKE, M.F., FREUND, H.J., \& KOMPF, D. Activation of frontoparietal cortices during memorized triple-step sequences of saccadic eye movements: an fMRI study. Eur. J. Neurosci. 13(6): 1177-1189, 2001.

HINKE, R.M., HU, X., STILLMAN, A.E., KIM, S.G., MERKLE, H., SALMI, R., \& UGURBIL, K. Functional magnetic resonance imaging of Broca's area during internal speech. Neuroreport. 4(6):675-678., 1993.

HOPFINGER, J.B., BUONOCORE, M.H., \& MANGUN, G.R. The neural mechanisms of top-down attentional control. Nat. Neurosci. 3(3): 284-291, 2000.

HUETTEL, S.A., SONG, A.W., \& MCCARTHY, G. Functional Magnetic Resonance Imaging. $1^{\text {st }}$ ed. Sunderland: Sinauer Associates, 2004.

HUNGRIA, H. Otorrinolaringologia. Sexta Edição. Rio de Janeiro: Guanabara Koogan, 1991.

JANSMA, J.M., RAMSEY, N.F., COPPOLA, R., \& KAHN, R.S. Specific versus nonspecific brain activity in a parametric N-back task. Neuroimage. 12(6): 688-697, 2000.

JEZZARD, P \& CLARE, S. Principles of nuclear magnetic resonance and MRI. Em Functional MRI. An Introduction to Methods (edited by Jezzard, P, Matthews, P.M., \& Smith S.M.), pp: 67-92. Oxford University Press, 2001.

KANDEL, E.R., SCHWARTZ, J.H., JESSELL, T. M. Principles of neural science. $4^{\text {th }}$ ed. New York: McGraw-Hill, 2000.

KARNATH, H.O. New insights into the functions of the superior temporal cortex. Nat. Rev. Neurosci. 2(8): 568-76, 2001.

KARNATH, HO. \& BROETZ, D. Understanding and treating "Pusher Syndrome". Phys. Ther. 83(12): 1119-1125, 2003.

KIM, J.J. \& THOMPSON, R.F. Cerebellar circuits and synaptic mechanisms involved in classical eyeblink conditioning. Trends Neurosci. 20(4): 177-181, 1997.

KIMMIG, H., GREENLEE, M.W., GONDAN, M., SCHIRA, M., KASSUBEK, J., \& MERGNER, T. Relationship between saccadic eye movements and cortical activity as 
measured by fMRI: quantitative and qualitative aspects. Exp. Brain Res. 141(2): 184-194, 2001.

KLEINSCHMIDT, A., THILO, K.V., BUCHEL, C., GRESTY, M.A., BRONSTEIN, A.M., \& FRACKOWIAK, R.S. Neural correlates of visual-motion perception as objector self-motion. Neuroimage. 16(4): 873-882, 2002.

KRAUZLIS, R.J. Recasting the smooth pursuit eye movement system. J Neurophysiol. 91(2): 591-603, 2004.

KRAUZLIS, R.J. \& MILES, F.A. Role of the oculomotor vermis in generating pursuit and saccades: effects of microstimulation. J. Neurophysiol. 80(4): 2046-2062, 1998.

KWONG, K.K., BELLIVEAU, J.W., CHESLER, D.A., GOLDBERG, I.E., WEISSKOFF, R.M., PONCELET, B.P., KENNEDY, D.N., HOPPEL, B.E., COHEN. M.S., TURNER, R., et al. Dynamic magnetic resonance imaging of human brain activity during primary sensory stimulation. Proc. Natl. Acad. Sci. U.S.A. 89(12): 5675-5679, 1992.

LABAR, K.S., GITELMAN, D.R., PARRISH, T.B., \& MESULAM, M.. Neuroanatomic overlap of working memory and spatial attention networks: a functional MRI comparison within subjects. Neuroimage. 10(6): 695-704, 1999.

LAGAE, L., RAIGUEL, S., ORBAN, G.A. Speed and direction selectivity of macaque middle temporal neurons. J. Neurophysiol. 69(1): 19-39, 1993.

LAZAR, S.W., BUSH, G., GOLLUB, R.L., FRICCHIONE, G.L., KHALSA, G., \& BEN$\mathrm{SON}, \mathrm{H}$. Functional brain mapping of the relaxation response and meditation. Neuroreport. 11(7): 1581-1585, 2000.

LEKWUWA, G.U. \& BARNES, G.R. Cerebral control of eye movements. I. The relationship between cerebral lesion sites and smooth pursuit deficits. Brain. 119: 473-490, 1996.

LENCER, R., NAGEL, M., SPRENGER, A., ZAPF, S., ERDMANN, C., HEIDE, W., \& BINKOFSKI, F. Cortical mechanisms of smooth pursuit eye movements with target blanking. An fMRI study. Eur. J. Neurosci. 19(5): 1430-1436, 2004.

LOBEL, E., KLEINE, J.F., BIHAN, D.L., LEROY-WILLIG, A., \& BERTHOZ, A. Functional MRI of galvanic vestibular stimulation. J. Neurophysiol. 80(5):2699-2709, 1998.

LOGOTHETIS, N.K. The neural basis of the blood-oxygen-level-dependent functional magnetic resonance imaging signal. Philos. Trans. R. Soc. Lond B. Biol. Sci. 357(1424): 1003-1037, 2002.

MAYBERG, H.S., LIOTTI, M., BRANNAN, S.K., MCGINNIS, S., MAHURIN, R.K., JERABEK, P.A., SILVA, J.A., TEKELL, J.L., MARTIN, C.C., LANCASTER, J.L., \& FOX, P.T. Reciprocal limbic-cortical function and negative mood: converging PET findings in depression and normal sadness. Am. J. Psychiatry. 156(5): 675-682, 1999. 
MEDENDORP, W.P., GOLTZ, H.C., VILIS, T., \& CRAWFORD, J.D. Gaze-centered updating of visual space in human parietal cortex. J. Neurosci. 23(15): 6209-6214, 2003.

MERRIAM, E.P., GENOVESE, C.R, COLBY, C.L. Spatial updating in human parietal cortex. Neuron. 39(2): 361-373, 2003.

MORT, D.J., MALHOTRA, P., MANNAN, S.K., RORDEN, C., PAMBAKIAN, A., KENNARD, C., \& HUSAIN, M. The anatomy of visual neglect. Brain. 126: 1986-1997, 2003.

MURI, R.M., HEID, O., NIRKKO, A.C., OZDOBA, C., FELBLINGER, J., SCHROTH, G., \& HESS, C.W. Functional organisation of saccades and antisaccades in the frontal lobe in humans: a study with echo planar functional magnetic resonance imaging. J. Neurol. Neurosurg. Psychiatry. 65(3): 374-377, 1998.

MURI, R.M., IBA-ZIZEN, M.T., DEROSIER, C., CABANIS, E.A., \& PIERROTDESEILLIGNY, C. Location of the human posterior eye field with functional magnetic resonance imaging. J. Neurol. Neurosurg. Psychiatry. 60(4): 445-448, 1996.

NAGATA, S.I., UCHIMURA, K., HIRAKAWA, W., \& KURATSU, J.I. Method for quantitatively evaluating the lateralization of linguistic function using functional MR imaging. Am. J. Neuroradiol. 22(5): 985-91, 2001.

NOBRE, A.C., SEBESTYEN, G.N., GITELMAN, D.R., MESULAM, M.M., FRACKOWIAK, R.S., \& FRITH, C.D. Functional localization of the system for visuospatial attention using positron emission tomography. Brain. 120: 515-533, 1997.

NODA, H. \& FUJIKADO, T. Topography of the oculomotor area of the cerebellar vermis in macaques as determined by microstimulation. J. Neurophysiol. 58(2): 359-378, 1987.

O'DRISCOLL, G.A., WOLFF, A.L., BENKELFAT, C., FLORENCIO, P.S., LAL, S., \& EVANS, A.C. Functional neuroanatomy of smooth pursuit and predictive saccades. Neuroreport. 11(6): 1335-1340, 2000.

O'DRISCOLL, G.A., STRAKOWSKI, S.M., ALPERT, N.M., MATTHYSSE, S.W., RAUCH S.L., LEVY, D.L., \& HOLZMAN, P.S. Differences in cerebral activation during smooth pursuit and saccadic eye movements using positron-emission tomography. Biol. Psychiatry. 44(8):685-689, 1998.

OGAWA, H. Gustatory cortex of primates: anatomy and physiology. Neurosci. Res. 20(1): $1-13,1994$.

OGAWA, S., TANK, D.W., MENON, R., ELLERMANN, J.M., KIM, S.G., MERKLE, $\mathrm{H}$., \& UGURBIL, $\mathrm{K}$.Intrinsic signal changes accompanying sensory stimulation: functional brain mapping with magnetic resonance imaging. Proc. Natl. Acad. Sci. U.S.A. 89(13): 5951-5955, 1992.

OGAWA, S., LEE, T. M., NAYAK, A. S. \& GLYNN, P. Oxygenation-sensitive contrast in magnetic resonance image of rodent brain at high magnetic fields. Magn. Resonance Med. 14(1): 68-78, 1990a. 
OGAWA, S., LEE, T.M., KAY, A.R., \& TANK, D.W. Brain magnetic resonance imaging with contrast dependent on blood oxygenation. Proc. Natl. Acad. Sci. USA. 87(24): 9868$72,1990 \mathrm{~b}$.

OHTSUKA, K. \& ENOKI, T. Transcranial magnetic stimulation over the posterior cerebellum during smooth pursuit eye movements in man. Brain. 121: 429-435, 1998.

OUCHI, Y., OKADA, H., YOSHIKAWA, E., NOBEZAWA, S., \& FUTATSUBASHI, M. Brain activation during maintenance of standing postures in humans. Brain. 122: 329338, 1999.

PARDO, J.V., FOX, P.T., \& RAICHLE, M.E. Localization of a human system for sustained attention by positron emission tomography. Nature. 349(6304): 61-64, 1991.

PAUS, T. Location and function of the human frontal eye-field: a selective review. Neuropsychologia. 34(6): 475-483, 1996.

PETIT, L. \& HAXBY J.V. Functional anatomy of pursuit eye movements in humans as revealed by fMRI. J Neurophysiol. 82(1): 463-471, 1999.

PETIT, L., ORSSAUD, C., TZOURIO, N., SALAMON, G., MAZOYER, B., \& BERTHOZ, A. PET study of voluntary saccadic eye movements in humans: basal gangliathalamocortical system and cingulate cortex involvement. J. Neurophysiol. 69(4):10091017, 1993.

PETRIDES M. Frontal lobes and behaviour. Curr. Opin. Neurobiol. 4(2): 207-11, 1994.

PETRIDES, M., ALIVISATOS, B., EVANS, A.C., \& MEYER, E. Dissociation of human mid-dorsolateral from posterior dorsolateral frontal cortex in memory processing. Proc. Natl. Acad. Sci. U.S.A. 90(3): 873-877, 1993.

PHILLIPS, M.L., YOUNG, A.W., SENIOR, C., BRAMMER, M., ANDREW, C., CALDER, A.J., BULLMORE, E.T., PERRETT', D.I., ROWLAND, D., WILlIAMS, S.C., GRAY, J.A., \& DAVID, A.S. A specific neural substrate for perceiving facial expressions of disgust. Nature. 389(6650): 495-498, 1997.

PIERRO'T-DESEILLIGNY, C., MILEA, D., \& MURI, R.M. Eye movement control by the cerebral cortex. Curr. Opin. Neurol. 17(1): 17-25, 2004.

PIERROT-DESEILLIGNY, C., MURI, R.M., PLONER, C.J., GAYMARD, B., DEMERET, S., \& RIVAUD-PECHOUX, S. Decisional role of the dorsolateral prefrontal cortex in ocular motor behaviour. Brain. 126:1460-1473, 2003.

PURVES, D.; AUGUSTINE, G. J.; FITZPATRICK, D.; KATZ, L. C.; LAMANTIA, AS; MCNAMARA, J. O.; WILLIAMS, S. M. Neuroscience. $2^{\text {nd }}$ ed. Sunderland: Sinauer, 2001.

RADEMACHER, J., BURGEL, U., GEYER, S., SCHORMANN, T., SCHLEICHER, A., FREUND, H.J., \& ZILLES, K. Variability and asymmetry in the human precentral motor system. A cytoarchitectonic and myeloarchitectonic brain mapping study. Brain. 124: 2232-2258, 2001. 
RAMBOLD, H., CHURCHLAND, A., SELIG, Y., JASMIN, L., \& LISBERGER, S.G. Partial ablations of the flocculus and ventral paraflocculus in monkeys cause linked deficits in smooth pursuit eye movements and adaptive modification of the VOR. J. Neurophysiol. 87(2): 912-924, 2002.

RAUCH, S.L., SAVAGE, C.R., ALPERT, N.M., MIGUEL, E.C., BAER, L., BREITER, H.C., FISCHMAN, A.J., MANZO, P.A., MORETTI, C., \& JENIKE. M.A. A positron emission tomographic study of simple phobic symptom provocation. Arch. Gen. Psychiatry. 52(1): 20-28, 1995.

REIMAN, E.M. The application of positron emission tomography to the study of normal and pathologic emotions. J. Clin. Psychiatry. 58 Supl. 16: 4-12, 1997.

RICHTER, W., SOMORJAI, R., SUMMERS, R., JARMASZ, M., MENON, R.S., GATI, J.S., GEORGOPOUlOS, A.P., TEGELER, C., UGURBIL, K., \& KIM, S.G. Motor area activity during mental rotation studied by time-resolved single-trial fMRI. J. Cogn. Neurosci. 12(2): 310-320, 2000.

ROPER, S.N., LEVESQUE, M.F., SUTHERLING, W.W., \& ENGEL. J Jr. Surgical treatment of partial epilepsy arising from the insular cortex. Report of two cases. J. Neurosurg. 79(2): 266-269, 1993.

ROSANO, C., KRISKY, C.M., WELLING, J.S., EDDY, W.F., LUNA, B., THULBORN, K.R., \& SWEENEY, J.A. Pursuit and saccadic eye movement subregions in human frontal eye field: a high-resolution fMRI investigation. Cereb. Cortex. 12(2): 107-115, 2002.

ROWE, J.B., TONI, I., JOSEPHS, O., FRACKOWIAK, R.S.J. \& PASSINGHAM, R.E. The Prefrontal cortex: response selection or maintenance within working memory? Science. 288(5471): 1656- 1660, 2000.

RUECKERT, L., LANGE, N., PARTIOT, A., APPOLLONIO, I., LITVAN, I., LE BIHAN, D., \& GRAFMAN, J. Visualizing cortical activation during mental calculation with functional MRI. Neuroimage. 3(2): 97-103, 1996.

RUSHWORTH, M.F.S., NIXON, P.D., EACOTT M.J., \& PASSINGHAM, R.E. Ventral prefrontal cortex is not essential for working memory. The Journal of Neuroscience. 17(12): $4829-4838,1997$.

SCHMID, A., REES, G., FRITH, C., BARNES, G. An fMRI study of anticipation and learning of smooth pursuit eye movements in humans. Neuroreport. 12(7): 1409-1414, 2001.

SCHNEIDER, E., GLASAUER, S., \& DIETERICH, M. Central processing of human ocular torsion analyzed by galvanic vestibular stimulation. Neuroreport. 11(7): 1559-1563, 2000 .

SCHNEIDER, R.J., FRIEDMAN, D.P., \& MISHKIN, M. A modality-specific somatosensory area within the insula of the rhesus monkey. Brain Res. 621(1): 116-120, 1993. 
SHINMEI, Y., YAMANOBE, T., FUKUSHIMA, J., \& FUKUSHIMA, K. Purkinje cells of the cerebellar dorsal vermis: simple-spike activity during pursuit and passive wholebody rotation. J. Neurophysiol. 87(4): 1836-1849, 2002.

SIMON, O., MANGIN, J.F., COHEN, L., LE BIHAN, D., \& DEHAENE, S. Topographical layout of hand, eye, calculation, and language-related areas in the human parietal lobe. Neuron. 33(3): 475-487, 2002.

SMALL, D.M., GITELMAN, D.R., GREGORY, M.D., NOBRE, A.C., PARRISH, T.B., \& MESULAM, M.M. The posterior cingulate and medial prefrontal cortex mediate the anticipatory allocation of spatial attention. Neuroimage. 18(3): 633-641, 2003.

SMITH, S. M. Overview of fMRI analysis. Em Functional MRI. An Introduction to Methods (edited by Jezzard, P, Matthews, P.M., \& Smith S.M.), pp: 215-227. Oxford University Press, 2001.

SNYDER, L.H., BATISTA, A.P., \& ANDERSEN, R.A. Intention-related activity in the posterior parietal cortex: a review. Vision Res. 40(10-12):1433-41, 2000.

STANESCU-COSSON, R., PINEL, P., VAN DE MOORTELE, P.F., LE BIHAN, D. COHEN, L., \& DEHAENE, S. Understanding dissociations in dyscalculia: a brain imaging study of the impact of number size on the cerebral networks for exact and approximate calculation. Brain. 123 (11): 2240-2255, 2000.

STOLERU, S., GREGOIRE, M.C., GERARD, D., DECETY, J., LAFARGE, E., CINOT'TI, L., LAVENNE, F., LE BARS, D., VERNET-MAURY, E., RADA, H., COLLET, C., MAZOYER, B., FOREST, MG., MAGNIN, F., SPIRA, A., \& COMAR, D. Neuroanatomical correlates of visually evoked sexual arousal in human males. Arch. Sex. Behav. 28(1):1-21, 1999.

STONE, L.S. \& LISBERGER, S.G. Visual responses of Purkinje cells in the cerebellar flocculus during smooth-pursuit eye movements in monkeys. I. Simple spikes. J. Neurophysiol. 63(5): 1241-1261, 1990.

SUZUKI, M., KITANO, H., ITO, R., KITANISHI, T., YAZAWA, Y., OGAWA, T., SHIINO, A., \& KITAJIMA, K. Cortical and subcortical vestibular response to caloric stimulation detected by functional magnetic resonance imaging. Cogn. Brain Res. 12(3): 441-449, 2001.

SUZUKI, D.A. \& KELLER, E.L. The role of the posterior vermis of monkey cerebellum in smooth-pursuit eye movement control. II. Target velocity-related Purkinje cell activity. J. Neurophysiol. 59(1): 19-40, 1988.

SWEENEY, J.A., MINTUN, M.A., KWEE, S., WISEMAN, M.B., BROWN, D.L., ROSENBERG, D.R., \& CARL, J.R. Positron emission tomography study of voluntary saccadic eye movements and spatial working memory. J. Neurophysiol. 75(1): 454-468, 1996.

TALAIRACH, J. \& TOURNOUX, P. Co-plannar stereotaxic Atlas of the human brain. Thieme Medical Publishers, New York, 1988. 
TANABE, J., TREGELlAS, J., MILLER, D., ROSS, R.G., \& FREEDMAN, R. Brain activation during smooth-pursuit eye movements. Neuroimage. 17(3): 1315-1324, 2002.

THACH, W.T., GOODKIN, H.P.., \& KEATING, J.G. The cerebellum and the adaptive coordination of movement. Annu. Rev. Neurosci. 15: 403-442, 1992.

TREMBLAY, L., \& SCHULTZ, W. Relative reward preference in primate orbitofrontal cortex. Nature. 398(6729): 704-708, 1999.

TROJANO, L., GROSS, D., LINDE, D.E.J., FORMISAN, E., HACKER, H., ZANELLA, F.E., GOEBE, R. \& DI SALLE, F. Matching two imagined clocks: the functional anatomy of spatial analysis in the absence of visual stimulation. Cerebral Cortex. 10(5): 473-481, 2000.

VANDENBROUCKE, M.W., GOEKOOP, R., DUSCHEK, E.J., NETELENBOS, J.C., KUIJER, J.P., BARKHOF, F., SCHELTENS, P., \& ROMBOUTS, S.A. Interindividual differences of medial temporal lobe activation during encoding in an elderly population studied by fMRI. Neuroimage. 21(1): 173-180, 2004.

VITTE E., DEROSIER, C., CARITU, Y., BERTHOZ. A., HASBOUN, D., \& SOULIE, D. Activation of the hippocampal formation by vestibular stimulation: a functional magnetic resonance imaging study. Exp. Brain Res. 112(3): 523-526, 1996.

WARDAK, C., OLIVIER, E., \& DUHAMEL, J.R. Saccadic target selection deficits after lateral intraparietal area inactivation in monkeys. J. Neurosci. 22(22): 9877-9884, 2002.

WATKINS, K.E., PAUS, T., LERCH, J.P., ZIJDENBOS, A., COLLINS, D.L., NEELIN, P., TAYLOR, J., WORSLEY, K.J., \& EVANS A.C. Structural asymmetries in the human brain: a voxel-based statistical analysis of 142 MRI scans. Cereb. Cortex. 11(9): 868-877, 2001.

WATSON, S.R;, BRIZUELA, A.E., CURTHOYS, I.S., COLEBATCH, J.G., MACDOUGALL, H.G., HALMAGYI, G.M. Maintained ocular torsion produced by bilateral and unilateral galvanic (DC) vestibular stimulation in humans. Exp. Brain Res. 122(4): 453458, 1998.

WEILlER, C., CHOLlET, F., FRISTON, K.J., WISE, R.J., \& FRACKOWIAK, R.S. Functional reorganization of the brain in recovery from striatocapsular infarction in man. Ann. Neurol. 31(5): 463-472, 1992.

WEISSKOFF, R.M. \& KIIHNE, S. MRI susceptometry: image-based measurement of absolute susceptibility of MR contrast agents and human blood. Magn. Reson. Med. 24(2): 375-383, 1992.

WOODS, R.P., CHERRY, S.R., MAZZIOTTA, J.C. Rapid automated algorithm for aligning and reslicing PET images. J. Comput. Assist. Tomogr. 16(4): 620-633, 1992.

YANTIS, S., SCHWARZBACH, J., SERENCES, J.T., CARLSON, R.L., STEINMETZ, M.A., PEKAR, J.J., \& COURTNEY, S.M. Transient neural activity in human parietal cortex during spatial attention shifts. Nat. Neurosci. 5(10): 995-1002, 2002. 
ZHANG, Z.H., DOUGHERTY, P.M., \& OPPENHEIMER, S.M. Monkey insular cortex neurons respond to baroreceptive and somatosensory convergent inputs. Neuroscience.94(2): 351-360, 1999.

ZILLES, K., SCHLEICHER, A., LANGEMANN, C., AMUNTS, K., MOROSAN, P., PALOMERO-GALLAGHER, N., SCHORMANN, T., MOHLBERG, H., BÜRGEL, U., STEINMETZ, H., SCHLAUG, G., \& ROLAND, P.E. A quantitative analysis of sulci in the human cerebral cortex: development, regional heterogeneity, gender difference, asymmetry, intersubject variability and cortical architecture. Human Brain Mapping. 5: 218-221, 1997. 